\title{
Family members' experiences of caring for a person with dementia at end-of-life.
}

\author{
By \\ Lucy Hester Nunns
}

A thesis submitted to the Victoria University of Wellington in partial fulfilment of the requirements for the degree of Master of Nursing

Victoria University of Wellington

2015 


\section{Table of Contents}

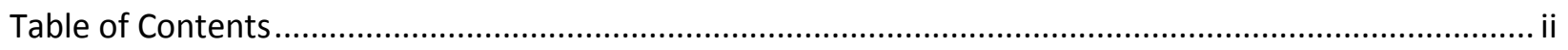

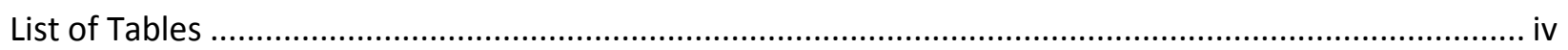

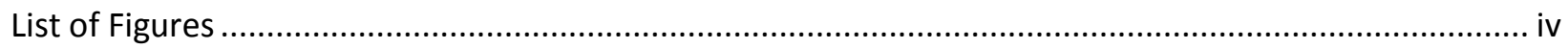

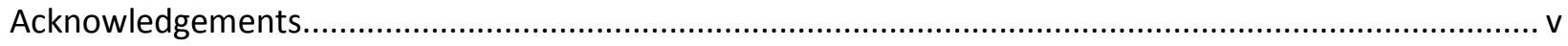

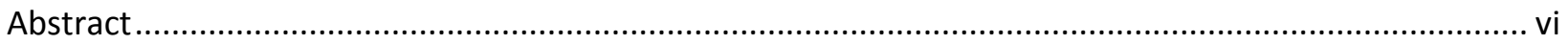

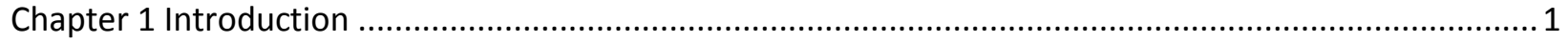

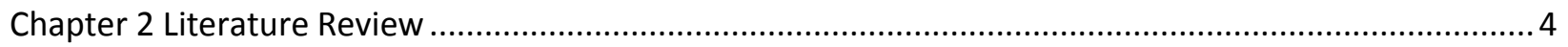

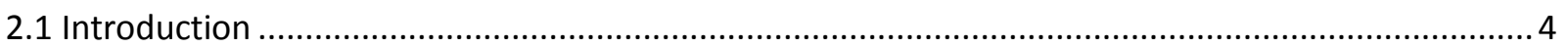

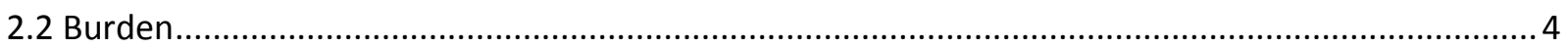

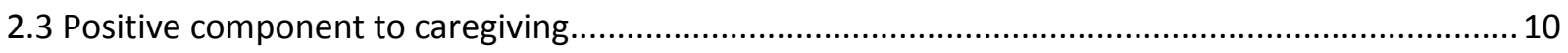

2.4 Emotional responses to the caregiving role ............................................................................... 12

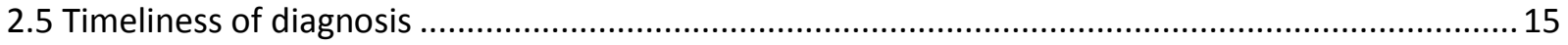

2.6 Advanced care planning and dementia care............................................................................ 17

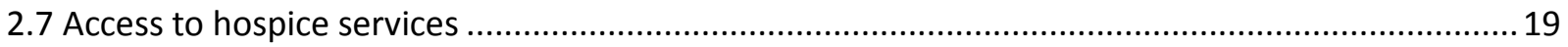

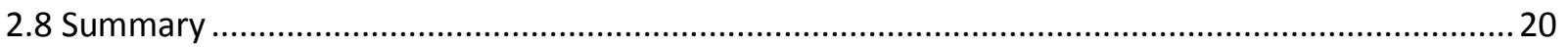

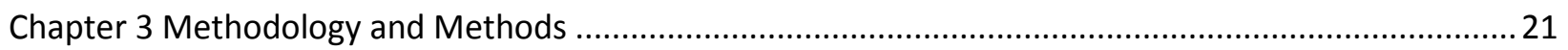

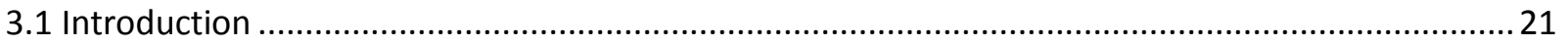

3.2 Qualitative and quantitative design methodology ..................................................................... 21

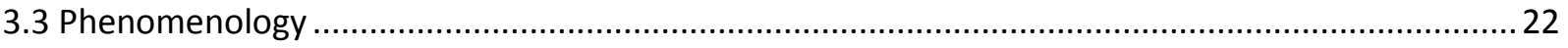

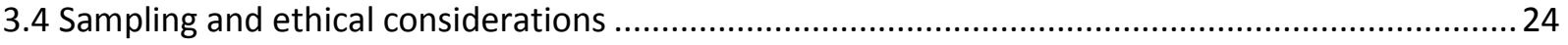

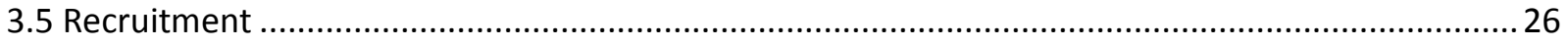

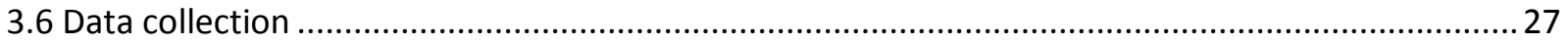

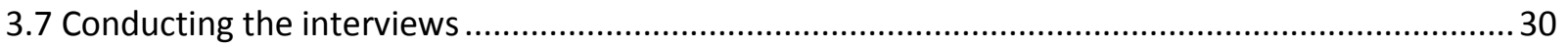

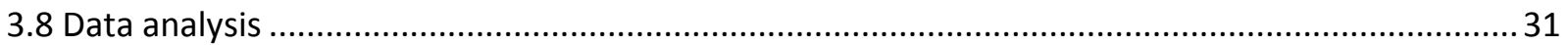

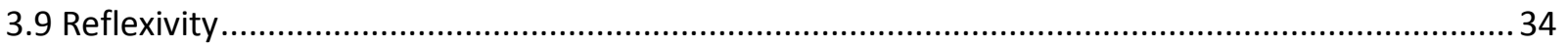

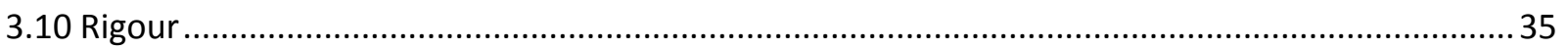

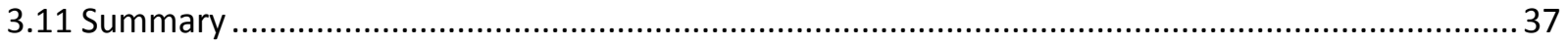

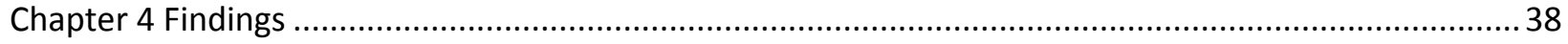

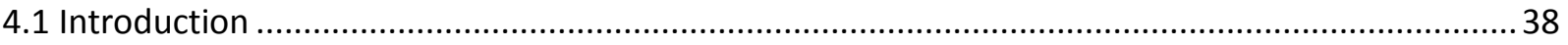

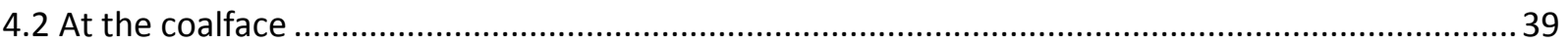

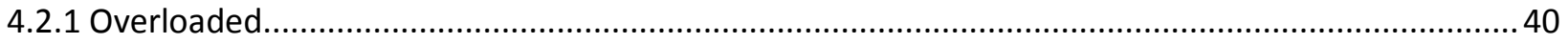

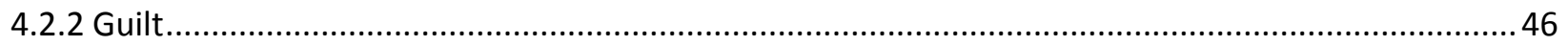




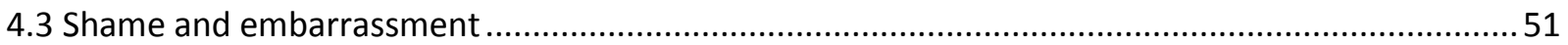

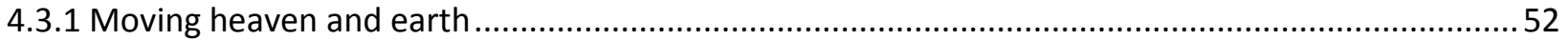

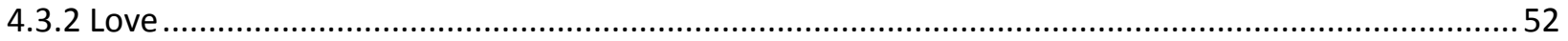

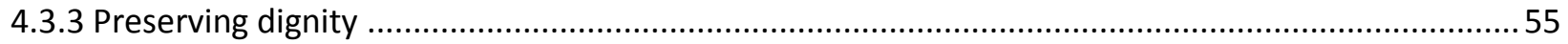

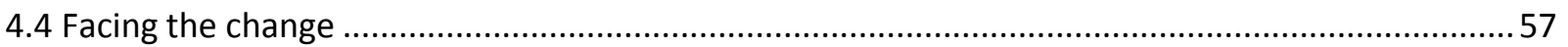

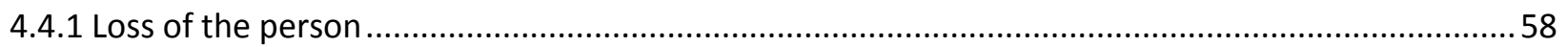

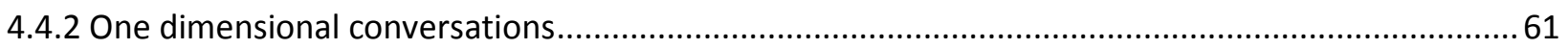

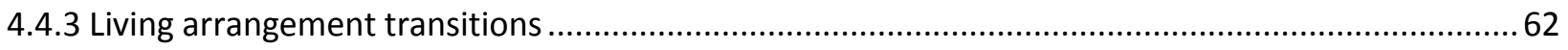

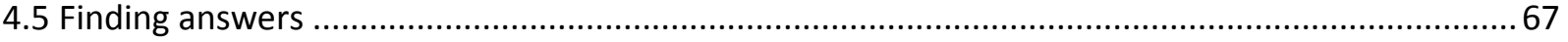

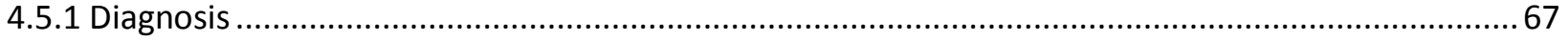

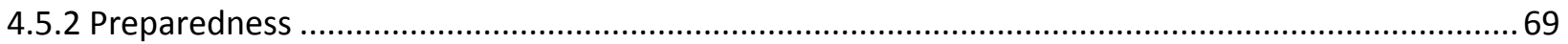

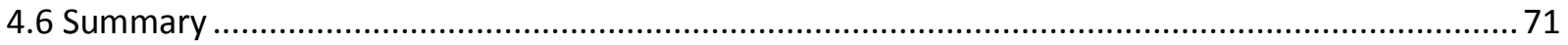

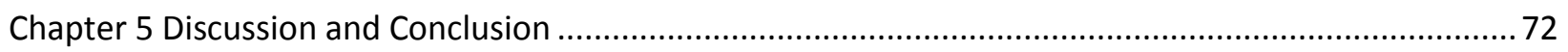

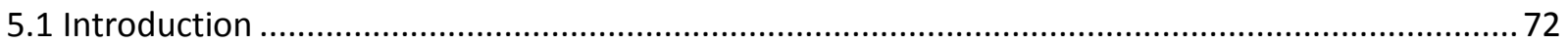

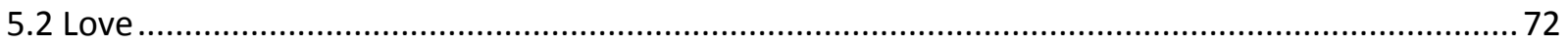

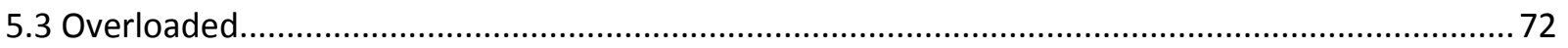

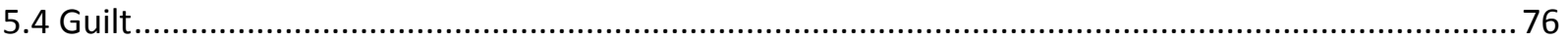

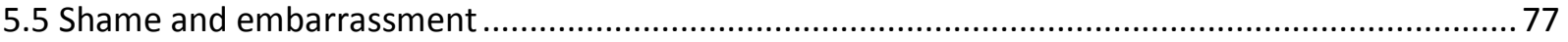

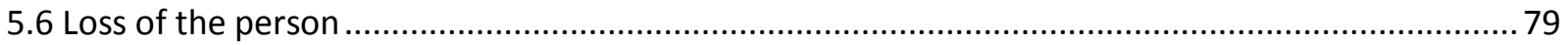

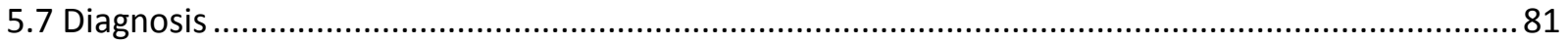

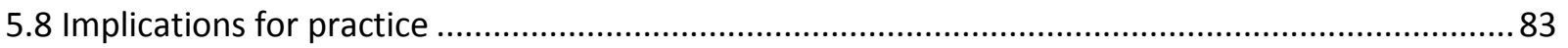

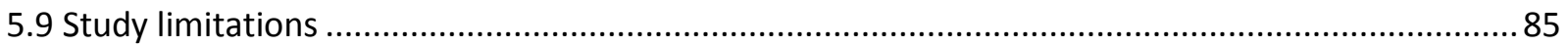

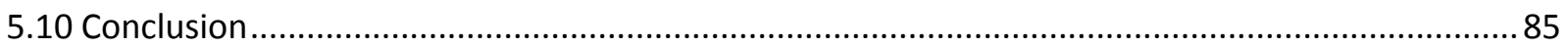

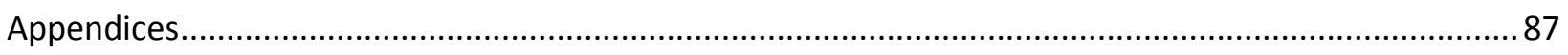

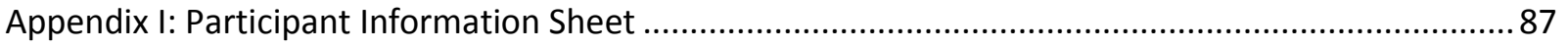

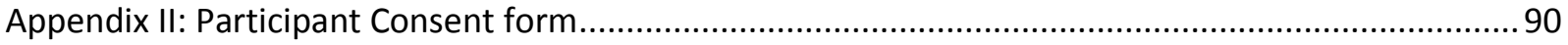

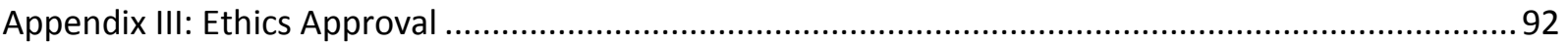

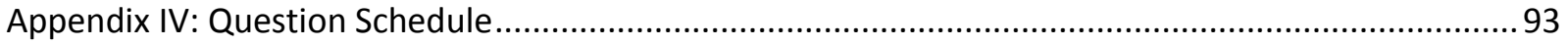

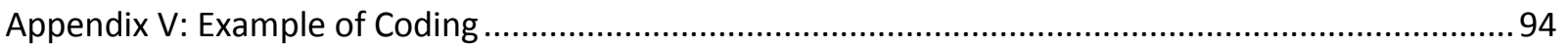

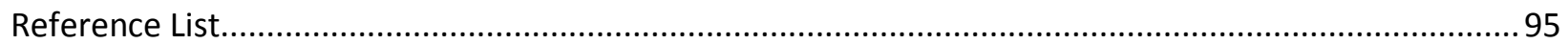




\section{List of Tables}

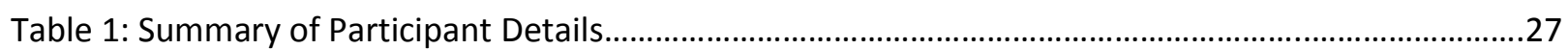

\section{List of Figures}

Figure 1: Themes derived from the narrative data..............................................................................39 


\section{Acknowledgements}

Firstly I would like to thank the participants who so willingly and graciously shared their stories of deeply personal experiences. By their generosity in doing this, they have given an eloquent and personal voice to this research. I would also like to thank my supervisor Dr Kay de Vries for being a very patient and encouraging mentor. Her guidance and wisdom were instrumental in supporting me to complete this work. To my colleagues who expressed interest and gave me encouragement throughout this process, my thanks are due. Special thanks must also be given to my parents, Rachel Bush and Richard Nunns whose belief in me and practical support in helping me throughout this journey have been invaluable. They are a constant source of inspiration and unconditional love. I am very grateful to my sister, Molly and her family, Jason, Eva, Leo and Thomas, who always made me so welcome at 'Casa Stein' on my frequent trips to Wellington and for their ongoing support of me in undertaking this study. And finally, I am very appreciative of the love and support I have received from my own family of Ben, Jessica and Koebi who have been patient, tolerant and kind while I have been preoccupied with this research. I am indebted to many people: participants, my supervisor, university staff, family members,

friends and colleagues. The interest, insights, wisdom, support and patience extended to me over the past two years have enabled me to complete this study. 


\begin{abstract}
Family member's experiences of caring for a person with dementia at end-oflife

Dementia is now recognised as a progressive terminal illness causing significant health-care needs for people with dementia and challenges to their family member caregivers. The purpose of this study was to understand the lived experience of family member caregivers of people with dementia at end-of-life. The research was conducted using a phenomenological approach and data were analysed using Colaizzi's framework. Five family members were interviewed about their experiences of caregiving for six people with dementia. Four themes were revealed. These were: 'Being at the Coalface' with subthemes of overload, and experiencing guilt, shame and resentment; 'Moving Heaven and Earth' with subthemes of love and preserving dignity; 'Facing the Change' with subthemes of loss of the person, living arrangement transitions, and one dimensional conversations; and the fourth theme was 'Finding the Answers' with subthemes of diagnosis and preparedness. All the themes are closely interrelated and throughout all of the participants' narratives, 'love' was the one constant that wove the themes together. This study gives voice to the inner experiences of the family caregivers who were supporting people with dementia in New Zealand. The findings of this study have elucidated many implications for practice and areas for innovation in supporting family member caregivers of people with dementia. This study has identified that the areas in most need of improvement are timely diagnosis, access to wrap-around support services, advance care planning opportunities and optimal care at end-of-life.
\end{abstract}




\section{Chapter 1 Introduction}

Dementia is now recognised as a progressive terminal illness with high health-care needs. People with dementia die as a consequence of advanced dementia and are also at risk of dying of another illness with dementia as a comorbidity (Mitchell et al., 2005). People with dementia are at risk of both over-treatment with potentially non-beneficial interventions, as well as under-treatment of symptoms, at the end-of-life (Birch \& Draper, 2008; Torke et al., 2010; van der Steen, 2010) and few gain access to specialist end-of-life care services (de Vries \& Nowell, 2011; Sampson et al., 2010). Understanding and clinical recognition of when patients with dementia are entering the terminal phase of illness is poor (HarrisonDening et al., 2011; Robinson et al., 2010; Teno, 2011).

The aim of this study was to gain an understanding of the experiences of caregivers of people with dementia at end of life. The objectives were too understand decision making issues and dilemmas that occur for caregivers when planning end of life care for persons with dementia to explore experiences of preparedness and support for dementia caregivers, before, during and following the death of the person with dementia.

Common challenges faced by family/caregivers of people with late-stage dementia relate to lack of preparedness for end-of-life discussions, guilt and stress associated with the institutionalisation of their loved one, unfamiliarity with death in general and death due to advancing dementia, limited understanding of the natural cause of late-stage dementia, unfamiliarity with setting goals and making decisions on behalf of another, and confusion about what actions, or inactions, might 'cause' the death of their relative (Black et al., 2009; Forbes et al., 2000; Gessert et al., 2001; Givens et al., 2009; Hirschman et al., 2008, 2010).

Multiple losses that accumulate during the disease process contribute to caregiver grief. However, grief may be complicated by ambivalence where caregivers want the actual death to occur, while at the same time striving to maintain a close relationship with their loved one (Sanders \& Corley, 2012). There is growing evidence that people with advanced dementia also experience bereavement in relation to their illness and the emotional expression of this grief can have a significant impact on caregivers (de Vries \& McChrystal, 2010). Provision of supportive interventions to caregivers may improve outcomes for patients in terms of the 
quality of home care, particularly when opportunities to express thoughts and feelings are enabled (Carlander et al., 2011).

Advance care planning discussions enable family/caregivers to plan for the future and feel more supported in making decisions regarding patient care. There are multiple benefits that can result from these discussions. These include the potential for better resolution of caregiver bereavement, reduction in admissions into care homes and from care homes to the acute hospital sector. The Advance Care Planning: A Guide for the New Zealand Health Care Workforce was launched in August 2011. Unfortunately this guide does not include advice on Advance Care Planning for people with dementia and their family/caregivers as the Advance Care Plan relies on the patient being competent to share in the planning process. Many family members never seriously consider their loved one's preferences for lifesustaining treatment until they are called upon to make a critical decision in the midst of a medical emergency. The stress evoked by these types of situations can be significantly reduced by enabling opportunities for families to discuss and document end-of-life preferences in advance (Volicer, et al., 2002).

While there is a dearth of research articulating the New Zealand experience of caregiving and dementia, the New Zealand Dementia Impact Report released in 2011 provides insights into the present situation and perhaps, more importantly it makes projections for the future. Presently $1.1 \%$ of the population are living with dementia, $60 \%$ are of these are female. It is estimated that by $20502.6 \%$ of the population will have dementia. Importantly, this report estimates that presently only $60 \%$ of those living with dementia are diagnosed, meaning that the actual number of people requiring care, support and input will be significantly higher. It is incumbent upon policy makers and health care professionals to plan for these numbers and develop healthcare systems and processes that recognise and accommodate the needs of not only the person with dementia but also those supporting them. "Improving the lives of those with dementia" is a key document published by the Ministry of Health in 2014 that has nine guiding principles for developing and implementing systems within New Zealand to reduce the risk of dementia, improve diagnosis and services to those with dementia. Importantly these principles are not only focussed on the person with dementia but also assisting the people who are supporting them. This study highlights many areas for improvement. This commitment from the Ministry to improve care to those with dementia in New Zealand is an important initial step. 
Contemporary research into this phenomenon indicates that New Zealand has an ageing population and the number of those being diagnosed with dementia is only going to increase. How this condition can be best managed is a question that engages not only health professionals but anyone who is affected by dementia in someone close to them and there are very few people whose life has not been affected by dementia in some way.

This general truth has come home to me more recently with the diagnosis of my father who is in the early stages of vascular dementia. He was diagnosed with Parkinson's over ten years ago. For a long time I thought some of the changes in the way he approached life and some of the changes in his behaviour and personality were part of his Parkinson's. The diagnosis of dementia has been a sad discovery for all his family, but in some ways we recognise that at least now we are able to ask the right questions to ensure that we have the right support and that my father is involved in the decision making processes for as long as he is capable of being part of these. Therefore, while my interest in the care of those with dementia and support for caregivers began in my professional life as a registered nurse, it has become a much more personal journey.

In chapter two I present a selective review of the literature addressing the issues of: burden; positive components to caregiving; emotional responses to the caregiving role; timeliness of diagnosis; advanced care planning (ACP); and end-of-life care services. In the first part of chapter three I present a general overview of qualitative and quantitative research approaches and then focus on the phenomenological research design used to conduct the study. The second part of chapter three addresses the methods of sampling, recruitment, data collection and data analysis. In the findings chapter (four) the four main themes, each with four subthemes, are presented followed by chapter five in which I discuss these themes in light of relevant literature. In chapter five I also discuss the study limitations, implications for practice and provide a conclusion. 


\section{Chapter 2 Literature Review}

\subsection{Introduction}

In this chapter I present a selective review of the literature. While little of the available research on experiences with dementia and caregiving and end-of-life decision making had a New Zealand context, international research on this subject was immense. In the past 20 years information, literature and research around this subject has increased exponentially. For this reason the literature had to be reviewed selectively. This literature search was confined to countries where there were similar social and health services to those in New Zealand. This literature search was primarily conducted in two phases. A broad understanding of what was already known about caregiver experiences in caring for person with dementia at end-of-life was required - therefore an initial literature search was conducted to assist in setting up the study. The second phase of this literature review was undertaken once the data had been analysed and themes drawn from the analysis. Those themes were then used to focus the second phase of the literature review. All literature from both phases is critically discussed in this chapter. Both searches were undertaken utilising the electronic database CINAHL, Ovid and PsychInfo with search dates confined to works post 1994. A wide range of search terms were used and were combined with the keywords of: caregiver, fatigue, burden, dementia, grief, end-of-life and bereavement.

The majority of care provided to people with dementia is provided by family members, friends or neighbours (Lloyd et al., 2014) and caregivers are primarily women (Fudge et al., 1997; Ory et al., 1999; ter Muelen \& Wright, 2012). With numbers of those with dementia expected to increase dramatically and associated costs and demand on health dollars and services, informal family caregivers are being recognised as an increasingly valuable resource (Lloyd et al., 2014). The literature was examined under topic areas that I found to be predominant within the field and relevant to this study. These were: burden; positive components to caregiving; emotional responses to the caregiving role; timeliness of diagnosis; advanced care planning (ACP); and end-of-life care services.

\subsection{Burden}

The concept of caregiver burden in association with caring for someone with dementia has been studied extensively. It is acknowledged that because of the progressive nature of dementia requirements of caregivers will increase over time and the care recipient's needs will become more complex and unpredictable (Samia et al., 2012). As care demands increase 
there are likely to be continual changes in status, role expectations and responsibilities within families and informal care networks (Gaugler \& Teaster, 2006). In recognition of the potential longitudinal effects on informal caregivers, some researchers have begun to conceptualise this caregiving role as a career (Gaugler \& Teaster, 2006).

Much is made of the breadth of the caregiving role as it pertains to the care of a person with dementia and it is widely acknowledged that the complexities that exist in this role mean that is it likely to be far more challenging than caring for someone with a physical illness, such as cancer, or a physical disability (Lloyd et al., 2014; Williams et al., 2013). Not only are the caregivers of those with dementia expected to engage in physical assistance and coping with challenging behavioural problems and distressing changes to personality but they are also often having to navigate their way through complex health care and support services (Lloyd et al., 2014).

In mental health, stigma for the family of the person with the illness is acknowledged as a predictor of caregiver burden. Research undertaken Werner and colleagues (2012) sought to examine whether there was a correlation between family stigma and caregiver burden for those caring for a family member with Alzheimer's. Structured interviews were conducted with 185 participants. While this study reported lower levels of reported stigma associated with caring for someone with dementia than those caring for someone with a mental illness, the researchers acknowledge that the impact on the person and family as a result of caring for a person with dementia are more pronounced in those caregivers who perceived that there was a stigma attached to being associated with the person with dementia. Examples of stigma as perceived by the caregiver included where there was distancing from the person with dementia from friends or acquaintances. Similarly feelings of shame were also found to greatly increase the likelihood of burden for caregivers of relatives with Alzheimer's.

Neufeld and Harrison (2003) posit that burden, particularly for female caregivers, is created in part by unmet needs. This study utilised the analysis of repeated in-depth interviews of eight female caregivers all of whom cared for a relative with dementia. This comprehensive qualitative study elicited a number of areas where these women felt that there was a lack of support from their social networks which resulted in increased perceptions of burden associated with the caregiving role. These were unmet expectations where things such as offers of support or for continued social interaction after diagnosis failed to materialise. 
Unfulfilled expectations also centred on treatment of the person with dementia by existing social networks - such as negative comments about the person with dementia or where the women felt criticised about their ability to provide care. The study also highlighted the way that social networks could be simultaneously encouraging and uplifting, and discouraging and demeaning. This added to the burden for the women caregivers, as the attitudes of social networks often seemed to be confusing and contradictory.

It is anticipated and accepted that coping with this kind of role and associated workload is potentially going to be at the expense of the caregiver's own family life, career and ultimately their own health, with caregivers of people with dementia more likely to suffer with symptoms of anxiety and depression than caregivers of people with other diseases or disabilities (Razani et al., 2007). A literature review of eight qualitative studies on what quality end-of-life care for dementia is from the perspective of family carers was undertaken by Davies et al. (2014). They highlighted that the huge commitment that this caregiving role necessitates has the potential to socially isolate the caregiver. Furthermore it was identified in a grounded theory study exploring the experiences of 23 female primary caregivers of relatives with advanced dementia in Spain (De la Cuesta-Benjumea, 2011) that assuming this role may erode the sense of self in the caregiver.

The journey of the caregiver for someone with dementia is punctuated by a series of changes and transitions associated with deteriorating function and the challenges that these changes present. Arguably one of the most challenging decisions that family caregivers face is whether to admit their loved one to a formal care facility for ongoing care (Cho et al., 2009). Hennings and colleagues (2013) conducted a longitudinal study of 10 participants which sought to gain insight into the experiences of caregivers of people with advanced dementia who resided in a formal care facility. The results of this study indicated that not only was the decision to admit a person to an aged residential care facility challenging for the caregiver, so too was having their loved one in formal care. Hennings et al. (2013) found that the participants in their study identified this time as difficult and challenging. The caregivers found it a struggle to find their place, maintain their identity and define their role as caregiver in the formal care facility where many of their day-to-day responsibilities had been taken over by others. Additionally this study identified that the caregivers felt their self-identity had been eroded by the role of caregiver, and that this posed difficulties when trying to maintain their own life and connections within the community. This study expressed this as 
the caregivers trying to live in 'two worlds' and acknowledged that walking this tightrope created feelings of overload and distress.

The work of Sanders et al. (2008) through their study of levels of grief amongst caregivers of people with dementia further recognised the impact that the caregiving role had on the person undertaking the role and their ability to cope with the challenges. This research was part of a larger study which utilised mixed methods to explore caregiver experience. All participants in the larger study $(n=201)$ were assessed using grief rating scales and those who scored highly on the assessments were recruited into the smaller study $(n=44)$. The researchers identified a number of themes from interviews and questionnaires undertaken with the 44 participants involved. Recurrent themes and issues around loss of freedom, life stressors and coping strategies were raised. Experiences of high levels of grief impeded the caregiver's ability to undertake paid employment, engage in social activities or attend to other family commitments. This finding is supported by the work of Ory and colleagues (1999) whose study of 1,509 caregivers which used questionnaires to explore, understand and compare the experiences of caregivers caring for someone with dementia and someone without dementia. It was highlighted that those caring for someone with dementia cited more issues and challenges in relation to their role when compared to non-dementia caregivers. Specifically noted was the burden this role created in regards to paid employment. Those caring for someone with dementia reported passing up of promotions, actively seeking less demanding roles and some reported having to leave paid employment completely. Converse to the findings of Ory et al. (1999) and Sanders et al. (2008), research undertaken by Edwards et al. (2002), which sought to examine the incidence and experience of role strain and depressive symptoms of those caring for a loved one with dementia while in paid employment, suggested that, in comparison with non-employed caregivers, there was little evidence of increased depressive symptoms or role strain. Edwards and colleagues (2002) qualified these findings by positing that while paid employment does not specifically or necessarily disadvantage or impact on the caregiver in regards to depressive symptoms and role strain, other contextual factors related to the employment such as hours of work per week and the paid work undertaken might increase both experiences of depressive symptoms and role strain. Edwards and colleagues' (2002) findings did concur that the ability to meet the fixed demands of the paid employment and the variable requirements of the caregiving role was a difficult balancing act and could lead to experiences of overload. 
The mental health of the caregiver has undergone a high level of scrutiny in the literature as it has been acknowledged that the caregiving role and associated workload can have a detrimental effect on the mental health of the person delivering the care. Declining functional ability and abnormal behaviours associated with dementia have been found to exacerbate psychological distress and perceptions of burden in caregivers ( $\mathrm{O}$ 'dwyer et al., 2013; Razani, 2014). A study that explored the lived experience of 153 patients with Alzheimer's disease and their caregivers found that those caregivers identified that they had little or no time to themselves and that they had issues with obtaining enough quality sleep, declining physical health, issues in their work place and family problems associated with their role as caregiver (Schubert et al., 2008).

Research into contemplation of suicide by caregivers related to the burden of caring for someone with dementia revealed that, of 124 participants in one study, $26 \%$ had contemplated suicide at least once in the past year (O'Dwyer et al., 2013). This study was conducted across three countries with participants sourced from Australia, the United States and the United Kingdom. An online survey was used to elicit responses which were then transferred into statistical software for analysis. The findings of this study were indicative of the overwhelming stress that a proportion of caregivers feel when faced with the challenges of looking after someone with dementia with over one in four respondents identifying suicidal ideation in relation to their caregiving role. This study was significant because it was the first study that had investigated this phenomenon in relation to caregivers of people with dementia, it was an international study enabling comparison across countries and it had a relatively large sample. Of note are the findings of a study in England by Campbell et al. (2008) who carried out a cross-sectional study of 74 patients (who had previously been clinically diagnosed with dementia) cognitive ability to carry out day-to-day tasks and of their behavioural and psychological symptoms. They used a multiple regression analysis to evaluate the multiple variables that caregivers experience and found that it is not the objective physical load created by the person with dementia that creates feelings of burden in caregivers, rather it is more often the subjective interpretation of the situation by the carer and resilience in maintaining the role that determines the burden experienced.

Of interest is the works of Samuelson et al. (2001) whose research in Sweden, with eight family caregivers of relatives with dementia, found that a predictor of burden within the caregiving role was the nature of the spousal relationships prior to diagnosis and onset of 
associated symptoms of dementia. Integral to their work was the notion that the more secure, loving and intimate the spousal relationship was prior to diagnosis, the less likely the caregiver was to experience stress and overload associated with their caregiving role. In addition correlations were found regarding ambivalent spousal relationships and increased experience of feeling overloaded. This concurs with the findings of a study into spousal relationships by Davis et al. (2011) where the researchers carried out a content analysis of baseline interviews with 40 Alzheimer's disease and Parkinson's disease spousal caregivers enrolled in a home care skill-training trial. Caregivers identified their care relationship as a source of care burden and concluded that the nature of the pre-illness relationship between spouses influenced both the quality and duration of the caregiving relationship to some degree. Indeed the researchers felt the correlation was so significant that it warranted further study to be able to better understand the role of caregiving in the context of dementia and to develop support systems to counteract issues encountered as a result.

While a considerable amount of the literature focuses on the effect that the burden of providing cares to someone with dementia had on the mental health of the caregiver, it was also recognised that there were associated effects on the caregiver's physical health. In a study that explored the ramifications of unmet need in dementia caregiving it was found that those caregivers who had depression ratings at baseline testing were more likely to develop physical issues in relation to the caregiving role than those who did not register as having had depression ratings on baseline testing (Gaugler et al., 2004). Similarly caregivers experienced a higher incidence of negative emotions such as hostility, and sadness and also a general decrease in positive emotions when compared with non-caregiving counterparts by Bakker et al. (2013) and Pinquart and Sorenson (2003). In addition to the negative effects on the caregiver's mental health, research conducted into the physical health of caregivers of people with dementia over time in relation to the health of non-caregivers also found that this cohort was at greater risk of developing hyperlipidaemia, hyperglycaemia and issues with their immune system (Papastavrou et al., 2007; Pinquart \& Sorenson, 2003). Papastavrou et al. (2007) conducted a study based in Cyprus which investigated the burden associated with the care of a family member with dementia and also the impact that this burden had on the physical and emotional health of the person undertaking the caregiving role. One hundred and seventy-two participants were involved in this study which concluded that of the participants $68 \%$ felt they were highly burdened by the role of caregiver and that $65 \%$ exhibited depressive symptoms. The finding of research undertaken by Papastavrou and 
colleagues (2007) was in concordance with an earlier meta-analysis of literature conducted by Pinquart and Sorenson (2003). This meta-analysis involved a review 84 articles comparing the physical and psychological health of caregivers and non-caregivers. Findings from this meta-analysis indicate that even after the death of the person requiring care, the physiological and psychological effects of this work were ongoing with caregivers reporting ongoing depressive symptoms and physical issues such as raised blood pressure which were attributed to their time as a caregiver.

The work of Dunham and Cannon (2007) also uncovered other contributing factors to caregivers' experience of burden. Their research involved interviewing 26 employed women each of whom was also a caregiver to a family member with dementia. The study examined the power imbalance that exists in caregiving relationships. Dunham and Cannon (2007) eloquently described the caregiver relationship, especially for woman, as a 'tug of war for control' especially in the early stages of the disease. They found that most of the participants took over aspects of care when the care recipient was no longer able to do these for themselves. Thus the caregiving role was assumed slowly as cognition and physical functioning decreased - a process they described as 'progressive surrogacy of decision making'. This research showed that while the participants identified that they were the more powerful within the caregiving relationship - they often felt powerless, and this increased their experience of overload and burden. The researchers identified that the participants required medical input and advice to help them understand and make sense of their new role and their family member's illness. However this study also identified that overload also results from a perceived lack of understanding or acknowledgement by health professionals of the important role caregivers play in care, which exacerbated their feelings of powerlessness and lack of control (Dunham \& Cannon, 2007).

\subsection{Positive component to caregiving}

Proportionately more research has been conducted into the caregiving role that focused on understanding the stress and burden this role placed on the person providing the care than on the positive aspects of the caregiving role. However studies undertaken on determining the positive aspects associated with the caregiving role suggest that there are positive characteristics and features of the caregiving relationship that are often overlooked (Cohen et al., 2002; Boerner et al., 2004; Shim et al., 2013; Williams et al., 2013). Cohen and colleagues (2002) explored the positive aspects of caregiving and discovered that, of 289 
participants who were caregivers caring for seniors in the community, $73 \%$ felt positively about at least one aspect of their caregiving role, with a further 20 participants able to identify more than one positive aspect of their caring role. Feeling positively about the caregiver role was found to be associated with lower depression scores, decreased experiences of burden and better health of the caregiver. Positive feelings were associated with fulfilment, companionship and the knowledge that they were contributing to the provision of care that increased the quality of life of their loved one (Cohen et al., 2002). Further to this, caregivers were reported as experiencing satisfaction and positive associations with the role especially in regards to fulfilling the role to a high standard and making the person they were caring for comfortable (Jervis et al., 2010; Schneider et al., 1999).

Despite the multiple challenges associated with the caregiving role Boerner et al. (2004) suggest that many opportunities for rewarding experiences exist and that the caregiving role can uplift the caregiver by giving them feelings of competency in the role and importance. Shim et al. (2013) utilised thematic analysis of the narratives of 11 participants to assist in understanding the lived experience of caregivers. The researchers identified that participants in their study were capable of viewing the caregiving role in a different and more positive way through utilisation of a reframing process whereby they chose to view their role in a positive light and drew strength from past challenges and learning. While still acknowledged that this type of caregiving could be burdensome and challenging, they also suggested it could be a time of personal growth (Shim et al., 2013). By finding purpose in the role, while challenges still existed, participants were able to recognise the worth and meaning in the work they were undertaking.

Further to this, Butcher and Buckwalter (2001) explored the concept of how caregivers could redefine the issues and challenges that the caregiving role presented, by interpreting or conceptualising them as 'blessings'. This study, which focused specifically on how the caregiver was to find worth and meaning in their role, found that those caregivers who made the personal choice to focus on positive aspects of the role were more empowered to sustain the role of caregiver over time. This is important given the often drawn out trajectory of decline that is associated with dementia. Similarly, the work of Williams and colleagues (2013), which explored how caregivers coped with the burden associated with the caregiving role and illness, found that participants tended to focus on positive aspects of the caregiving role in an attempt to cope, particularly when they felt that there was little they could do about 
the negative impacts of the disease on their loved one. In their exploration of the experiences of 13 caregivers they established that the majority of the participants utilised a variety of coping strategies and remaining positive was found to be a protective factor in helping them to manage the negative impacts of the disease. According to Semiatin and O'Connor (2012) there is a correlation between self-efficacy and acknowledgement of positive aspects within the caregiving role with those caregivers who displayed high self-efficacy being more able to recognise positive aspects of the caregiving role. This is possibly because those who possess self-efficacy and feel competent within the role of caregiver are much more likely to be able to pro-actively manage issues as they arise while still preserving their relationship with their loved one (Semiatin \& O'Connor, 2012).

\subsection{Emotional responses to the caregiving role}

Although aspects of the caregiving experience are positive, literature would suggest that it is possible to experience positive and negative emotions simultaneously and that the majority of literary commentary and research around the issue of providing care to a person with dementia does focus on the more negative aspects of the role.

Commentary on caregiving by Brodaty and Donkin (2009) suggests that there are various reasons that motivate family members to assume the role of caregiver to a loved one with dementia. The reasons that they cite range from positive reasons, such as love and spiritual fulfilment to more ambivalent reasons, such as guilt or a sense of duty (Brodaty \& Donkin, 2009). Research undertaken by Cohen et al. (2002) on determining whether there are positive aspects to the caregiving role suggested that those who took on the role based on more positive motives or those who were able to identify positive aspects of the role were less likely to suffer some of the negative impacts associated with the caregiving role.

Guilt is one of the more pervasive of the emotions evoked by the caregiving role. Work by Nolan and Dellasega (2000) suggests that guilt is potentially a by-product of the necessity of caregivers who have taken on the proxy decision maker role having to make decisions in regards to care of their loved one without adequate support and that guilt was closely linked to a sense of failure. Nolan and Dellasega (2000) based this observation on a study that was undertaken in both the United States and the United Kingdom where they recruited caregivers into the study who had in the past four weeks had to admit a family member with dementia to an aged care facility. This study sought to articulate the lived experience of caregivers as 
they made these difficult decisions. Additionally, guilt in relation to caregiving and dementia has been associated with family feeling overwhelmed by a sense of moral duty or obligation to undertake this activity (ter Muelen \& Wright, 2012). There is a strong association with guilt and decision making but more specifically guilt is experienced if the person with dementia requires admission to an aged care facility (ter Muelen \& Wright 2012).

In contrast to commentary by ter Muelen and Wright (2012), a study conducted by Jervis et al. (2010) into caregiving amongst native American elders suggested that while it is viewed negatively as a moral obligation by some, other caregivers view this sense of duty as a positive way in which to demonstrate reciprocity, love and caring for their relative. This study highlighted the cultural components and expected norms that impact on perceptions of caregiving. The study found low levels of experiences of burden associated with caregiving and attributed this to collective care provision by a number of people, strong links and reciprocity within relationships with elders and cultural expectations and acceptance of provision of care. This is an important concept when reflecting back the issues that individuals cite as being challenges in caregiving such as loss of freedom and isolation. This has implications for health professionals working in this field and attempting to support caregivers in maintaining their role while still reserving their sense of self and personal health. Romero-Moreno and colleagues (2014) explored the concept of guilt as it related to caregiving and dementia. Their study of 851 informal caregivers, comprising just under $80 \%$ female caregivers and proportionately more daughters than wives, found that a moderator of guilt was only present for the daughters - where daughters reported lower leisure activities it was associated with higher levels of guilt and depressive symptoms, suggesting that involvement in leisure activities and involvement in other social networks may provide protective factors against experiences of guilt and depressive symptoms.

Shame and embarrassment are some of the other emotional responses experienced by caregivers. Husband (2000) undertook a qualitative study to understand the lived experience and concerns of people with dementia in relation to receiving their diagnosis. This was a clinical case series trial of 10 participants who were all in the early stages of their illness. The Mini Mental State Examination (MMSE) was conducted to ensure cognitive ability to consent to participation. Two standardised open ended questions around concerns about their diagnosis and how learning of their diagnosis had affected them were used to begin the interview. Content analysis and frequency counts were drawn from field notes taken at the 
time of the interview. Findings revealed that those participants experienced concerns around their diagnosis which had the capacity to affect their self-esteem, decrease their quality of life and lead to self-stigmatisation through social withdrawal and hypervigilance to cognitive deficits and decline. While this study was relatively small it provides valuable data that enables insight into the lived experience. It is of relevance to the caregiver experience as caregivers have also expressed concern regarding stigmatisation and quality of life once diagnosis is made public. Similarly the research of Williams et al. (2013) found stigma and embarrassment to be a major concern with caregivers increasingly isolating themselves and the care recipient from social occasions in an attempt to preserve dignity and limit shame. Commentary by Holmerova et al. (2007) stressed the importance of preserving the dignity of the person with dementia or supporting the caregiver to facilitate this. Their discussion around definitions of dignity, in the context of a terminal disease such as dementia, included important learning for health professionals regarding challenging their own perceptions of dignity at end-of-life when decisional capacity is compromised. Holmerova et al. (2007) assert that specialist dementia units are required to adequately cater to the specific and variable needs of patients with dementia and to maintain their dignity.

In regards to emotional responses to the role, of fundamental importance, was the presence of love. McIntyre and Cole (2008) developed a poignant spoken word performance entitled 'Love Stories' which was based on data from caregivers about their experience in caring for a loved one with dementia. Both of the researchers had experiences with caregiving for a family member. To elicit data they launched a public exhibit of autobiographical images of caregiving and Alzheimer's disease. Visitors were encouraged to make written comments and family caregivers were invited to view the work and to talk with the researchers about their experiences. People were also encouraged to make audiotaped interviews. Analysis of these interviews, comments and conversations formed the basis for their performance. Emergent themes within this research focused primarily around love and reciprocity. This is in keeping with the findings of research by Jervis et al. (2010) who found that reciprocity in relationships and love for the person they were caring for were fundamental to the caregiving role in Native American communities. Of note was the discovery by the researchers of the extraordinary lengths that the caregivers would go to, to provide innovative, creative and person-centred care to their loved one that ensured preservation of their dignity. However this research also highlighted the tension that exists in delivering this exemplary care and in 
catering to the needs of the caregiver. This contributed to experiences of burden and overload.

\subsection{Timeliness of diagnosis}

It is acknowledged that timely diagnosis is integral to improving dementia care (VernooijDassan et al., 2005) and that the diagnosis of dementia is pivotal to obtaining the support and input that both the person with dementia, and ultimately their caregivers, required to both live with the disease and also to sustain the caregiving role. However research undertaken by Teel and Carson (2003) exploring experiences in dementia diagnosis suggests that for the person with dementia and their caregivers the time between presentation of concerning symptoms and diagnosis was a time of anxiety and uncertainty which required extreme diligence on the part of the person or their caregiver to obtain answers (Teel \& Carson, 2003). Analysis of the literature suggests that wide variations exist internationally regarding both the initial diagnosis of dementia, timeliness of the diagnosis and then subsequent disclosure of this to the person and their family (Iliffe et al., 2009). It is suggested that this could be related to the uncertain aetiology and high variability in presenting symptoms (Iliffe et al., 2003).

Research originating from the United Kingdom suggests that, from the onset of symptoms or family concerns to diagnosis takes between 18-30 months (Bamford et al., 2004). It is evident that there are a number of variables that present as obstacles to the timely recognition of symptoms and diagnosis of dementia. Hansen et al. (2008) posit that GPs are central to diagnosis of dementia and to ongoing care because they are the health professional that carers and patients with dementia will present to most often. Despite this, GPs are often slow to diagnose dementia (Hansen et al., 2008). Studies of GP practises in the United Kingdom have suggested that one reason for this is that there is wide variation in GPs knowledge and confidence around local policies or processes that would have guided them in the diagnosis and management of patients with dementia (Fox et al., 2013) and that many GPs felt insufficiently educated to respond to the needs of both the person with dementia or their family (Downs et al., 2000). Fox and colleagues (2013) discovered that the majority of those GPs canvassed, using questionnaires mailed out to their practices, were concerned around their lack of knowledge and awareness of follow up services for newly diagnosed patients. While dementia is one of the leading causes of disability in older age contributing to $11.2 \%$ of all years lived with disability according to the Global burden of disease (World Health 
Organisation, 2002), it remains significantly under diagnosed with British studies estimating that approximately $50 \%$ of those over 65 year olds who experienced cognitive issues and reported these to their GP were not initially diagnosed by their primary care physician (Boustani et al., 2003).

Just as there are significant issues surrounding obtaining a diagnosis, so too are there concerns around the disclosure of the diagnosis to patients and their families. GPs cited disclosure as one of the more difficult and distressing aspects of dementia management (Bamford et al., 2004; Iliffe et al., 2009) as this diagnosis can bring with it proliferative stigmas and misunderstandings (de Vries et al. 2010) and can also cause extensive distress. Research into this phenomenon has highlighted that there are inherent risks in regards to both disclosure and non-disclosure of a diagnosis of dementia. The reasons against diagnostic disclosure include the fear of causing emotional distress, stigma associated with dementia and the decreased cognitive ability of the person precluding them from understanding the implications of the diagnosis (Bamford et al., 2004). Additionally, Bamford et al. (2004) cite lack of confidence on the part of medical staff tasked with delivering the diagnosis, as being likely to prevent this disclosure. Conversely, reasons in favour of diagnostic disclosure include adopting a more patient centric view and collaborative approach of involving the patient early in the trajectory of the disease so as to facilitate discussions around future care options and advance care planning and to maximise treatment opportunities while the patient is still cognitively capable (Bamford et al., 2004; Mitchell et al., 2013). Research conducted by Steeman et al. (2007) indicates that those in the early to moderate stages of dementia are able to appropriately and accurately report symptoms, answer questions and provide reliable responses regarding their vision for their future care. Furthermore Mitchell et al. (2013) argue that timely diagnosis is the first step to living well with the disease. Within the literature a number of negative consequences from disclosure have been noted, such as a detrimental effect on the person's self-esteem, personhood and confidence (Pratt \& Wilkinson, 2003) and, when questioned, concerns regarding the harmful consequences of disclosure are cited by GPs as being sufficient reason to avoid or delay frank and clear discussions regarding diagnosis with patients (Van Hout et al., 2000). Additionally when articulating their experience of conversations around diagnosis with their GP, families and patients found it exceptionally difficult if they were given a provisional or vague diagnosis citing it as confusing and upsetting (Pratt \& Wilkinson, 2003). 
Issues from the family/person point of view surrounding the process of disclosure have centred on lack of information or follow up referrals, the insensitive manner in which the disclosure was delivered and little or no opportunity to address the emotional issues that surfaced as a result of the diagnosis (Bamford et al., 2004; Pratt \& Wilkinson, 2003; Van hout et al., 2000; Williams et al., 2013). Literature on this subject suggests that on balance those with dementia would prefer to know their diagnosis, suggesting it is a predominately positive and proactive step, despite the potential for initial angst and distress (Dautzenburg et al., 2003; Moniz-Cook et al., 2006), and that awareness of diagnosis is associated with empowerment of the individual (Keightley \& Mitchell, 2004).

It is also acknowledged that patients have a right not to know a diagnosis if they believe it is likely to cause a disproportionate amount of stress and angst (Buckman, 1996). However it is the overall consensus within the literature that the advantages of disclosure outweigh those of non-disclosure because it ultimately affords the patient and their families, the ability and opportunity to be involved in decision making and to have their voice heard about treatment options and future care (Cornett \& Hall, 2008; Whitlatch, 2013). A sensitive and thoughtful approach by the health professional to disclosure of the diagnosis and careful assessment and gauging of the response to the diagnosis by both the person with dementia and the family has the potential to limit or negate the psychological harm to the person and it is imperative that diagnosis be disclosed at such a time that allows for the person with dementia and their family to raise issues and discuss concerns (Cornett \& Hall, 2008, Mitchell et al., 2013).

\subsection{Advanced care planning and dementia care}

Recognition and acknowledgement of the progressive trajectory of dementia necessitate the planning of future care while the person is still cognitively able to participate in the discussions. However issues surrounding timely diagnosis and the disclosure of this diagnosis continue to hinder the commencement of advance care planning (ACP) processes. ACP involves a process whereby information and support is given by health professionals to assist individuals in planning and articulating their end-of-life preferences (Brooke \& Kirk, 2014). It is intended that the person's primary health care provider will initiate a number of discussions around end-of-life care with the outcome of these discussions ideally being a set of agreed actions that guide care and interventions at the end-of-life and are referred to as 
'Advance Care Plans' (Brooke \& Kirk, 2014; Gessert et al., 2001; Whitlatch, 2013). It is acknowledged that ACP has the potential to not only improve the end-of-life care and experience for the terminally ill person, it can also improve the experience for family as well.

Within the literature there is evidence that the uptake of ACP processes and discussions by those with dementia is on the rise (Garand et al., 2011). However, the involvement in ACP by people with dementia is far less than those with other terminal illnesses such as organ failure or cancer (Brook \& Kirk, 2014). The acquisition of a diagnosis and timeliness of that diagnosis are fundamental to the ACP process because the person must have the cognitive ability to engage in the process and express their preferences and desires for their end-of-life care (Brook \& Kirk, 2014). Thus it is imperative that these processes are commenced early within the trajectory of the disease. It is evident from the literature that without agreed upon parameters around preferences for care and ACP and end-of-life discussions, many family caregivers lack the knowledge and confidence to fulfil the capacity of a proxy decision maker, preferring to leave some of the more complex decisions to health care professionals, effectively rendering the voice and preferences of the person with dementia silent (Davies et al., 2014; Whitlatch, 2013).

Central to the process of ACP are the discussions between health care professionals and the person with dementia and their family. Of importance to the process is the willingness of the person with dementia and family to engage in the process and the health professionals' competence and confidence in leading these conversations and completing the process. Inadequate or confusing communication with health care professionals has been cited as a complicating factor in planning for future care (Cherlin et al., 2005). It is acknowledged that there is a proportion of those with dementia who do not want to be involved in discussions around ACP (Fried \& Drickamer, 2010). However Brooke and Kirk (2014) suggest that preliminary attempts at discussing and ascertaining patient views regarding involvement in $\mathrm{ACP}$, even if they are not acted upon, are not futile, as it provides the opportunity to raise awareness that dementia is a terminal disease and may facilitate timely discussion of pressing concerns that the person or family may have. Therefore opportunities to discuss ACP should not be shied away from, rather acknowledged as being a positive step in the retention of selfautonomy for as long as possible for the person with dementia and as providing some certainty for those who will become the decision makers. This viewpoint is supported by Gessert et al. (2001) following their study into end-of-life decision making by families and 
how they were supported by health professionals who, while advocating the importance of completion of ACP, acknowledge that these conversations on the subject help to normalise discussions about the dying process (Gessert et al., 2001). Limited knowledge regarding dementia on the part of the families may explain their reticence to be involved in ACP as it is suggested that it is not commonly understood that dementia is a terminal illness (Gessert et al., 2001).

Health professionals' understanding of ACP processes and their merit is variable (Brook \& Kirk, 2014) which could explain why ACP is not offered to all people with dementia, despite a recommendation of the British Department of Health that ACP discussions should be offered to all people nearing the end of their life (Brooke \& Kirk, 2014). Other barriers to the undertaking of ACP have included decreased knowledge and understanding of the components of ACP, confidence in initiating the conversation and misunderstandings about how or what to document (Brooke \& Kirk, 2014).

\subsection{Access to hospice services}

Despite the fact that dementia is recognised as a progressive and terminal disease (de Vries \& Nowell, 2011) and numbers of people diagnosed with dementia are increasing, access and referral to hospice services remains unequal to other terminal illnesses such as cancer (Ouldred \& Bryant, 2008). A large study conducted by Teno and colleagues (2011) into American families' perceptions of the quality of end-of-life care their loved one received in aged residential care facilities involved 545 participants. The study highlighted that there were multiple concerns about unmet care needs and the quality of care that was provided in aged residential care facilities in comparison to care that was given to those who died in a hospice facility or were provided with hospice oversight to care. Those families who had hospice input described fewer issues with the quality of the care and reported fewer unmet care needs (Teno, 2011).

According to Gillick (2012) the management of end-of-life care for those with dementia is especially complicated as not only is the person not able to actively participate in their care and decisions, but also the trajectory of the disease is protracted. This means that those with dementia do not necessarily fit the brief of terminal illness for which hospices were designed (Gillick, 2012). This is in spite of care at end-of-life for those with dementia presenting unique and difficult challenges such as behavioural issues that require specialist and intensive 
input (de Vries \& Nowell, 2011) that aged care facilities are not necessarily able to provide other than in a consultative capacity with hospice oversight of care. Because of the downward trajectory of dementia, where there is progressive functional and cognitive decline, most of those with dementia die in aged care facilities (Mitchell et al., 2009). There are also significant issues which preclude the timely involvement of hospice services in the care of those people with dementia who are close to dying because the nature of dementia is such that it is difficult for many health professionals to tell when the person with dementia is about to die (Cherlin et al., 2005). In one study, caregivers of those enrolled in hospice felt unprepared for the death of their loved one as few were provided with information and family demonstrated limited understanding of the incurable nature of dementia (Barry \& Priggerson, 2002).

Those who die from dementia, or other dementia related issues such as repeated infections, in aged care facilities generally receive hospice services in the form of oversight of their care and advice to aged care staff. However many studies have highlighted that there are significant questions raised about whether, without hospice oversight, aged residential care facilities are able to provide the same quality of care to those with dementia as they do to those with other terminal illnesses (Teno, 2011). Similarly decreased staffing levels and lack of education provided to aged care facility staff in comparison to those of hospice facilities may preclude the delivery of high quality care and further research needs to be conducted into this.

\subsection{Summary}

Due to the extensive nature of the literature surrounding this subject, literature was reviewed selectively. In this chapter I have presented a selective review of the literature including burden, positive aspects of the caregiving role, emotional responses to the caregiving role, timeliness of diagnosis and advance care planning processes and access to hospice services. Justification for examining the experiences of caregivers of people with dementia at end of life is well demonstrated by the lack of research into this phenomenon within a New Zealand context. 


\section{Chapter 3 Methodology and Methods}

\subsection{Introduction}

I begin this chapter with a general overview of qualitative and quantitative research approaches. This is followed by a discussion on phenomenological research design and its benefits and potential limitations when utilised and applied to this study. The second part of this chapter addresses the methods of sampling, recruitment, data collection and data analysis. The concepts of reflexivity and rigour are also discussed.

\subsection{Qualitative and quantitative design methodology}

When deciding on what research methodology was most appropriate to achieve the objectives of this study, which were too understand decision making issues and dilemmas that occur for caregivers when planning end of life care for persons with dementia to explore experiences of preparedness and support for dementia caregivers, before, during and following the death of the person with dementia, it was important to consider the different characteristics and benefits of both qualitative and quantitative approaches. Quantitative research is borne out of a positivist paradigm and generates data that focuses on specific and precise measurements in relation to the given phenomenon the researcher is wishing to test (Campbell, 2001). Quantitative research utilises the generation of hypothesis and statistical analysis of findings to support or disprove the original hypothesis. Data derived from the application of quantitative methodology is characterised by the ability to generalise findings and provide causal explanations (Patton, 2002). In quantitative research the researcher is considered to have no bias and should be able to demonstrate neutrality and impartiality (Patton, 2002)

Conversely qualitative methodologies seek to understand, and give voice to, complex concepts relating to human experiences and realities (Windle, 2006). The purpose of qualitative research is to position the researcher in the world of the participant (Chase, 2005). Data is produced through contact with people in their own environment and encouraging them to tell their story in their own words in an attempt to understand their personal experiences via the analysis of the rich in-depth data that this research method produces (Chase, 2005). Application of qualitative approaches to research is of use when little is known about a specific phenomenon or where quantitative scrutiny has not been able to provide sufficient detail about lived personal experience (Schreiber \& Stern, 2001; Windle, 2006). Qualitative methodologies are useful in enabling the researcher to uncover and understand feelings, emotions and thought processes that conventional quantitative methods 
do not necessarily investigate or articulate with the depth necessary to reveal the lived experience of the participant (Broussard, 2006). Traditionally an argument that has been used to discredit qualitative research is that the sample size and methodology used are not conducive to producing research that is of sufficient worth, validity or generalisable (Tracy, 2010). Nevertheless, qualitative researchers accept that it is possible to conduct research about a topic that generates multiple realities as the data is sourced from multiple individuals with different, albeit similar, experiences. This differs from quantitative methods where a position is taken that there is a single reality that can be tested using a large sample of respondents (Broussard, 2006). Systems have been devised to increase and demonstrate the reliability and worth of qualitative research. These include member checking (Silverman, 2011), reference of quotes back to original transcripts within the presentation of the findings and making available the original transcripts (Tracy, 2010). Strategies such as these ensure that the research process is transparent and visible and therefore affording other researchers the ability to follow the process used and understand how conclusions about specific phenomena have been drawn (Bailey, 1996).

As little research has been conducted into the area of end-of-life challenges for caregivers of people with dementia in New Zealand, a qualitative design using an Interpretative Phenomenological approach was deemed to be appropriate to investigate this area of interest.

\subsection{Phenomenology}

Phenomenology was originally developed as a philosophical movement (Silverman, 2001). Fundamental to phenomenology was the desire to understand the lived experience from the perspective of the person experiencing it (Patton; 2002). This methodology is concerned with eliciting an account of the individual's perception of an event or experience, as opposed to developing or constructing an objective statement of the event (Patton, 2002). Phenomenology is concerned with the construction of meaning from the data provided, not necessarily the truth, to enable the researcher to reinterpret theoretically (Bailey, 1996). The development of phenomenology as a research method began in Germany prior to the First World War. While there is much literature about the development of the phenomenological movement, most of this is dominated by the works of Husserl and his student Heidegger (Dowling \& Brown, 2010). Husserl believed that it was necessary to study objects, participants and phenomena objectively (Holloway \& Wheeler, 1996). This approach necessitated the suspension of preconceived ideas and beliefs, a process known as 
'bracketing', to ensure that these did not affect the collection of the data or the participants' recollection or articulation of the experience (Dowling \& Brown, 2010). This has been referred to as the descriptive tradition of phenomenology (Lopez \& Willis; 2004).

Heideggerian phenomenological methodologies challenged the ability of researchers to objectively observe the world as Husserl had prescribed. Rather Heidegger introduced the concept of the hermenuetic circle (Heidegger 1950), an approach now known as a hermenuetic position; that it is impossible to conceptually bracket away any preconceived ideas or commonly held beliefs and that the emphasis should be on acknowledging and understanding one's own beliefs and accepting that the process of research is not a one way transaction (Koch, 1999). Heidegger (1927) believed that phenomenology was a solution for the problem of people losing touch or their grasp of being and the truth of being in the world. Heidegger believed that research should be viewed as a dynamic process that relies on rapport and connection between the researcher and participant and that the researcher is not there as a passive observer. On the contrary there is an active role for the researcher to undertake in the process of understanding the lived experience of the participant (Smith \& Osbourn, 2008). This was referred to as the interpretative tradition (Lopez \& Willis; 2004). Interpretation by the researcher is seen as an active affective synthesis in understanding (Patton, 2002). Furthermore the researchers' own perceptions and ideas are seen as integral to making sense of the participants' experiences through the process of interpretative activity (Smith \& Osbourn, 1998).

The development of field notes, conversations and interviews and the application of an interpretative approach enable the researcher to interpret and make sense of phenomena through the meanings that those being studied attributed to them (Chase, 2005). Interpretative Phenomenology is a two phase process whereby the participant attempts to make sense of their experiences and perceptions through the articulation of their story and the researcher collaborates with the participant to interpret and gain meaning from their stories and experiences (Lopez \& Willis, 2004). Heideggarian philosophies supported the notion of "co-constitutionality" (Koch, 1995). This is related to the belief that the meaning and emphasis that the researcher places on particular themes or concepts is a blend of both the researchers' and participants' feelings and thought processes, thus emphasising the collaborative and interactive aspects of Interpretative Phenomenological methodologies. 
In my study the application of an Interpretative Phenomenological methodology was felt to be most appropriate because the of the Heideggarian belief that the researcher cannot detach themselves from their own presuppositions (Smith \& Osbourn, 1998). This was also applicable to my own personal situation. During the course of this research I was devastated to learn that my own father, who had been living with Parkinson's disease for over 10 years, was diagnosed with vascular dementia. I recognised it was impossible for me to suspend my feelings or thoughts in regards to the phenomena I was studying as I was now immersed in it. I had become, in collaboration with my mother, a caregiver to my father with dementia. Rather I chose to adhere to the principles of reflexivity to assist in this process. This is discussed later in this chapter.

\subsection{Sampling and ethical considerations}

Sampling is integral to the overall research design. Few rules exist regarding sample size in qualitative studies. However, phenomenological studies, such as this one, tend to involve small samples of people who share a common experience (Abrams, 2010; Patton, 2002). Various issues, such as social isolation, the stigma associated with dementia (both actual and perceived) and challenges around talking about death and dying compounded to make this a relatively difficult population to access. Because of these challenges I decided to use snowball sampling (Handcock \& Gile, 2011; Penrod et al., 2003) strategies to recruit participants into my study.

Snowball sampling has merit in these types of situations as individuals identified to be included are then used to locate other potential participants (Penrod et al., 2003). One of the challenges identified with snowball sampling is that the network of members will be selflimiting (Penrod et al., 2003). The snowball method of recruitment does not claim to generate a statistically representative sample as recruitment relies on the identification of future participants by previous participants who are all socially linked. This limitation of snowball recruitment meant that all those recruited to this study were women and all but one was caring for a parent. Difficulty was experienced in the recruitment phase of my study as, while multiple potential participants were identified, the sensitive nature of the subject matter was considered prohibitive to involvement in the study for many.

Gate-keeping by ethics committees and health professionals has been cited as one of the greatest barriers to recruitment of vulnerable patients to research studies, significantly more 
than patient or family refusal (Ewing et al., 2004). However, gate-keeping by health professionals or the Ethics Committee was not a significant barrier in this study. Rather, because snowball methods for recruitment were used, other participants, who had already been approached earlier and who were pivotal to the recruitment of more people into the study began to make judgements about who should be included and why. Reasons for not allowing me access to these potential participants varied. In one instance a participant felt that recounting the death of the person with dementia would be too harrowing and distressing for the caregiver, and therefore she was not prepared to even broach the subject of the study with her. I assumed, that, based on her own views about bereavement and how traumatic it may be to talk about it, 'protective' gate-keeping occurred.

Once the interviews were conducted I found a very different reaction. Most of the participants appreciated the opportunity to tell their story and also to constructively contribute to an area they felt needed greater understanding and insight. Therefore not only was I precluded from accessing important different perspectives, but those potential participants also missed out on the opportunity to tell their story. Talking to another person about experiences has been cited as being potentially cathartic by facilitating an increased awareness of their situation and assisting the person to make sense of their own experiences and reactions to those experiences (Rosetto, 2014). This viewpoint is supported by Murray (2003) who, when reflecting on the interviews she conducted for her own study, felt that the interview process, in which participants were encouraged to give voice to their own experiences, was the first step in assisting these participants to make sense of their reality and to reconciling with it. Further to this Drury et al. (2007) posit that interviews can assist the participant to not only make sense of what has occurred, but also to grow from the experience. Drury et al. (2007) suggest that interviews provide opportunities for those engaging in them, such as the opportunity to develop solutions to issues that were presented and also the opportunity to acknowledge and reconcile with issues of concern. Drury et al. (2007) acknowledge that the therapeutic nature of interviews may not be as vague and as ethereal as reasons cited by other academics. It may be as simple as the opportunity to tell their story to an interested and impartial person that is recognised as therapeutic by the participant.

Various agencies such as the Alzheimer's Society were approached regarding this study, but I was unable to contact anyone who was interested in assisting me with this research. It could 
be suggested their reason for doing this was to protect the caregivers, who they may consider to be vulnerable and open to coercion, from involvement in time consuming research projects (Henderson \& Addington-Hall, 2005). However another major barrier to recruitment appeared to be that few agencies, or support networks remained in regular or formal contact with bereaved caregivers. While the care agencies appeared aware of potential participants, contacting them proved problematic as they were all past or discharged clients, not active ones.

\subsection{Recruitment}

As this study was concerned with the understanding of human experiences, ethical approval was required to ensure the safety and wellbeing of the participants. A proposal was prepared outlining the aims and context of the study and submitted to the Ethics Approval Committee at Victoria University. When discussing personal experiences with bereaved and potentially vulnerable participants, ethical issues come to the fore as it is paramount that the safety and well-being of the participants is both proactively considered and actively protected. All participants were given information about the study prior to meeting for the interview (Appendix I: Participant Information) and in addition written consent was obtained from all participants at the time of interview (Appendix II: Written Consent).

Recruitment began once ethics approval was received (Appendix III: Ethics Approval). My intention had been to recruit eight to ten participants however, as discussed above I was not able to achieve this. A sample of five participants was recruited utilising snowball recruitment methods for potential participation identification. All five participants met criteria for inclusion in that they shared the common experience of having been a caregiver of a person with dementia and were now bereaved. One participant has been a caregiver for both her mother and her father; therefore while there were five participants, six stories formed the basis of the findings as her experiences of caring for each of her parents had been both physically and emotionally different and had raised different issues (Table 1).

The length of time spent by each participant as a caregiver could be measured in time from diagnosis of dementia to death, however this is a crude measure as all of the participants identified that there had been some noticeable changes in behaviour and cognition that had prompted them to get assistance from health professionals prior to the actual diagnosis. Additionally, all of them identified that they had assumed the role of caregiver to varying 
degrees at the time of change, rather than at the time of diagnosis. For all but one of the participants the formal diagnosis was quite late in the continuum between impact of the disease and death. One participant, Marion, insisted that she and her sister were never told what was happening to their mother, despite their account of their mother's symptoms of decreasing cognition being accepted and recorded by the GP.

Table 1: Summary of Participant Details

\begin{tabular}{|l|l|l|l|l|l|}
\hline $\begin{array}{l}\text { Participant } \\
\text { (pseudonym) }\end{array}$ & $\begin{array}{l}\text { Relationship } \\
\text { with person / } \\
\text { people with } \\
\text { dementia }\end{array}$ & $\begin{array}{l}\text { Employment } \\
\text { Status }\end{array}$ & $\begin{array}{l}\text { Support } \\
\text { Networks }\end{array}$ & $\begin{array}{l}\text { Length of time } \\
\text { as a caregiver * }\end{array}$ & $\begin{array}{l}\text { Type of } \\
\text { Dementia }\end{array}$ \\
\hline Diane & Daughter & Full time & Sibling/Family & Mother 4 years & Vascular \\
\hline Patricia & Daughter & Full time & Sibling/Family & Father 3 years & Alzheimer's \\
\hline Sue & Daughter & Part Time & Siblings/Family & Mother 3 years & Alzheimer's \\
\hline Sue & Daughter & Part time & Siblings/Family & Father 4 years & Vascular \\
\hline Marion & Daughter & Full Time & Sibling/Family & Mother 4 years & $\begin{array}{l}\text { Unsure but } \\
\text { likely vascular }\end{array}$ \\
\hline Ann & Wife & Retired & Adult Children & $\begin{array}{l}\text { Husband 17 } \\
\text { years }\end{array}$ & Alzheimer's \\
\hline
\end{tabular}

All participants had in common the experience that the intensity and type of caregiving changed as the dementia progressed and symptoms of disease became more pronounced. Their caregiver roles began at time of changes in behaviour and cognition not necessarily at time of diagnosis and the amount of time that this group of participants spent in the caregiving role ranged from four to seventeen years.

\subsection{Data collection}

The purpose of interviews is to give the researcher insight into experiences and perspectives that are not easily observable by giving voice to the participant's story (Patton, 2002). Interviews, as a method of data collection, facilitate examination and understanding of complex issues. Semi structured interviews with each participant were used as a method for data collection. Each interview lasted between 60 and 90 minutes.

In conducting qualitative interviews there are three traditional approaches. They are the standardised open-ended interview, the informal conversational interview and the final approach which utilises an interview guide to structure the interviews (Patton, 2002). Standardised open-ended questioning involves careful consideration of the wording of 
questions prior to the interview to ensure that all participants are subject to the same amount of prompting and stimuli and also those questions are asked in the same order in each interview (Patton, 2002). The informal conversational interview is considered to be the most open-ended of the qualitative interviewing formats. It allows for maximum flexibility for the researcher to move the interview in whatever direction is most appropriate to enhance and maximise opportunities for the participant to tell their story (Patton, 2002). The third format is the use of the interview guide to structure the interview. While this format initially appears somewhat regimented in its approach, in fact the development and use of a guide allows for spontaneity within the interview as the guide ensured that the interview was developed and shaped around the same subset of questions and topics (Patton, 2002).

While the above are described as separate approaches and entities, benefits exist in each of the formats and they should not be considered as mutually exclusive (Patton, 2002). Interviews within a phenomenological study are open-ended. However, for this study, a combination of both the open-ended approach and the use of an interview guide was considered the best approach to conducting the interviews for data collection as I was new to undertaking research and to conducting interviews in a research study. A schedule of possible questions and topics to cover was developed and utilised to ensure that all areas of interest were discussed, where practical and appropriate (Appendix IV: Question Guide for Interviews). It was also used as a prompt as I was a novice researcher and this schedule helped me to focus on exploring the story with the participant, rather than focusing on the process of the interview. Open-ended questions were incorporated into the interviews to encourage free dialogue from the participant so that they were able to draw on and explore their own experiences and feelings without having to follow a particular line of specific questions. The use of open-ended questioning gave capacity within the interview for answers that were not necessarily anticipated or had been contemplated by myself, thus potentially enabling and affording insight into a different perspective that would add depth and understanding to the data (Bryman, 2004).

A disadvantage of open-ended questioning that is often cited is that the use of too many openended questions can result in decreased responses as the participant may feel overwhelmed and unsure of how they should respond (Bryman, 2004). I found that careful use of openended questions gave a degree of flexibility to the interviews which meant that I, or the 
participant, could adapt the course of the interview to deal with challenges such as when participants became particularly distressed or there were parts of their story that I felt needed to be revisited again. Similarly, flexibility in the types of questions being asked or prompts used was essential to establish sufficient trust and rapport for the participant toffee comfortable and able to tell their story. An example of this was in one of the interviews where a participant was asked about the death of her parent. At that point in the interview she felt unable to discuss this and motioned with her hands that she was unable to answer the question. Together we moved on to the next question. However, as the interview progressed, the participant took me back to my original question and was able to describe in detail the death of her parent and feelings associated with this event.

Acknowledging that I was a novice researcher and had much to learn regarding the research process and interviewing techniques, it was suggested that I have a pilot interview that could subsequently be used to refine my interviewing technique and enhance my understanding of the research process. This interview was conducted with a person who had cared for her relative with vascular dementia, but whom I had known through other circles. Once this interview was conducted and transcribed it was sent to my supervisor for analysis and critique. This step was invaluable in increasing my confidence with the interview process and conducting the interviews.

During this study I kept a comprehensive research journal which contained field notes that were written immediately after the interviews were concluded. Clarke (2009) recommends the use of a research diary, not only because it provides transparency to the phenomenon being researched, but also because it places a spotlight on the thought processes of the researcher and their analysis of the data and personal journey and development of their capabilities as a credible researcher. I found that my research journal assisted in giving context to the interviews and as such assisted me to develop a higher level of understanding and intimacy with the data than might have been reached if I had relied solely on the transcribed interviews and audio tapes. Commentary by Clark (2009) supports the use of a research diary both to grow and develop skills as a researcher and also as useful in acknowledging and celebrating successes. The research journal can also be used as a place to aid the process of reflexivity and development of the research through the recording of ideas, presuppositions and ideas related to the research which can then be either developed or acknowledged as potentially adding bias to the research (Jasper, 2005). The notes from my 
research journal were used as the basis for discussions with my supervisor and peers. In my research journal I would write notes about how the interview had gone, whether I had encountered difficulties or any special ethical considerations that were encountered. In some cases, even after the recording had stopped the participants would keep talking and this conversation was recorded in the field notes and as appropriate transferred into the findings.

\subsection{Conducting the interviews}

Initially phone contact was made with each potential participant to ascertain their interest in being involved and also to explain the context and aims of the study. If they expressed interest in participating I then offered to meet them prior to the interview. The reason for offering this initial meeting was twofold. The collection of rich data through interviewing relies primarily on the relationship between the researcher and the participant (Bowling, 2002). In offering to initially meet with potential participants prior to the actual interview, I had hoped that some of the relationship building would occur in this preliminary session. The second reason for this meeting was to be able to provide the potential participant with the information sheet regarding the study (Appendix I) and a copy of the consent form (Appendix II) so that they could ascertain both the purpose of the study and also what they would be consenting to, should they ultimately agree to take part. Additionally I felt that, even if the preliminary meeting did not result in someone who wished to be involved in the study, they may be able to provide me with valuable links to people who might consider being involved. Most of the participants declined this offer to meet prior to the interview.

All potential participants were provided with the information sheet and a copy of the consent form via e mail and were told that I would contact them again via phone within a week to ascertain whether they were prepared to proceed with being recruited into this study. During this phone call I also reiterated how their privacy would be protected and that involvement within this study was strictly anonymous. Once it was ascertained that they would like to be involved, appropriate times, as set by the participant, were agreed upon to meet and conduct the interview. Participants were given the option of deciding the venue for the interviews. It was essential that they felt comfortable in the interview setting to ensure that they felt free to share their experiences and story. Despite offers to come to their homes, most declined this opting for more neutral territory. One interview was conducted in the person's home, two in their workplace and two in my workplace. 
At the interview, time was spent reviewing the information sheet and also the consent process. Once I was comfortable that they understood the process and that they had no further questions the consent form was signed by both parties. This process of checking and ensuring their comprehension of what was involved varied in the time required with each participant. During the interview I continued to ask them whether they were still willing to be involved and in this way was constantly ascertaining their ongoing consent to involvement. This was particularly important when they became distressed during the interview process. The constant reaffirmation of willingness to consent throughout the interview is recommended by Parahoo (1997) who maintains that participant consent to involvement in qualitative research should be viewed as a process open to consideration and review, rather than a single transaction which guarantees ongoing consent.

Following this each participant and I worked together to ensure comfort and privacy in the interview setting. In workplaces this meant signs were put on doors to ensure no interruptions and in all settings I ensured that tissues and water were available as it was anticipated that talking about such an emotive subject was likely to bring emotions to the fore. I checked in with the participants to ascertain if there was anything else they felt they would require during the interview to ensure their comfort or safety before commencing the recording. Participants were also reassured that throughout the interview that they were in complete control and that they could stop the interview at any time.

Once the recorder was going, to begin the interviews, as is common with phenomenological interviewing, an open-ended question was used to encourage them to share with me their experiences of caring for someone with dementia. Interview techniques such as paraphrasing and reflecting back and the use of minimal encouragers such as nodding were utilised to keep the interview flowing.

\subsection{Data analysis}

In qualitative research the analysis of the data is not deferred until the end of the data collection, but it begins early in the process. The coding for this study began at the end of the first interview with significant field notes being written in my research journal on potential themes and pertinent thoughts regarding the interview and participants' experience. It was imperative that a framework for analysis was adopted that enabled fluid movement throughout the framework, not just in a linear fashion, so as to be able to accommodate the 
recruitment of new participants as they became available. Colaizzi's Method for Analysis (1978) allowed for rigorous analysis of the data through the application of prescribed steps and also the flexibility to move easily between the steps to include new data or subsequent insights made it appropriate for use to guide analysis of the data generated for this study.

The first aspect of Colaizzi's framework is concerned with the reading and rereading of the description of the phenomenon to elicit understanding of the lived experience of the participant. The audio recordings were sent to a confidential transcribing service identified by the university and professionally transcribed and subsequently sent back to me (Appendix VI: Example of Coding). In this study analysis of the data commenced immediately after the first interview with review of the field notes produced and consideration was given to aspects of reflexivity. As soon as the transcript was returned to me all lines of the transcript were numbered continuously for easy retrieval of data extracts. I read and listened to it simultaneously while checking line by line to ensure accuracy of the transcript. This audio tape and transcript were then checked by my supervisor. I found that, while the initial reading of the transcript and listening to the original recording were useful to ensure accuracy of the transcripts, each time I returned to the transcripts I heard the story slightly differently, often becoming much more aware of the significance of particular things that they had said. Hesse-Biber and Leavy (2002) describe the listening to the transcripts as a process of deep describing and interpretation. Initially, while listening to the audio recordings and reviewing the transcripts I focused on words and accuracy, following this when I knew the words well; I was free to focus more on tone of voice, intonation, pauses and emotion. This process gave me a richer and deeper understanding of the person's experience. This latter part of the re reading and re listening to the participant stories gave dimension and feeling to the stories which is integral in phenomenological research. In doing this I became very familiar with the transcripts.

The second phase of Colaizzi's framework is concerned with the extraction of key statements from the data that pertain directly to the phenomenon being investigated (Wojnar \& Swanson; 2007). Extraction of these key statements assisted in the formulation of themes and subthemes and also in attributing meaning to experiences. I employed various methods to assist with this process and found that colour coding participant responses regarding specific themes to be the most effective. I also collated tables of quotes that I identified as 
representative of the data or just ones that resonated with me as meaningful in the context of the research.

An essential component of Colaizzi's framework is the categorisation of themes. This is to identify themes that are common to all participants (Wojnar \& Swanson; 2007). I utilised the tables of significant statements to assist with this step in the framework. The tables were reordered to identify common themes and experiences. Initially these were collated under descriptive headings as a starting point. However, as understanding of the stories and as my confidence grew, these were changed to interpretative headings. As each participant was recruited I developed a deeper and more contextual understanding of the experiences. This occurred with both the individual story and also the collective experience that developed through the interpretation and synthesis of the individual stories into common themes. This part in Colaizzi's process is known as "Describing".

The final part of analysis of data, according to Colaizzi, involves returning to the participants and eliciting member validation and accommodating suggestions from them in the final work. I returned my summary pages and depiction of themes to two participants and was satisfied after discussion with them that the interpretations I had made about the data married with their perceptions of their own experiences. This is also referred to as member checking, validation interviews or participant confirmation (Buchbinder, 2010). Buchbinder (2010) suggest that that there are two purposes of this process. Firstly it is to ascertain that what has been recorded truthfully reflects the participant's recollection of the events and their story and also that the story is not distorted by the researcher's own bias and presuppositions. Secondly the validation interview serves to redress the potential for power imbalance which may occur in the interviewing process. Returning to meet with the participant and having them validate their story as collected by the researcher is a way of acknowledging that the participant had an active role to play in the collection of data and has not just been a passive subject. This view point is supported by Finlay (2003) who suggests that this process of member checking is integral to the quality of the research as it recognises the role the participant has to play in collaborating with the researcher to reconstruct and reflect on realities. I received an email from one participant who I had returned to for confirmation and validation of her story thanking me for the opportunity to retell her experience and also for the sensitive way in which I had recounted her experience. Additionally the other participant with whom I conducted member checking was also grateful for the opportunity to be 
involved and felt that telling her story had been cathartic. The notion of the interview being a therapeutic encounter is comprehensively discussed in section 3.4.

An important and interesting aspect of the data analysis to consider is that the retelling of their experiences by the participants is not a clear route to the truth (Atkinson \& Delamont, 2006a, 2006b). Central to Heideggerian methodologies is the concept that humans are interpretative by nature and thus apportion significance and meaning to experiences within their lives (Draucker, 1999). Furthermore humans do not exist in isolation, they are contextual beings whose context, environment and beliefs shape not only their experiences but also how they respond to them (Campbell, 2001). A mixture of participant generated information, data and the researcher's understanding of the phenomena blend to create what Heidegger termed the hermeneutic circle. It is from the merging of these three entities that the findings of Interpretative Phenomenological data will be generated (Koch, 1995). It is therefore, important to acknowledge that findings are a constructed truth. This acknowledgement does not detract from or lessen the validity of the findings, rather it positions them as a study of human beings who, in trying to make sense of the world in which they live, will apportion meaning and articulate their stories in different ways from one another (Frid et al., 2000). Giorgi (1994) argued that objectivity within phenomenological enquiry was impossible. Rather understanding and acknowledgment of the researcher's subjectivity was pivotal to the process of phenomenological enquiry. Fundamental to the quality and rigour of this type of research is the ability of the researcher to approach the subject of enquiry with openness and a willingness to understand the world of the participants from their viewpoint (Finlay, 2009).

\subsection{Reflexivity}

Reflexivity is classified as the hallmark of quality in qualitative research (Sandelowski \& Barosso, 2002). Reflexivity as a technique allows for researchers to consciously acknowledge the many ways that they influence the research finding. Reflexivity as a process emphasises the importance of acknowledging one's own perspective and the impact it may have on the study being undertaken (Patton, 2002). Reflexivity requires the researcher to look inward at the way they affect the research but also outward at other things that may affect the findings such as the way that the researcher and participant interact and collaborate to create data and apportion meaning (Alvesson \& Skoldberg, 2000). In this way reflexivity could also be classified as a journey of self-discovery and awareness. 
It is important to be explicit about the process of reflexivity to ensure legitimacy and rigour of the data produced (Tufford \& Newman, 2010). Reflexivity involves setting aside, but not abandoning, any preconceived ideas about the subject being researched. This enables the researcher to meet with the participant and understand the participant's view and experiences without clouding these with their own preconceived ideas and prior knowledge. Giorgi (1997) suggests limiting the processes of reflexivity and bracketing to the analysis phase. The primary reason cited for delaying this process until analysis was that the engagement and interaction with the participant should be the primary focus, not the setting aside of the researcher's views. However, I found Ahern (1999) and Rolls and Relf (2006) explanation of reflexivity more in keeping with the application of reflexivity that I had undertaken throughout my research. They suggested that it was important to examine and uncover preconceptions prior to undertaking the research project and to consider it as an ongoing process throughout the course of the research.

There were several tactics I utilised to assist with reflexivity. The first was my keeping a very thorough research journal. I utilised this journal to identify thoughts and feelings about undertaking the research and also contextual factors such as my ethnicity, age and occupation that might impact on my ability to undertake the research. It was in this journal that I noted thoughts and feelings about readings I had completed. As suggested by Ahern (1999) this journal was used to articulate possible areas of role conflict, such as researcher versus nurse. I also used it to gather field notes following taped interviews. I used this journal as a basis for discussions with other researchers.

To assist further with the process of reflexivity I met regularly with another student who was undertaking her masters and I was able to discuss with her issues that had surfaced. Extensive time was also spent with my supervisor reviewing the transcripts of my initial interview and subsequent transcripts to ensure that areas requiring improvement in my interview technique were addressed and that I was not influencing the participant's responses through the use of, for instance, leading questions.

\subsection{Rigour}

De Witt and Ploeg (2006) suggest that the concept of rigour in qualitative research is best established by the research itself having the means to demonstrate that it has integrity and is 
competent and is able to reveal the legitimacy of the research process and is representative of the truth (Tobin \& Begly, 2004). Patton (2002) utilised a framework to identify rigour and described the credibility of qualitative research as being dependent upon three facets of enquiry. They are rigorous methods, credibility of the researcher and a philosophical belief in the value of qualitative enquiry. These three points will be used to comment on the rigour of this study. The use of rigorous methods can be demonstrated in a number of ways. Careful consideration was given to the type of research being undertaken and the nature of the experiences that I wanted to give insight to. I read widely to increase my knowledge of the various types of methodologies available and was able to confidently decide on Interpretative Phenomenology as the method of choice. Reliability and validity are considered to be the hallmarks of rigour in qualitative research; however these are not applicable principles in qualitative research (Parahoo, 1997). Rather, Parahoo (1997) maintains that truth and credibility are appropriate alternatives when considering the rigour of qualitative research. Checking with participants to ascertain whether they believed it to be an accurate representation of their stories was a way to ensure that my interpretation of the participant stories was truthful and accurate and that it resonated with them as a reflective reconstruction of their experiences and story inside a bigger context of the collective truth of all the participants' experiences combined. Credibility of this study was also maintained through careful selection of the participants to ensure that they all had shared knowledge of the phenomena being investigated and met the agreed criteria.

The application of the reflexive process also assisted in upholding rigour in this study. Prior to the study I took time to examine my own belief systems that may impact on the collection of data or the interpretation of the experiences. Once I was aware of my own father's diagnosis I took time to consider how this might impact on the research and I sought professional advice from my supervisor as to whether this might be considered as a conflict of interest. Kramp (2004) acknowledges the need to incorporate your own perspectives into the research as it may open the path to a new way of viewing the research findings and experiences. I found that my experience with the area of interest enabled me to have a greater understanding of the participant experience and served to enhance the research while not impacting upon the data collection or analysis. Additionally my personal experience with a new diagnosis of dementia within my family enabled a deeper and more empathetic understanding of the lived experience of the participants. I was however careful not let my own experiences determine or bias findings. 
With a background of over 20 years in nursing and an intense interest in the care of older adults I felt well qualified to be interested in this field of research. However my credibility as a researcher was yet to be developed. As mentioned previously I spent time reading widely regarding differing methodologies and application to this study. I was guided and mentored well by my supervisor and feel that my ability, and thus credibility, as a researcher has developed exponentially throughout this study.

Moustakas (1994) determined that phenomenological enquiry was best utilised to understand several experiences of the same phenomena to inform the development of practice or policy. As a nurse, my desire in conducting research and understanding experiences is to continually improve the standard of nursing care, health care processes and delivery of care to individuals. The aspects of phenomenological research, interviewing, communicating and actively listening, are familiar to nursing and therefore resonate as an appropriate way in which to understand and gain insight into the experiences of others (Overcash, 2004). Similarly research generated via these methodologies resonates with other nurses and therefore can be used to inform practice and change cultures within health organisations.

\subsection{Summary}

Within this chapter methods and the philosophical foundations of Interpretative Phenomenology methodology have been articulated and discussed. This chapter focused on a summary of types of qualitative and quantitative research methods. Additionally this chapter has included an explanation of the type of sampling utilised, recruitment into this study, data collection and analysis. 


\section{Chapter 4 Findings}

\subsection{Introduction}

Analysis of the data revealed four main themes each with four subthemes (Figure 2). The subthemes for 'At the Coalface' were overloaded and experiencing guilt, shame and resentment. These reflected the workload, both emotional and physical, that the participants associated with the role of caregiver. 'Moving Heaven and Earth' was conceptualised under the subthemes of love and preserving dignity. This theme and subthemes centred on the love and care that motivated the participants to undertake the role, despite the challenges it presented. 'Facing the Change', in conjunction with the subthemes of loss of the person, living arrangement transitions and one dimensional conversations, draws together and describes the experience that caregivers were confronted with when dementia changed the person they had always known and the challenges that this presented. 'Finding the Answers' and subthemes of diagnosis and preparedness depict and articulate the lived experience of the participants in determining a diagnosis and support for themselves and the person with dementia in order to assist them in maintaining the caregiving role. While four distinct themes with their subthemes were revealed within the data, the interplay of these themes within the wider context of all of the narratives cannot be overstated. It is important that these themes be viewed as an integrated and composite package as this acknowledges the fluidity between all of the themes and the experiences of the participants as a whole.

Throughout the findings I refer to the family member with dementia as the 'loved one'. This decision was based on how, throughout all of the participants narratives 'love' was the one constant. Even when aspects of the role became too much, it was love that drew all of the participants back into undertaking the role. Despite exceptionally challenging and distressing circumstances and the wide range of activities that this role encompassed, love permeated the care that they delivered, the guilt, sorrow, resentment and grief they experienced and the decisions they were forced to make.

One of the participants was atypical insomuch as she was a spouse who had been a caregiver for 17 years, while the others were all adult children who had been caregivers for relatively short periods of time. While, analysis of the data demonstrated clear similarities of experience, exceptions are specified in the following presentation of the findings. 
Figure 2: Themes derived from the narrative data

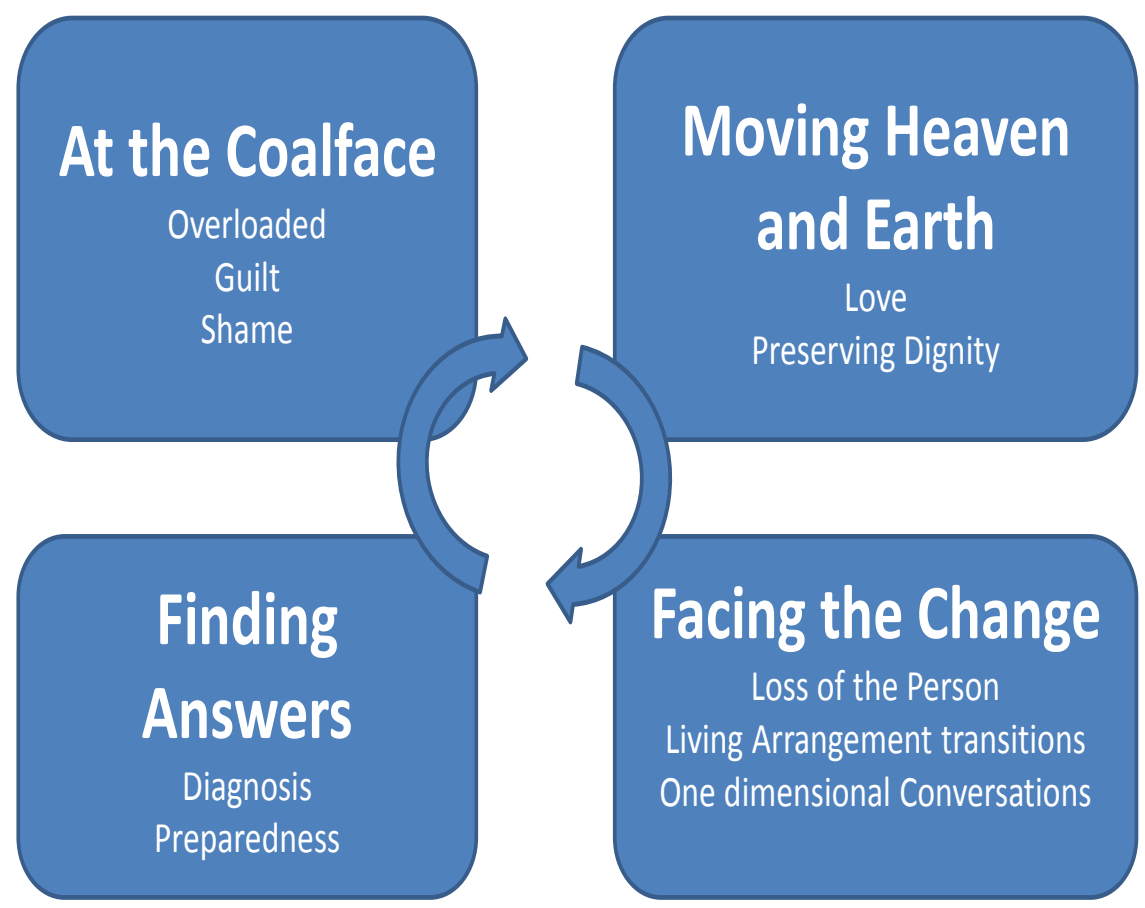

\subsection{At the coalface}

There are similarities between a literal coalface and the metaphorical coalface of caring for someone with dementia. While undertaking the role of a caregiver may not be as risky and physically as challenging as being a coal miner, the stressors in this role are as immediate and constant and sustained as they would be in a coal mine. Neither the literal or metaphorical coalface would be a job for the faint hearted. 'At the coalface', as a theme, conceptualises the responsibility that was felt in undertaking this role and the provision of constant oversight and care. The emotions that were engendered by being at the coalface included a sense of being overloaded and experiencing guilt, shame and resentment. 
At times being at 'the coalface' meant providing the day to day care that required difficult actions or interventions that forced the caregivers to distance themselves from their relationship with the person with dementia just to get the job done:

For me because I was a nurse I sort of wasn't a daughter anymore, I felt like a nurse. Like I'd be trying to sit on top of him putting a tablet in his mouth and he'd be trying to bite my fingers and I wasn't a daughter anymore (Patricia:74).

Other times being at 'the coalface' was accepting that not everyone was understanding or sympathetic to the pressures and strains that the caregiver was going through and that a certain amount of tenacity and pragmatism was required to be able to sustain the caregiving role. It was also acknowledging that while the role was very real for the people involved, those family members who were on the peripheries in other locations and away from the day to day grind did not always appreciate how difficult it was:

It was such a special time and it was such an awful time. I was the one that was most annoyed with my mother because I was here with her through that long senior journey or whatever it was. I was the one that noted that she had changed (Sue:15).

\subsubsection{Overloaded}

While only one of the participants within this study resided with the person with dementia as a caregiver, all participants found that the burden of delivering some physical cares, providing day-to-day oversight, negotiating care services within a complicated healthcare system and ensuring safety and decision making on behalf of someone else was, at times, onerous - especially when trying to support the person with dementia to live with as much independence as possible and balancing this within the context of their own lives and commitments. Frequently this sense of being overloaded caused tensions for those in the caregiving roles.

Sometimes this tension manifested as an internal angst for the person in having to make a decision for a person who still wanted to make their own decisions but was unable to do so coherently and lacked understanding of potential consequences. For the caregiver, having to make these decisions added to their feelings of burden and responsibility. There was also the constant dilemma over whether the decisions they had made were the right ones, particularly when the decisions that needed to be made were not agreeable to the person they were being made about: 
I would go and pick her up [from the aged residential care facility] and she would wail and it was just the pits... then I would take her back there and she couldn't articulate it "What's wrong with me?" she would say... she was surrounded by this behaviour that was so distressing for her but she couldn't articulate what that was and she couldn't even say "I don't want to go back" because she didn't know where back was (Diane:7).

Commonly those providing the care felt there was a tension between wanting to include their loved one in the decision making, but also realising that there came a point where the person was no longer cognitively able to make appropriate and safe decisions. Having that overall responsibility for their loved one's safety contributed to their feelings and experience of overload. This was particularly so when the person they were making decisions for did not want that oversight or for decisions to be made for them:

The buck stops with us, not with Dad and that was one of the most frustrating things, his right to make decisions and our duty to make those decisions for him clashed (Sue:22).

The following exemplar highlights the level and extremes that all experienced in some way at one time or another. All had questions and concerns as to whether decisions they had made in their role as caregiver and proxy decision maker were correct.

I think the worst part was one time he got out of his wheelchair and he was obviously hallucinating and he was touching things on the wall and crawling on the ground, and I couldn't directly take him to his room, he'd gone down the hallway and he was going towards the ramp that was concrete and I just thought Oh God, not a good mix. And trying to get him to come back when there's no comprehension and it really worried me and the doctor was just about leaving and I literally dragged him to my dad and he did help me get him back in his room and they gave him yet again some more medications. That's a quandary too because I know that the medications were compounding everything and making it worse, God it was just, you know, I don't know what else we could have done really. That's why his death was a blessing because there was no way out, I mean maybe they could have weaned him off medications, I don't think so, he was just too far gone (Patricia:16).

Five out of six of those with dementia in this study were admitted to an aged care facility. Of all the things that created experiences of overload, decision making and issues that were associated with admission to an aged care facility were the most painful, heart wrenching and stressful: 
I don't know whether the client base was different. I could be wrong but there were [younger] people there who were mentally ill in other ways who would just walk up and down the corridors constantly and it was just awful... and there wasn't room to move so that [older] people with walkers got knocked over and you would go to see her and she has a bruise on her head (Diane:6).

All participants used one or more strategies to manage the constant nature of the workload that was associated with their role to try to reduce the sensation of 'overload'. This burden was felt both physically and emotionally:

I had to put up with the manipulation when she was sick... you know I had to give her enema things, those suppositories to make her bowels work... I did it twice and I said to Mum I don't want to do this and I know she was really hurt but I knew that I'm not a nurse, I am her daughter (Sue:15).

Participants found that distancing themselves from personal care was beneficial in decreasing feelings of being overloaded in the caregiver role and it also had the positive effect of preserving the integrity and nature of the relationship:

I was included in his cares but [psycho geriatric facility] never let me or expected me to change his pad or anything like that. I liked that they did that so they tried to keep all the nursing jobs away from me as much as they could... I liked that they kept me, tried to keep me just as a daughter, not so much as a nurse (Patricia:7).

The role of caregiver was a mantle that was informally handed on or assumed. Because of the insidious and progressive nature of dementia it was not a transition that was planned or, in most cases, adequately anticipated. For the participants the responsibility for the role of caregiver was assumed partly out of love for the person with dementia and wanting what was best for them, but it was also due to proximity of location. For two of the participants, family support was forthcoming and did not require negotiation - however for two of the other participants, feelings of overload and the tension that this created necessitated the development of strategies to assist them in managing the workload:

Yeah so that was it and we finally, finally got it organised that [sister] would do one - we got it because it was starting to be a struggle in lots of ways so we worked it out that one would do a Wednesday and a Saturday and then have the whole week [off] and then the other would do that Wednesday and Saturday so it gave each of us a whole week off because visiting Mum got more difficult in what you'd talk about (Diane:10). 
In some cases the taking on of this responsibility caused resentment. While it was agreed that family networks were supportive at times, for some family dynamics, the interplay between family members and sharing or not of workloads had a part to play in creating some of the feelings of being overloaded within this role and this resulted in associated resentment. For all the participants there was an overwhelming sense of love for and commitment to the individual with dementia. However there was also resentment, in that some perceived they had been 'left' shouldering the burden over other family members:

It does cause a division because we two down here at the coalface started getting tetchy with that lot up there [siblings in another location who were not as forthcoming with offers of support or assistance] with all that we had to do because not only are you going the, you're actually doing the physical running around, especially once she was out at [a facility] that's a wee way to go, and also you've got all that emotional... if you didn't go you felt guilty (Diane:10).

For those caregivers who felt that they were somehow expected to take on more of the caregiving, it could feel very lonely when other members of the family were perceived to not be as involved in the caring as they should be:

[Sister] and I did that yeah we worked it out sort of. I'm the hero here I really am, sorry I am in that family. I tried not to say that but it was me, even when others were here [sister] would do Tuesday and Friday and that was it. Never the weekend and I would think why? But I because I thought oh I've got to be that? I've got to be the tough guy here I never said "Shit! I bloody work all week, why don't we alternate weekends to take Mum out" but then you feel really guilty that you are feeling that (Diane:10).

It was all pretty sad actually, I decided that I would get all the family together to try and get support from them, so that they understood, what it was like for me and for him. I think it was a complete and utter disaster. It was awful....I was just actually looking for them to say okay we will all pull together. Yeah my mind was in turmoil and the results of the meeting which I hoped would result in some understanding and harmony simply did not happen (Ann:18).

However there were also situations where support from family members was gratefully received because sharing of the caregiving role meant not just sharing the physical work but also assistance with the emotional toll that the caregiving role exerted on them. It meant someone else to share the decision making with and to share ideas with: 
[Son] was here quite a lot of the time.... I don't know how he coped with him really... it was quite good [for me] because [spouse] stayed with [son] and I could be here for quite a long time and then I'd go backwards and forwards (Ann:4).

My brother was home in [name of city] by that stage and he said to me "You've done Mum's journey, I'll do Dad's" like as in not completely on his own but I'll bear it, I'll take it away, it was such a relief (Sue:4).

My younger sister that was still alive, we got on really well and so we were always on the same page and we never argued and we sort of cared for Mum pretty much the same way (Marion:2).

For some of the participants there was a discord between desperately wanting to care for and to do what was best for their loved one, but at the same time resisting the burden and overload that was associated with this. Ann used a diary in the early stages of her husband's illness to try and record her feelings about being a caregiver:

I was lying in bed trying to analyse my feelings and one thing stood out, I felt like I am on the edge of a spider's web and [spouse] was the spider weaving me into the centre, to be caught with no escape. Now I know that sounds over dramatic and pathetic but the isolating feelings that were occurring just wouldn't go away (Ann:5).

These things were just so incredibly harrowing. But then she would... she'd want to go home - "I'll come live with you, I'll pay you" [she would say].... Well I mean even if you weren't working full time you couldn't [be a full time caregiver] (Diane:19).

Experiences of being overloaded were described in different ways in the narratives, but most articulated it as a sense of overall responsibility and of a duty to care for their loved one. This sense of overload experienced by caregivers that accompanied the constancy of the role, the need to always be the one who was overseeing everything, who was 'on-call' for any crisis situation, in spite of the person not necessarily wanting that oversight:

As time went by I found it harder to manage, if I was home he would follow me nonstop asking me the same questions (Ann:6).

I lived not that far away from [the care facility] and one morning they rang and Dad was just screaming the place down and he had all the nurses on top of him and they couldn't give standing orders in that hospital, they couldn't give IM or 
subcut medications so they needed my help to try and get an oral tablet down him. He was spitting, it was just terrible (Patricia:2).

I would phone the firewood people, every fire person in [name of town] and right out over [name of town] way and beg them not to deliver firewood to his house" [as he was no longer safely able to look after the open fire in his house]. Things like that were really, really hard (Sue:4).

Concern regarding whether or not the care they gave, such as engaging in deceptive practices and minor subterfuge, was right or appropriate, compounded participants' feelings of overload. Not only were they having to engage in activities, such as negotiating with traffic authorities, sometimes without satisfactory resolution, but they were also expending emotional energy then questioning the decisions they had made regarding care:

He had his car a big car and he was driving and I tried to get [help], I went to the traffic, I said look you should take his licence off him. "No, no" [they said]. So they said "oh well, we'll give him another drivers' test", so what does [spouse] do? He goes and gets all the books and studies them, [and says to me] "I'm busy [studying] all weekend, what if I fail?" I said "that's ok we can manage if you do". He goes and they pass him... well, where does that leave it? ... I had seen him do some pretty bad things so we decided we'd take his keys away and [son] got a false key for his car. So he came home from day care and apparently he'd forgotten something his hat or something so he goes to get into his car, the carer was here waiting, and of course the car wouldn't go, so he goes and rings up the $A A$ [to help] doesn't he. Well the AA came and fortunately I came in and with that we took his car away (Ann:17).

Taking on the role of caregiver and decision maker for a loved one with dementia presented unique challenges due to the progressive deterioration in cognitive function. The need and desire to protect their loved one meant compensating for loss of function. This created feelings of overload as the caregiver was having to try and pre-emptively prevent issues from occurring:

After Dad died I probably managed her money, I managed not her chequing account at all she had open slather on her chequing account but she had shops so I managed, Mum had no idea, she'd never worked, no idea you know she could use the cheque book when she wanted to and I felt that was tricky, I found that quite tricky. I found it tricky because she would say "Have I got enough money in there for [a particular item] should I, I don't know whether I should do that" and I'd say "Mum you know you've got all the money you need to do whatever you want to do" and a couple of times she did some quite big things without telling me and I hadn't transferred the money in and then her card would decline and I'd get these terrible SOS's "There's no money" and I would feel terrible because I hadn't looked at it for a day or two (Marion:3). 


\subsubsection{Guilt}

Guilt, as a subtheme of 'At the Coalface' was present for all of the participants to varying degrees. Feelings of guilt appeared to be generally associated with the failure to fulfil some moral standard that the carers had set themselves. Guilt was present in regards to uncertainty about the appropriateness of decisions they were required to make and their sense of preparedness to make these decisions, whether enough was done, whether their decisions were right and also the calibre of the care they provided. In the context of this study the informal caregiving role was not one that was contracted in to, rather it was gradually assumed, most of the time, out of necessity and a sense of moral responsibility as a result of there being a long term relationship, rather than by deliberate choice. This moral responsibility was initiated because the person in the caregiving role felt that they should want to be loving and caring towards the person that required the care and caring for the person with dementia was one way of expressing their love, yet there were times where the nature of the situation had produced feelings or actions, such as resentment, frustration and anger, and then guilt would accompany these emotions. This meant that guilt was not a one dimensional emotion - it was multifaceted involving anger, grief and resentment. Similarly, feelings of guilt varied in intensity and focus and also in what triggered experiences of guilt. At times it was directed at the situation, at other times the person with dementia, a family member or at the caregivers themselves. The number of decisions required, the situations they were placed in as caregivers and the constant nature of the caregiver role challenged the caregivers' moral standards of good care and compassion:

They found her and she had fallen in her bedroom and there was some blood on the floor and I don't know how long she had been there for... now then - that's the thing about living on your own (Marion:9).

Some of the decisions were made by medical staff with participants feeling that little or few alternative options were identified, and it was the caregivers who were left with the 'what if' questions:

\section{I mean I know chemical restraint isn't the answer but I don't know what the other} answer would have been (Patricia:3).

The concept of 'what if' is poignantly articulated in this excerpt from Sue's interview where she discloses that, even years after her mother's death, she takes water to bed because she 
worries about whether her mother received enough hydration when she was dependent on others. Conceptually the concerns regarding water were representative of deeper concerns about whether her mother received appropriate care or whether she was suffering and specifically whether the family provided enough care to make her comfortable at the end of her life:

I still go to bed every night with a glass of water on my bedside table....But looking back I feel a responsibility of care for Mum and I wonder if we swabbed her mouth out enough and I wonder if she had enough [to drink when she was reliant on family for her oral intake].... It's kind of traumatic really (Sue:14).

In some cases the person with dementia was injured in some way as a result of their physical deterioration. The result, for example, might be bruising. Caregivers often felt guilty about these injuries even when they had not been personally responsible for them:

He couldn't walk or stand anymore and he'd be forever falling over, he had so many injuries from falling because he'd just stagger into things and fall over (Patricia:5).

The caregiving role placed a huge responsibility on the shoulders of those undertaking it. This burden and ensuing overload sometimes resulted in resentment:

I could not stifle feelings of resentment rising in me towards [spouse], there was simply no conversation and no joy in small things (Ann:9).

But then paradoxically, feeling resentful produced feelings of guilt. In all cases participants struggled with the guilt of wishing the person with dementia to die rather than continue in their present state:

The realisation that he is fit and healthy and could be like this for a very long time did not give me good vibes. To even [have thought] like this is dreadful (Ann:11).

I wished that he would just die because he was dying and he was just so angry (Patricia:2).

[Mother had been diagnosed with pancreatic cancer]... who says this isn't the best solution? I know that sounds horrible but who says this isn't the best outcome that Mum is spared another three years going downhill because there is 
only one direction for her to go with her Parkinson's and with her dementia - it's not going to get better (Sue:6).

Even after death it was important to acknowledge that while death brought sadness, it also brought relief as demonstrated in a eulogy that Ann had written following the death of her husband:

"I wish to say goodbye to [spouse]. I cannot weep as this I did well over a decade ago. I am sad but pleased that this final ordeal is over for you. Over15 years ago you became distanced from your family not by your wish but the illness that overtook you".

Some also expressed regret at having to balance the caregiving role with their own home life and that this sometimes meant they were not as compassionate as they felt they should have been:

It just felt like she's getting older and she's losing these faculties and we just deal with it the best we can and you know I think, I don't think I was always so patient about being with her either (Marion:6).

If you're not doing quite as much you feel... and that's the interesting thing too because you want to be with her as much as you can because she is so bloody miserable (Diane:4).

Guilt was experienced when participants realised that they might have unwittingly contributed to any damage or pain that the person with dementia experienced. In the quote below, Sue's mother had been diagnosed with pancreatic cancer. Despite this being out of her control as she was not provided with enough information to care for her mother appropriately (and there were health professionals who had encouraged her to carry on feeding her mother) it remained an extremely harrowing experience:

One day Mum chowed down a whole lot of food and then it slowed down and then [GP] came in and said "What's everyone doing, what's your mother doing? Oh it's cruel" Actually I think what he did say was "This is just prolonging the time that your mother has to suffer" or something like that. He was right but I wish he had kept it to himself (Sue:16).

The guilt experienced as a result of this incident was compounded by others' judgements of her capacity to provide appropriate care. While knowing that she had potentially caused her 
mother more pain was one thing, perceiving that she had done the 'wrong thing' in the eyes of the doctor added to the guilt she experienced. Logically she knew the GP was correct, but hearing this information from a health professional only served to make her feel worse. This was coupled with her own awareness that she had caused her mother to suffer. Lack of information about her mother's health state meant that Sue was not able to recognise that her mother was nearing the end of her life and this, coupled with the pancreatic cancer, would be having a profound physiological effect on her digestive processes. Thus feeding her mother would have been perceived by the GP as cruel, rather than the act of love and caring that Sue had intended it to be.

Feelings of guilt and distress often accompanied decisions that were necessary, due to continued decreased cognition or to maintain the person's safety, but were very unpleasant for the decision maker, such as deciding to put the person with dementia into a care facility or reaching decisions about end-of-life care and ceasing interventions.

Most of the participants expressed distress regarding not only transferring their loved one into residential care, but also the actual decision making process that was involved in putting them into a facility. Additionally participants identified a disparity between the care they felt their family member needed or that they would like in place for their loved one and the care that was actually able to be provided in aged residential care facilities. Participants that had been involved in putting their family member into care all agreed that it was a difficult experience.

For Ann it was especially challenging as, even though she knew that her children loved their father, she felt that they did not understand her experiences of caring for him, and therefore had limited understanding of both her needs and his:

One of the hardest things I think was when I actually had to put him into care because although I had my family he portrayed pretty good when he saw them because he still remembered the family and they didn't think he was like [he was for me]... there was only [son] and I that really saw him you know in that downward repetitive stage (Ann:4).

This guilt was further compounded when family members inferred that the wrong decisions had been made and that the caregiver was in some way selfish. Additionally love for the 
person with dementia made other family members act in ways that removed the decision making from the primary caregiver, such as choosing a care home facility that was not close to the primary caregiver.

Also acquaintances would express criticism and judgements, albeit sometimes, obliquely, at actions caregivers had taken. This increased feelings of guilt:

[Spouse] was such an organised person... he kept notes about everything and that is why he could function so well. And he showed a very good [front] I mean even when I was putting him away [neighbour] over there [asked what we were doing] I said "He's going into care", "Oh" [said neighbour] "we'll miss him". I said "You don't have to live with him" [people] never lose their social graces, they can always sort of cover and this is what makes it difficult for people to see where [the person with dementia is] really at. (Ann:3).

As traumatic as the initial decision was to make, participants often had to contend with their own rumination over the decisions they had made and whether they were right, but also in some cases, they had to also cope with others' doubts about the decisions they had made. This added to the distress and regret experienced:

She [the person who had travelled with him to a care facility in another location] came back and said "Your daughter doesn't agree with it.... She said that my daughter had said "Oh he is not ready for this" "Why?" said [the person who had travelled with him to a care facility in another location]. [Daughter] said "I can see it in his eyes" (Ann:5).

Admission became a decision that was inevitable but completely unenviable. Only one of those involved in this study was spared this and even though all of the experiences with this occurred some years ago, all talked with regret and distress about the decision making:

Actually that's an emotional journey walking around those type of places... that was so difficult... You're busy trying on that first day just to get them in there, keep them sweet and not upset them, you don't want them to have nightmares in the night you know? You just want to walk out of there in two hours' time and go whew! we survived that. Mum didn't scream and cling onto me with her fingernails... but it was all about smoothing the way and not talking about anything that would upset her (Sue:10). 
It came as a shock to some that they could not necessarily have their loved one placed in the home of their choice - it was dependent on bed availability. Some of the facilities were considered less than ideal and because caregivers, in most cases, did not have the luxury to be 'choosey' they were forced to move their family member into what they considered to be a substandard environment. Concerns centred on not only the physical facilities, but staffing levels and safety of their loved one:

There was nowhere there was only [name of facility] and it's just disgusting. It's not the staff's fault... It's just disgusting. Thank God Dad wasn't alive to see her there. And I had to take her up there by myself (Diane:5).

Even after death, the activities and emotional workload of caregiving still carried on. Caregivers were often responsible for things such as the clearing out of units and at times this exposed them to aspects of the deterioration in function of their loved one that had gone undetected by them while the person was still alive:

After Mum had died and I was clearing her little flat out I found all these little notes she had written to herself. They were notes telling her how to do simple things like make a cup of instant coffee. The notes were carefully hidden away. She must have known something was going wrong before we did which make me feel really bad about not doing more to try and work out what exactly was going on when we noticed it. The notes were about how to do the most simple of things (Marion:17).

\subsection{Shame and embarrassment}

A sub theme and feature of the theme of 'At the Coalface' was shame and embarrassment. Shame and embarrassment are inextricably woven into preservation of dignity and protection of the loved one. This was a pattern for some of the participants as their loved ones progressed through the course of their dementia. Shame and embarrassment, as these terms pertained to this study, were not the type that would be felt or experienced if a family member was caught committing a criminal offence. Rather it was more feeling shame and embarrassment for the person with dementia on their behalf. The participants wanted to protect their loved one from hurt and ridicule in the face of a disease that the participants perceived had made their relative behave in abnormal and undignified ways. It was also about the lengths a family member or caregiver would go to, to preserve the facade of the life that they had once shared to the outside world: 
It was difficult for mum too because her life was quite traumatic looking after my dad, he was so difficult.... She was always trying to cover up and make it a normal family ..., a normal relationship (Patricia:5).

Occasionally I got phone calls and it was like the head teacher phoning, the head teacher phoning to say that your child was misbehaving and they were too hard, like in the too hard basket... and I thought well I didn't know that (Sue:7).

I felt embarrassed for mum because it turned out she wasn't having a shower every day even though she said she was...but it was such a change. She had always been someone who'd been meticulous about those things - knowing it had been important to her I battled with her to have a shower every day (Marion:6).

We were out walking and we met [a long term friend] and he says "Oh, who's that old lady there?" trying to be funny and smart and she got really upset (Ann:4).

\subsubsection{Moving heaven and earth}

Within this study the participants articulated their desire to go to absolutely any length to care for and protect their loved one with dementia. 'Moving heaven and earth', as a colloquial saying, indicated the person was prepared to go to any length and exhaust every resource to obtain a desired outcome.

'Moving heaven and earth' encapsulates the desire by the participants to care for their relative with dementia in a holistic and loving way, at times this desire to care came above all else and personal needs were put side. Within this theme were the subthemes of 'Love' and 'Preservation of Dignity':

It was the frustration with my [step father]. I knew that he wasn't wrong as such, there was no right or wrong, it was just that I had things I wanted to see happen and I wanted a lot to be let go so that mum could get the care she needed... He would have moved heaven and earth to [help her]... he would have sold his soul to save Mum from this (Sue:9).

\subsubsection{Love}

Love and caring for the individual motivated many of the actions of the caregivers. To the outside eye, some of the activities undertaken by the caregivers could have seemed misguided or unkind, but on closer inspection it was apparent that the things done or not done were a way of protecting and preserving the integrity of the person with dementia. These were done out of love and compassion for the person with dementia and in some cases, from a desire to 
keep their relationships and essence of the person intact. In some cases it was about another family member's desperate need to keep everything as normal as possible:

She'd see spiders coming down from the ceiling and [stepfather] would pay for a cleaning company to come and de-spider the house.... I used to get furious... but that was his way of placating Mum and keeping her happy and I'm sure that happens and it's not right and it's not wrong it just is but it used to wind me up because I guess I was probably battling with his denial (Sue:11).

Issues regarding placement of family members into care facilities were discussed by all the participants and they also recounted how caring and love for their family member was a factor in determining the care facility:

Looking back she was possibly in the wrong facility, wrong place for her. I know we made some [decisions]... I think this is across the board-loved ones make decisions on how a facility looks. We want our parents to be in attractive surroundings (Sue:7).

However love and concern caused caregivers to fiercely advocate for their loved one in circumstances where they believed that appropriate or sufficient care (both physically and emotionally) was not being provided for their loved one. The ultimate expression of love was that caregivers were prepared to take actions that they knew would test their limits in caregiving:

[The Hospital] rang up [name of care facility she was admitted from] and said do you have facilities with morphine and oxygen, because generally that's what we do at this stage - we send them back to where they came from. I said "No! I'll take her home [rather than send her back to the facility she was in], it's just not happening" (Diane:8).

Expressions of love and caring were poignant and detailed when it came to the end-of-life. At times this was because of things that were done or said in the time close to death. Other times it was because of the way that these experiences were retold. Even where the participant was not with the person when they died, the relief that it had been peaceful was articulated through all of the narratives:

It was wonderful, a nurse brought a bed in, I had a bed beside her and I'd dozed off actually holding her hand and when I woke up, I had only dozed off for about an hour or so then I woke up and she had gone and it was great to have that opportunity (Marion:14). 
It was actually lovely, he'd been peaceful, I could have kicked myself [for not staying] you know there's that side of you oh why wasn't I there? but Dad just... he had like you know when you're sick or you've got a cold or flu or whatever, you sleep more. That's how Dad died. Dad didn't die being resuscitated or he didn't die from being burnt or he didn't die from having a hip operation after he'd broken his hip, he died in a bed in a caring environment and it wasn't the best way to die but it was certainly pretty darned good (Sue:20).

The importance of a peaceful death was prominent in all of the narratives. All the participants stressed their desire for their loved one to die comfortably and expressed gratitude for any care that alleviated troublesome symptoms. Those who were with their loved one when they died talked with extreme love and caring about the experience. While the actual dying process was distressing, as was losing their loved one, the ability to be with them, time to say goodbyes and to be close at this final part of their journey was important:

It might be about a week before she died, yes it was because she was talking, you know she was still talking...not loudly but as I got out the Nat King Cole songs [sister] and I would sing with her and the whole family came home which was great, we had some cool times too which was really good... and so yes we got our mother back... we got her back and that was just lovely. I rubbed lotion on her arm and I wouldn't touch her for years prior to that you know, and it was just so, it was a real, it was a privilege to have something, that's what it was - just awesome (Sue:17).

So he was on the, well I don't know, he was on a syringe driver and then he had hospice input and of course they're beautiful... they really were and the syringe driver [was on] for maybe two days and it was perfect (Patricia:6).

Then he got really bad at the end and so they shifted him down [to the hospital wing] but they had hospice come in and they were all wonderful to him (Ann:6).

However, the time leading up to and after the death were distressing for some of the participants. Despite knowing that their loved ones were ill, the death of their family member still came as a shock. Not being prepared or knowing what to expect complicated the dying process and confused some of the caregivers. In some cases this was coupled with lack of compassion from healthcare staff. For one of the participants an outbreak of an infectious disease in the care facility meant that normal rituals in relation to death, such as touching the 
person or kissing them were unable to be observed. This left the caregiver with unresolved feelings of guilt, resentment and distress:

[Mum] came in just before he was dying and I was there and I was saying "Look how calm and peaceful he is" and he was but it was because he was near death and Mum just thought that was horrible because he was near death, she couldn't see [the positives] but she hadn't seen him being like a stallion running around the room or crawling around a room [therefore she had nothing to compare it with] (Patricia:5).

[After she had died and we went to visit her] they were still in lockdown, so we had masks and rubber gloves, it was not ideal. So we went into Mum's room... we weren't allowed to touch her because well they said don't because the place was just full of bugs. They were really thinking about us but I really wanted to [touch her]... One particular person who was the nurse was far more interested in [telling us what was] wrong with her ... [the nurse] had had the bug... [I wanted to say] "Shut up! She's died, I'm not interested!"... But of course I went "Oh no" (Diane:18).

\subsubsection{Preserving dignity}

All participants accepted and understood that the person with dementia also experienced distress about their condition. A central thread that was repeated through all of the interviews was the desire to mitigate or eliminate risks and threats to the erosion of the person, their personality and the essence of them as an individual. Central to all of this was the desire on the part of the participants to preserve their family member's dignity. Even after death, dignity and preservation of previous social standing were important:

I was quite into getting his teeth into his mouth as soon as I could so he looked a bit more like him and straightening him up a bit as he'd been fighting for so long, so just to yeah I was more into just doing things like that really, I couldn't have shaved him before so I shaved him then and things like that. More for his dignity because I think that's such a big part that's what he just lost all through his dementia and you know he was a businessman and he did have dignity, so I tried to do that for him at the end (Patricia:6).

Based on what they knew of their loved one prior to diagnosis, participants were concerned that somehow the person would do something, and while it would not embarrass the caregiver, it would have been deeply embarrassing and shaming to the person had they been sufficiently cognitively intact to be aware of what they were doing: 
It was really difficult for Mum too... her life was quite traumatic - She was always hiding, pulling the curtains so the neighbours couldn't see him doing things or trying to get him to be quiet (Patricia:5).

For some of the participants 'preservation of dignity' meant protecting the person with dementia from making mistakes in front of others as a result of their failing memory, and also to protect the individual themselves from potentially comprehending the extent of their disease through failure to complete tasks they had always been competent at:

He'd be saying I must get onto my accounts you know, all of those things were still, in his memory you know which made it really difficult to, as I said you know you had to sort of slowly keep taking the stuff away so he couldn't see it and then he wouldn't remember. And you'd feel like you're being pretty nasty to him, but it was easier to do that (Ann:12).

Participants also cited examples of the 'dehumanising effect' some care practices had on their perceptions of their loved one and some events became symbolic of all that was lost and changed as a result of the dementia:

He was just too far gone but you know minimal brain cells left in many ways and you really couldn't recognise him either at all. And sometimes he'd be wearing someone else's clothes too which was really different and then you really couldn't recognise him (Patricia:1).

The preservation of their loved ones dignity was hugely important. At time tactics were employed to preserve dignity:

...I think because I was a nurse I took over that role really and explained things to $[\mathrm{Mum}]$. So Mum got all the information through me... I was pretty adamant you know that Mum wasn't to go and visit because it was really disgusting what had happened to him. And Dad was being fed in a high chair with a bib on with pureed food, no teeth, you know just - she wouldn't have recognised him, it was horrible... I wouldn't let [my daughters] visit until the end when he was with the syringe driver on (Patricia:13).

For some there was relief as the person with dementia had increasingly failing cognition. It was seen as a protective factor to dignity:

...She was wandering into other people's rooms and getting into their beds. I mean thank God she couldn't remember because her dignity, Mum would be just mortified to think that she was doing that (Diane:4). 
Her memory just went to the point where at the end she would keep wandering down to the hairdresser because she thought it was the day to have her hair done and it wasn't. You know they would be lovely to her and they'd send her home and she would forget - which was good, but then it was also unfair because she couldn't recall what she needed to do (Marion:5).

However there were also interactions and experiences that the participants cited as positive and contributed to preservation of dignity. Any attempt by others, such as health professionals, other family members or friends, to maintain or enhance the dignity of their loved one was appreciated. Even some of the smallest acts, such as remembering a loved one's name correctly or recalling things that they had said, had the greatest impact and were what participants held onto in the midst of what felt like a totally dehumanising experience:

Oh [Geriatrician] he said things about Mum that were [correct]...which meant he knew who she was, you know he didn't know her that well I don't expect that but you knew in his head that he had a picture of [my Mum] because he'd say something that she'd said or done. He was caring, he was realistic, he was just amazingly fantastic (Diane:14).

Other positive experiences occurred where staff tried to provide care in a way that maintained the integrity of the person with dementia as an individual and thus assisted in preserving dignity:

By God it was like a little family up there. So [the facility]... the staff up there... Dad was only there for three or four weeks and you know two or three of them turned up to his funeral... I'd go up there and the blimming manager would be reading a letter out to one of the residents in her room and I think that's cool, that's the guts of it really isn't it - rather than a big room sitting on your own (Sue:7).

\subsection{Facing the change}

'Facing the change' encompassed the sense of loss that the progressive dementia trajectory had on their loved one. 'Facing the Change' recognises the fluidity of the trajectory of dementia and the effect that this had on the role of the caregiver, but also on the ever changing nature of the issues they were confronted with in the role of informal caregiver and the decisions they had to make. Three sub themes were borne out of the data and sit within 
'Facing the Change'. They were 'loss of the person', 'one dimensional conversations' and 'living arrangements'.

\subsubsection{Loss of the person}

Changes in personality and behaviour of the person with dementia meant, for some of participants, that their loved one became someone who was dramatically different from the person they had known. This also produced a sense of 'loss of the person', the basis for the relationship the caregivers had enjoyed with the person they were now providing care for changed irrevocably:

She was yeah, so it's just really difficult at the end, they're just nothing like they'd been. She was a very vibrant woman and she, you know she used to sew and she made cakes, wedding cakes and wedding frocks and she was always dressed beautifully and sew beautiful stuff for us and had a fabulous garden, all of those things you know and everything got taken away from her as time went by (Marion:7).

The losses that occurred due to the changes in the person and erosion of their personality were devastating to the caregiver and also caused feelings of helplessness:

His circle diminished quite rapidly. It was quite hard to witness and to not be able to assist in a constructive way. He had always been so very much in control of his life and everyone's around him (Ann:5).

Recognition of this shift in the relationship was painful for the participants to not only acknowledge but to also acclimatize to. The foundation on which their relationship was built was being steadily eroded and it was heart wrenching for the participants to accept that the person they were caring for was no longer the same person:

I think my father was very blessed that he got pneumonia because if he didn't I don't know what would have happened to him. He might still be alive wearing a nappy, and being fed in a highchair, not able to walk. He'd run marathons, he'd done everything, my Dad was a very fit person... he just wasn't the same person, he was like a drug addict in many ways and he was very confused as well and that underlying anger (Patricia:3).

Prior to the formal diagnosis it was very difficult for the caregiver to understand the gradual process of dementia. This time in the journey of the person with dementia was hallmarked by frustration, grief, confusion and profound sadness for the caregivers. Their loved ones could no longer be relied on to act in the way they always had, or to fulfil familiar functions: 
...then things started to go wrong, I couldn't understand what was wrong and I finally thought this is just not working, I thought I left it too late to leave him, because things were so unhappy. I think I just thought you know he was.... We just weren't getting on and we were arguing all the time (Ann:1).

My mother was like my best friend as a teenager really in a way...even though I had awesome friends, she was.... Anyway I won't go into all of that stuff. But she was great and she was always positive and always, she was everything you know, she was just one of those really cool people who cares about everybody and everything and then she turned into somebody that was the other way and everything was about her and it was about her because she was vulnerable and it was the Parkinson's and it just dominated our lives really (Sue:17).

There was recognition on the part of the caregivers that their loved one was changing in irreversible ways. As the loved one's cognition deteriorated, familiar ways, such as the way they communicated or the things they discussed were being lost:

She seemed quite detached from emotions on some level so I suspect that was all part of it because it became more obvious. She was a wonderful caring compassionate mother and suddenly she was kind of out here and sort of nothing much really cut her very greatly and she was very cheerful when Dad was diagnosed and was going to die in quite a short time but afterwards she just sort of picked up the pieces very quickly and it was kind of like you know it was just we sort of noticed complete detachment (Marion: 1).

For him going through [this] process, he wasn't the same person so I don't think mattered. Like I couldn't talk to him about rugby or we couldn't go for a walk along the beach ... he didn't remember [anything]... maybe he'd remembered his parents you know he called them their first names, maybe a little bit about his family but in the end I think Dad was so medicated that nothing got through to him really. In the end he didn't even know who I was... he either thought I was mum or he did nothing because I visited a lot. [I would] sometimes bring his favourite snacks - it didn't work. He used to like folding things [and] organising things... photos didn't matter, he didn't have any recollection so there was nothing I could really do like music... nothing really (Patricia:9).

Further progression of the disease meant 'loss of the person' and manifested as their loved ones ceasing partaking in activities that they had always enjoyed and that the caregivers associated with them:

I mean she got to the stage where she wouldn't, you know she loved her music, she'd have her music on, then she wouldn't remember to turn her music on, she'd 
just sit there quietly... she didn't read anymore and I don't think I understood that for quite some time. Of course she didn't read because she couldn't remember what she was reading. She'd read the page and she'd been an avid reader, that was the sort of... one of the first things that you noticed and... then the music was off (Marion:5).

I think it was before he was diagnosed and there was that film, an Irish film on where they won $\$ 8$ million and nobody knew who had won and it was so funny, I said "Oh come on, you've got to go" ... normally you could hear [spouse] laughing all over the theatre you know [he] just loved anything like that, and he got out and he came out and said "That was a silly film" but of course he couldn't follow it you see (Ann:7).

Most of the participants described this loss as being a gradual deterioration of their personality where key attributes were diminished or became absent. However, for one of the participants, physical aggression characterised the cognitive deterioration and loss of the person in a much more pronounced and affronting way:

He ended up just becoming even more psychotic ... [similar to other residents] and Dad was way up there with them, it was disgusting, he was getting all angrier and angrier and he was like a horse on all these medications just fighting more and more until he couldn't walk, he had to wear a nappy, he had to be fed in a high chair and this was just a progression (Patricia:2).

The day-to-day caregiving and oversight ceased when the person with dementia died which, while it was the final and absolute loss of the person, was met with varying emotions both up to and after death. The catastrophic effects of dementia on their loved ones, as they had known them, meant that, while they were still distressed when the person with dementia died, some felt a sense of relief. This relief stemmed from both a belief that the person had been lost to them many years prior to the actual death and which put an end to the feeling that they were 'already dead', but also relief on behalf of their loved one - knowing they were no longer suffering:

[Mother] is so sad and lonely and anxious. So it's like an ongoing thing I think and I never thought of that... I thought you know for me I mean I love my father but I'm pleased he's not suffering or tormented anymore and he's free. I never thought, I thought it would be the same for mum that she would be free but she's not free... [Mother] can't live, it's horrible... She feels guilt and sometimes says I feel so lonely I wish dad were still alive and I thought "Oh my God" because he put her through so much (Patricia:12). 


\subsubsection{One dimensional conversations}

The possibility of being 'alone but not lonely' was in stark contrast to the subtheme of; 'one dimensional conversations'. This was because what the narratives uncovered, for the most part, was the complete opposite. All but one of the participants were employed and all had social networks and the company of the person they were caring for. Some, however, experienced acute loneliness and grief as a result of the progressive trajectory of dementia. Changes in the person with dementia's personality meant that the relationship with person undertaking the care giving role also changed and this caused feelings of loss and, at times, loneliness:

The conversations weren't there, that was probably the first thing. There wasn't an easy casual conversation. Like you wouldn't chat about I don't know, I mean I can imagine her going on about the lady with the tattoo, you know she wanted to be an air hostess, but her opinions had all gone. It was all just questions and answer, it really was one dimensional conversations if you know what I mean (Diane:3).

She was absolutely bereft as [partner] had gone away for three weeks to see family and she was just like a naughty kid. [sister] and I spent our Sundays taking her out and she wasn't happy at all with us. Well, she didn't know what she wanted coffee wise. She didn't want to be here with this and "[partner] he will be home tomorrow? "No he won't be home tomorrow mum, a few more sleeps yet" (Marion:8).

Even the very diagnosis of dementia brought with it a sense of loneliness and grief for what was to come. Participants also articulated the idea that they were in this on their own for a lot of the time as others did not understand the diagnosis or facets of their new role as caregiver:

What I did was I did my grieving right then, right at the beginning because I knew that this was not going to be good... going to be awful, quite scary really and so I can remember crying all the way home (Ann:3).

[Mother] suffered from huge anxiety and loneliness and I think a lot of it is to do with Dad being so sick for so long and that it was just such a chronic thing for so long (Patricia:11).

The caregiving journey and subsequent bereavement were at times very confusing. Participants said that they were unsure about future steps and in some cases expected that 
they would feel one way at the time of death and were surprised that when it actually happened they did not feel that way.

She is suffering from huge anxiety and loneliness. So [I went from being] a carer for a father with dementia when I am back in [name of town] now I'm a carer for a widow of a man who had dementia and it's actually as bad as Dad in many ways because she's so sad and lonely (Patricia:11).

\subsubsection{Living arrangement transitions}

For some of the participants the transition in relation to living arrangements was traumatic and produced feelings of guilt. Only one of the five participant's relative was able to remain in an apartment in a retirement village, the rest were admitted to formal care facilities. However this sub theme of 'Living Arrangement Transitions' does not merely relate to care facilities. It is also focused on the experiences of the caregiver in trying to support their loved one to live as independently as possible while they were still able to make choices. However this subtheme also encompasses their experiences in transitioning their loved one into care facilities and the effect that this had on those involved in this study.

The timing of engagement with support services and entry into care was different for each participant. Variations in timing were indicative of the oscillating nature of dementia, the reserves and support networks available to each caregiver and also the caregiver's willingness to accept or acknowledge the need for assistance. Assisting their loved ones to live at home with support proved to be challenging for some as it was such a gradual process of deterioration:

[Dad said] he would leave the house feet first only and he actually meant it. So two years he dug in and [brother] and I went to see his GP who was actually away, unfortunately we got one of the female doctors at the practice who we didn't know and she was not keen on any intervention or going to see Dad because she didn't know him and I sat there and cried. I was so bloody mad. I mean I understood on one level, but dad had burnt a hole in his carpet and up the wall because he had put embers into a plastic bucket and things like that and he continued to fall (Sue:3).

Commonly participants reached what they considered to be a crisis point where they felt they were no longer able to guarantee the safety of their loved one and that admission to a formal care facility was necessary: 
I said to [GP] I can live with the fact if Dad fell over and broke his hip and subsequently died in the hospital but I could not live with the fact if Dad burnt himself to death. I said that's a different thing, that would be negligence on our part and just something else because Dad falling over is... it is wilful... but Dad having a fire is wilful but he probably didn't realise (Sue:19).

The interplay between family members and expectations of the person providing care meant that participants felt a sense of obligation to maintain the caregiving role - even when it was having a deleterious effect on their own personal life. Participants sought ways to balance family expectations and their own self-identity:

I had people come in and stay with him while I went out say for a night or for a day or something they'd come in but finally I found, I thought right and he had to go to day-care all day (Ann:9).

Even though [step father] loved her and did everything for her he left it so late [to get support] that one day he just got so frustrated and kicked a little side table, you know a little nest of tables and that went and hit Mum on the leg, it bounced along like they do and he was the most mild mannered guy so that was the beginning of us [initiating help], my sister came up to [city] and we went and saw the Doctor and said "please can we get a diagnosis for Mum" (Sue:2).

At times it proved difficult to get the support that the caregivers felt was required:

So nothing happened. Six months later I pushed again and [GP] made another referral to the geriatricians and the nurse and the geriatrician came round... [My step father] started being a bit more honest about how hard it was and how mum was doing... within two to three days she had moved to [a facility]. So [in the end] it was quite fast. So that was quite hard (Sue:2).

Other times gaining support followed a logical, gradual progression which paralleled the gradual decline in function:

She was living on her own and we felt pretty comfortable about that.... And then she got ill...So at that stage she had gone from living [independently] so then she had to go and live in the apartment in [a facility] so here she is, it's a gradual step (Diane:2). 
However, for some of the participants, the transition into a formal care facility was relatively quick. Often it related to some sort of perceived crisis situation, such as the caregiver not coping or sudden deterioration in the way that the loved one was functioning:

We organised with a guy at [a facility] who was working with Dad... he was Dad's case manager and he was going there for respite care to see if they could get medications and things organised and really he didn't leave from there. He ended up just becoming more psychotic (Patricia:2).

For some of the caregivers some of the most distressing experiences arose from the necessity to place their loved one into a care facility for more constant care and oversight:

There's nowhere to put her stuff that's safe .... And then she's wearing someone else's clothes (Diane:6).

Those participants who had admitted their loved one into formal care facilities all expressed opinions, both positive and negative, about their experiences of the care facilities. Most of the participants had had experiences with acute hospital settings while caring for the person with dementia. Of all those participants who had experiences with the acute hospital settings, perceptions were positive:

It was great that I could come and stay [when her mother was admitted to an acute facility] and you know my kids, we could all just come in and talk and she could hear us. Everyone was so accommodating. Yeah, I wouldn't have liked her being in hospital and me not there at all. So that was perfect, I thought it was great. (Marion 16).

She got sick and then [she went into an acute ward] and they were lovely. They were so great that I wrote a letter to [management in the hospital] (Diane 161).

Admitting their loved one into an aged care facility after having had them in an acute care environment was a shock. Not only were they having to cope with their own grief and guilt about admission to a care facility but also the staffing levels, physical environments and also the lack of professionalism and education of the people they were entrusting the care of their loved one to were deeply distressing for those who had undertaken the caregiving role:

I don't know how they enjoy their jobs and they don't show it in their faces and they don't tell us, it's just obvious that there are two caregivers and one nurse on all night for that whole facility that's with both wings, that's for the rest home and the hospital. What kind of sick system does that? You know there should have 
been at least a nurse on each end or whatever and two caregivers so you like double the staff - it would still be minimal. I don't know I'm only guessing but it's yeah.... It comes down to money (Sue: 21).

I think he was in care [there] for about five years I think, four or five years but during that time they obviously had difficulty getting staff and when we went over there he was just looking awful, just like a hobo you know (Ann:5).

There was also an understanding of how difficult caring for their loved ones could be for the care homes and also for those home care agencies who were trying to support the person with dementia to live independently. This tied very much into shame, as those who had undertaken the caregiving role knew that their loved one would be horrified if they had any understanding or comprehension of how they were behaving:

They're very busy there eh. Like one time when I was there that Sunday morning when I could hear him from my place and he was just vicious. We were waiting for the on call duty doctor to give him an IM injection and at the same time, so Dad was in the psychotic part of the hospital right in the front, not the dementia wing, the dementia wing had someone slipped over in their porridge.. and there were three staff and me with my Dad... I think I had a lot of empathy for the staff there too because they were fair. Sometimes Dad would have three staff with him to try and hold him down or calm him you know, easily three staff and there might be if you're lucky five on a morning shift (Patricia:13).

The actual facilities themselves, in terms of care they were able to provide, staffing levels and types of other patients with the facilities, were also cited as an issue in coming to terms with transition to formal care. Leaving their loved one in these facilities was a harrowing experience for the caregivers. It was also a very painfully conflicted time. They knew that their loved one had reached a point where they were no longer able to be supported at home, but the caregivers were horrified at many aspects of the care facilities and felt it was a decision that they were forced into making by the situation and deteriorating function - they truly felt there were no other options. Not only was it emotionally devastating but there was little support available to them in making this decision and in becoming reconciled to it:

We had her name down at [facility]... but anyway there was nowhere for her to go there was only [another facility] and it's just disgusting. It's not their fault. It's not the staff's fault, it's just... it's just... just disgusting. (Diane:6). 
It was hard to accept that at the end of their life this person, with whom they had had this enduring loving relationship and in whose care they had invested so much time, emotion, energy and love into caring for, was not entitled to the very best of care. It was heart wrenching for the caregivers to realise that dementia, which had already taken so much from their loved one, was also going to preclude them from the right to die in a hospice setting. Quite clearly articulated in the interviews was a desire for their loved one to receive the best care possible. For a variety of reasons, aged care facilities, particularly at the end of their life, did not meet these expectations and desires. Participants felt that their loved one had received second rate care by not being admitted to hospice when it had become obvious that they were imminently dying:

It was difficult because we wanted Mum to be in the hospice and she wasn't eligible to be in the hospice, which was really hard... it was lovely in there and compared to what Mum had in [care facility] it was quite different and I was saddened (Sue:13).

I wish mum had died at the hospice, but she didn't. She died and they did the best they could do, mum had pancreatic cancer, nobody was going to stop her dying, but rest home care or the hospital part of the rest home is so grossly understaffed. (Sue:21).

The magnitude of the decisions that participants were expected to make were both emotionally and physically taxing, especially when the person they were making decisions for did not want those decisions made for them or did not agree with the outcome. Lack of preparation and understanding of different formal care facilities meant that the decision to admit their loved one to a facility was even more traumatic. While it was distressing for them, it was made even more traumatic for the caregivers with the realisation that it was, at its most simple and basic level, a business deal for the care facility. This caused feelings of resentment and anger. Negotiating their way through the placement process and understanding levels and types of care and legal requirements was challenging and distressing for some participants:

It's big stuff [making a decision about formal care for a loved one] I don't know it might have been helpful if when loved ones go into a facility whether there's a brochure or a little checklist that people might compile, there probably even is one and I probably ignored it - I don't know... you know but it could say this is probably bringing up some issues for you and perhaps you and your family could get together and talk about it (Sue:15). 
Similarly, lack of understanding about levels of care and legal obligations made decision making and the speed at which caregivers were expected to make these decisions distressing. Lack of preparation and understanding of what could be expected manifested as confusion and distress for the participants when they were expected to make decisions quickly. Sadness about not only their own lack of preparation and understanding about what was happening was apparent, but also their concern for their loved one and empathy for how distressing it must have been for them to be removed quickly from familiar surroundings:

So they came in from the hospital or whoever the powers that be and did this really quick test on her and then told me she's got dementia and she can't stay here anymore. Now that is really hard. It was like she had to go the next day (Diane:4).

\subsection{Finding answers}

The final theme is titled 'Finding Answers'. What the narratives revealed was that there was huge variability in obtaining a diagnosis and preparedness of the caregivers in terms of information they required to undertake the role. The subthemes that presented themselves under the heading of 'Finding Answers' were 'Diagnosis' and 'Preparedness'.

\subsubsection{Diagnosis}

For all of the participants a formal diagnosis from a health professional was difficult to obtain and the perception of one of the caregivers was that they were never told by a health professional what was wrong with their mother. For most, a diagnosis was made after a significant period of their having noticed symptoms of decreasing memory and cognitive changes:

So I came back shell shocked you know completely [after informal diagnosis by son] and so then of course I went to the local doctor who sent him to, she believed me straight away you know what was going on, sent him to the specialist you know... the neurologist and of course he sent back and I've still got the letter here, a letter about him and saying well he was no worse or no better than anybody his age and of course [husband] saw this and he said have you read this?. So I went back to the doctor and said where does that put me? (Ann:38).

While all of the participants had noticed changes in their loved one's behaviour and cognition, for some the diagnosis came as a surprise: 
She was Mum $90 \%$ of the time. They were really subtle changes and so she always recognised us but it's just, yes so that's what I am saying we didn't really think it was dementia, we thought oh she's had a stroke or she's had a heart attack but then we spoke to one of the geriatricians up there and he suggested that was what it probably was (Diane:2).

You know we talked [with medical staff] about her memory but probably at the height of that with the doctor, they didn't ever give her a diagnosis, call us in and say look this what is happening to your mum and this is where you can get some help. She went to a geriatrician but he never called us either and said well your Mum actually has, this is what is happening with the brain and we were not formally told anything (Marion:6).

Not securing a timely diagnosis caused the participants to lose prime opportunities to involve the person with dementia in meaningful discussion around end-of-life decision making and advanced care planning. The narratives revealed that while various discussions were had by some caregivers, these plenary discussions lacked depth and substance and therefore still relied on the judgement and caring of those in the caregiving roles:

She never talked about advanced care.... She never had an advanced care plan. So we would be in the category of leaving it up to [the acute medical team] (Marion:10).

She'd say "Oh dear I don't want to, if I have a stroke I do not want to be kept alive in a bed and you know she said just let me go (Sue:9).

Few had engaged in detailed discussions around end-of-life care as it pertained to quality of life or advanced care planning in regards to some of the more meaningful subjects such as withdrawal of treatment and thresholds for ongoing care. However, even in the presence of some kind of advanced planning, wishes were not always adhered to. The caregiver was forced into the position of deciding what they thought their loved one would have wanted when the time came:

So I went and saw the GP after [staff had treated him for an infection] and I said look you know we didn't want him treated, The GP said well I had to make him comfortable. I said of course you do but I said we don't want you to [treat him], there's no point really (Ann:6).

Mum was sent to hospital and yes it was pancreatic cancer... they were going to fly her to [another hospital] to have a test and I was so against that because I 
looked at her and I thought she was tiny, she's got a terminal disease, who says this isn't the best solution? (Sue:6).

The need to advocate for their loved ones right to die added to the burden of these kinds of decisions as some felt guilt at not wanting to prolong their life and that this was made more pronounced through the perceived judgement of these decisions by others, such as health professionals. It was up to the caregivers to make decisions around their loved ones end-oflife care due to the lack of advance care plans. However, sometimes this proved too difficult and the caregiver would defer to the opinion of medical professionals:

For him going through the dying process, he wasn't the same person so I don't think it mattered. Like I couldn't talk to him about rugby or we couldn't go for a walk along the beach or you know you couldn't, he didn't remember... but I think in the end Dad was so medicated nothing got through to him really...He did have a 'not for resus' and we had that in place you know I mean it was really just for Mum... so I made sure that Dad would die calmly when the time came (Patricia:9).

I don't think she would have wanted to be shipped home [acute care]... So I'm assuming what she would have wanted and I'm assuming at that stage really and guided by staff [acute medical facility] (Marion:10).

\subsubsection{Preparedness}

As previously identified none of the participants anticipated this role would be as complex and difficult as it was and few felt adequately prepared to undertake the role. Due to the fluctuating nature of the disease, many were acting in the capacity of a caregiver without adequately understanding what this would mean for them. Participant's frequently identified and cited lack of information as a hindrance to them in their role as caregivers:

No one said this is what is happening and this is where you can get some help. I know that it would have made it much easier. I think if I had had more understanding... I read a very good article not long after she had died and I thought "Gosh I wish I'd had that at the time" (Marion:6).

Additionally, convoluted ways to access support systems, such as needs assessment support services and geriatrician or neurologist opinions, were also deemed as barriers to obtaining timely support and information. Due to the fluctuating nature and presentation of dementia caregivers talked about how difficult it was to get the care and support they required because 
often their loved one presented a lot better than they did at home. Also it was difficult at times to get buy-in from health professionals who normalised dementia with the 'old age' label. Additionally participants also found that the path to obtaining a diagnosis or support was not clear cut, quite often they felt shunted around various departments within the healthcare system, prior to obtaining the care they felt they were crying out for. For some only a determined approach finally secured a diagnosis and also the support:

[We wanted] an assessment for her and the things we told him really surprised him about what Mum was doing... because she was a really beautiful woman who was dressed immaculately and could fake for the 10 minute appointment (Sue:39).

The head man, the neurologist, he said he was no worse or no better than anyone else of his age. [A complaint was made] and so this neurologist made an appointment with another neurologist in [another centre]. So I took him [to the appointment in the other centre] and we went to see this neurologist who he kept asking questions and he couldn't answer them and he said "Well, I could give you a diagnosis, but you really need to go see a psychologist”" (Ann:42).

Delays in obtaining a formal diagnosis meant that the ability of the caregiver to equip themselves with the necessary information and support to undertake the role was impacted on. This was complicated and confusing terrain for the caregiver to traverse. They wanted to maintain the dignity of their loved one, but this needed to be balanced with changes in their behaviour and personality that required attention. They wanted to support their loved one to maintain a sense of self identity and normality. The resulting delay in acknowledging and accepting the diagnosis was a hindrance to caregivers in that it meant they delayed preparing for their role. Not only were the caregivers trying to orient themselves through this confusing time, but they were also trying to accomplish this on behalf of their loved one who had limited capacity to accept, acknowledge or acclimatise to their diagnosis and the challenges that it would have presented:

He wouldn't even admit it. That was the hard part. I said you've got Alzheimer's I said "it is hard for you and it is hard for me" but it was pointless because he had forgotten it just like that. He was always like "I will beat this. I'm not going to let this beat me". There was no way he was going to admit that he had it, which would have made it much easier to deal with it and to make plans... but he was too proud really to even say that and he probably didn't want to know either (Ann:15). 
Knowledge about dementia, appropriate ways to deal with changes in behaviour and ways to decrease, or at the very least decompress the burden for caregivers were limited. Only one of the participants was linked in with the Alzheimer's society. Lack of preparation and information compounded to make the caregiving role a harrowing experience for some. There was also a sense of not being able to 'see the wood for the trees', they felt so engrained in the situation that they were unable to extricate themselves from it, even for a moment, to be able to work out appropriate next steps or where to go for help:

At this stage this was our first parent going through that and I thought I don't really know a lot about dementia units and care and I still don't know a lot more now (Sue:165).

If someone had said to me maybe actually would you like me to get someone from the dementia group to give you call I would have said yes. And why didn't I know to access that myself? Sometimes when you're in it you don't do you? (Marion:299).

\subsection{Summary}

The themes generated in this study highlighted not only the onerous task that undertaking the caregiving role was for the participants, but also the significance of love when undertaking this role. Integral to the fabric of all interviews was the constant nature of love and caring for their relative. It determined and motivated much of their decision making and precipitated many of the emotions, such as guilt, around the decisions they made. Lack of information regarding what dementia is, how it might manifest in their loved one and what to expect made an already difficult situation seem, at times, almost unbearable. Additionally, lack of assistance and support meant that resilience had to be built by the individual to enable them to sustain themselves in this role. The data also highlighted how alone and misunderstood they felt in undertaking the role, often by those closest to them. 


\section{Chapter 5 Discussion and Conclusion}

\subsection{Introduction}

The purpose of this study was to understand the lived experience of caregivers of people with dementia at end-of-life. In this chapter I consider the key findings and selectively address the themes of 'love', 'overloaded', 'guilt', 'shame and embarrassment', 'loss of person', and 'diagnosis' in the light of existing literature in the field.

\subsection{Love}

Throughout all of the participants' narratives, 'love' was the one constant. It wove all of the other themes together. Love sometimes motivated participants to act in what appeared to outsiders as obtuse or uncaring ways, such as engaging in deceptive behaviours. However, all participants had assumed the role of caregiver following a long emotional relationship with the person with dementia. Love pervaded and motivated a lot of their actions and emotional responses. This is supported by the research of Shim et al. (2013) whose research focussed on finding meaning within the spousal caregiving role. In their study, caregivers commonly cited love as the reason they were able to sustain this role, because love for their spouse enabled them to view their role as purposeful and with meaning. The compassion and empathy which was present in spousal relationships enabled them to treat their spouse with dignity and sensitivity despite challenging and difficult circumstances. This compassion continued even after the person's dementia had progressed to the point that the caregiver was no longer able to tell what the person was feeling.

\subsection{Overloaded}

Much of the literature focuses on 'burden' when discussing the caregiving role, particularly in relation to caregiving and dementia, however this has associated negative connotations. In this study the term 'overload' was used rather than that of 'burden' as I felt that it better reflected the experiences of the participants as caregivers. The concept of being 'overloaded', in relation to the care giving role, emphasises the way that the issues in relation to workload are multifactorial. In relation to this study overload conceptualises, not only the physical and day to day care that was required of the caregivers, but also the mental and emotional aspects of the role which combined to increase feelings of being overwhelmed and overloaded. The use of this term is intentional as, although participants did not refer to their role as a burden, they did refer to it in terms that were more adequately expressed by the term overloaded. 
In keeping with my study, it is widely accepted and acknowledged in the literature that caring for a person with dementia is likely to be more intensive and exhausting than caring for a person with a physical illness (Annestedt et al., 2000; Lloyd et al., 2014; Schulz et al., 1995). Caregiving can be a positive experience with some caregivers mastering the role with amazing resilience. However if the requirements of those receiving the care exceed the emotional or physical capacity of the person delivering the care and oversight, the role of the caregiver can become detrimental to that caregiver's health and wellbeing and result in overload (Bergman et al., 2011; Schwartz et al., 2003). Caring for someone with dementia, with its chronic downward trajectory, provides the caregiver with unique and difficult challenges because of the disease's effect on multiple systems (Davis et al., 2011). While the time spent in the caring role and the trajectory of the illness was different for each participant and their loved one, those involved in this study all identified that their experiences of overload dramatically increased as the symptoms of dementia, such as worsening cognitive functioning and behavioural disturbances, became more pronounced. Both cross sectional and longitudinal studies into this phenomenon have concurred with the findings of this study in that the severity of behavioural and psychological symptoms of dementia increases the stress on the caregiver (Razani et al., 2014). Furthermore it has also been associated with a decrease in overall physical and mental wellbeing of the caregiver (Fauth \& Gibbons, 2013; Gaugler et al., 2000). While none of the participants reported physical illnesses or mental health issues that they felt were attributable to their role as a caregiver, their perceived stress and sense of overload was tangible in each of their stories.

Hennings et al. (2013) considered that the caregiving role required a degree of flexibility and also that it had a dynamic component to it, with the caregiver expected to adapt as the relationship between themselves and the person with dementia changed and also the needs of the person who was being cared for increased. For those involved in this study the flexibility and adaptation required on the part of the caregiver, that Hennings et al. (2013) allude to, increased their feelings of overload exponentially. All but one of the participants had to juggle their caregiving commitments with family needs and paid employment and overload was experienced when the needs of the person they were caring for impacted on their employment activities. Discussions in the literature regarding the undertaking of these dual roles are conflicted as to whether those in paid employment and undertaking the caregiving role are more stressed and overloaded than their non-working caregiving counterparts with some suggesting that work outside of the caregiving role provides a protective factor in 
extending the caregiver's social networks (Edwards et al., 2002). However, the findings in my study suggested that due to the unrelenting and unpredictable needs of the person requiring care there was conflict between the requirements of their paid employment and the requirements of the caregiving role. My findings also concur with research conducted by Sanders et al. (2008) who identified that life stressors such as balancing caregiving with paid employment or raising dependent children, family conflict or personal health crises were associated with higher levels of overload than in those who did not have these challenges.

While social networks have been found to act as a protective factor by partly shielding the caregiver from the pressure and workload associated with the caregiving role, there has also been research conducted that has found a negative correlation between social networks and perception of support and encouragement in the caregiving role (Fudge et al., 1997). In my study conflict within the social networks and the tension and resentment that arose as a result of this conflict were also found to be factors contributing to feelings of overload. Conflict arose primarily within family groups and centred on the need for institutional care, decision making, sharing of workload and a perceived lack of support in the caregiving role. This finding was supported by Fudge et al. (1997) who acknowledged that conflict was less likely to occur in diverse and semi diverse social networks than in family networks. In contrast to these findings there were also participants in my study who found great solace in their family network and felt well supported. However disagreement within family networks was more prevalent in this cohort.

Social networks can play a pivotal role in supporting caregivers to maintain their role by providing support, affirmation and a sense of belonging and nurturing of feelings of worth (Burleson, 2003; Fudge et al., 1997). Support to those undertaking the caregiving role is essential to maintain relationships, cope with stressors and also to adjust to change (Fudge et al., 1997). Neufeld and Harrison's (2003) research into non-support and female caregivers found that often conflict within family networks was as result of unmet expectations. Unmet expectations were defined as including unfulfilled or missing offers of assistance, mismatched aid or incompetence on the part of the person providing help. Lack of assistance resulting in unmet expectations was evident in some of the participants in my research whose perception was that, in the absence of family support, they were left managing the caregiving situation alone. Families are defined by a unique culture of shared meaning and values; conflict occurs when there is a discord, mismatch or misunderstanding regarding expectations 
(Neufeld \& Harrison, 2003). Within my study this was evident where the participant felt that their role as caregiver, and the pressure that it was putting them under, was misunderstood or not adequately recognised or acknowledged when family members they had expected to help failed to do so. Health professionals have an integral role in supporting the caregiver by facilitating their awareness of the importance of their caregiving role, referring them to support agencies and enabling the caregiver to recognise the positive aspects of their work (Shim et al., 2013).

Recollections of parental relationships by participants in my study concurred with the results of Samuelson et al. (2001) whose study found that the nature of the spousal relationship prior to diagnosis was a predictor of burden; the less secure or ambivalent the relationship pre diagnosis the more likely the caregiver was to experience overload and burden. Participants in my study whose parent's had experienced positive spousal pre diagnosis relationships appeared to feel less stress and articulate fewer feelings of overload, whereas those who had had ambivalent relationships prior to diagnosis reached the point where they experienced overload much more quickly.

Participants involved in my study chose to undertake the caregiving role for a number of reasons, including a sense of responsibility and reciprocity, guilt and social norms and expectations, which are frequently cited in the literature as common reasons for undertaking this role (Murray, 2014). For most in my study, this role was assumed because of physical location, but for all of them there was an overwhelming sense of love and moral obligation towards the person with dementia that ultimately motivated them to undertake this role. Because this role was assumed, as opposed to being formally 'applied for', feelings of overload were increased due to a lack of experience, confidence and skill in caregiving. These findings are supported by the work of Murray (2014) who asserts that when caregivers are not prepared adequately for the role through specific education and training, both the caregiver and the person with dementia suffer. These findings were endorsed by those of Teel and Carson (2003) whose study of family experiences of dementia care where individuals involved in the study cited lack of education and preparation for the role as limiting their ability to fulfil and sustain the role of caregiver to a relative with dementia.

The caregiving role combined love and concern with day-to-day care; it had both emotional and social facets (Hennings et al., 2013). Although most of the participants in this study were 
not involved in hygiene cares or similar, they still had to negotiate the provision of these services and provide constant oversight in terms of assuring their loved one's ongoing safety and wellbeing while still encouraging and promoting independence.

\subsection{Guilt}

Guilt was an emotion experienced by most of the participants during their time as a caregiver and it pervaded many aspects of the caregiving experience. Research by Romero-Moreno et al. (2014) defined guilt as centred around three main components. These were guilt about doing wrong by the care recipient, guilt about failing to rise to the challenge of the caregiving and guilt about neglecting their own self-care and leisure. Also this research discovered that there was a correlation between those who still participated in and made time for leisure activities while in the caregiving role, and a decrease in the detrimental effects of guilt such as depression and anxiety (Romero-Moreno et al., 2014). This is not to say that guilt about the caregiving role and associated activities was not experienced, just that the detrimental effects associated with this were not as evident in those who practised 'self-care' by participating in leisure activities. While Romero-Moreno et al. (2014) do not draw conclusions as to why this would occur, it seemed that the participants in my study who were involved in leisure activities had wider social networks from which to gain support, relief and identity. These things helped to decompress the feelings of guilt and thus limited their detrimental effects. Similarly in this way, while those working found this stressful, there were positive aspects in that it provided a wider social network that the caregiver had access to.

As the symptoms of dementia worsened it was necessary for the caregiver to adapt to changes in cognition and behaviour. Attempts at engaging in rational discussion of presenting issues began to fail as the person with dementia became progressively less able to process logical explanations. At times the necessary adaptations made the participants feel uneasy and guilty. One practice that made the participants in this study feel guilty was the engagement in deceptive behaviour to assist them in caring for the person with dementia. Relating this to the work of Romero-Moreno et al. (2014) this was guilt experienced as a result of doing wrong by the care recipient. Examples of deception in this study involved hiding work related papers and car keys and the buying into of hallucinations that the person with dementia was experiencing. In recounting their stories, participants expressed guilt and said that they felt ill at ease engaging in this type of behaviour. At the same time, however, they felt very few options were open to them. 
Blum (1994) recognises that this use of deception is borne out of a necessity to cope and that caregivers will eventually normalise this behaviour as being in the best interest of all involved. However Blum (1994) also acknowledges the quandary that this presents for the caregiver in that undertaking deceptive behaviours produces feelings of ambivalence and, in some, a sense of betrayal of the person with dementia, which can be difficult to reconcile with their love of the person. This echoes the findings of my study where the participants articulated this inner tension regarding the necessity of lying to the person with dementia to assist them in caring for their loved one. There were also situations where the person with dementia was not lied to, but deceptive behaviour occurred in order to protect them, such as asking wood suppliers not to supply wood, or making fake keys for the car in an attempt to stop the person with dementia from driving. Though they knew that their reasons for doing it were appropriate, it did not prevent the caregiver from feeling guilty and uneasy.

McIntyre and Cole's (2008) research into the lived experience of family caregivers found that many of them felt guilt, but not all of them could articulate what they were feeling guilty about - one of the participants in their study even went so far as to say they felt guilty all the time, about everything. Participants within my study articulated their experiences of guilt as oscillating - feelings of guilt were not always present, but at different times most aspects of the caregiving experience produced feelings of guilt of some description. Often the need to put their own needs ahead of the person they were meant to be caring for contributed to feelings of guilt which, linking it back to the work of Romero-Moreno et al. (2014) would be an example of guilt in relation to self-care. Examples of this included the need for the caregiver participants to advocate for their own needs to be able to sustain the role of the caregiver - such as putting their loved one into day programs or formal care facilities. These findings concur with those of Werner et al. (2011) who reported that family caregivers of people with dementia who withdrew from care and opportunities for support experienced higher levels of burden, specifically experiences of guilt.

\subsection{Shame and embarrassment}

While there were times where the participants felt embarrassed by their loved one, such as when they were using foul language or being obnoxious to paid caregivers, the concepts of shame and embarrassment as they pertained to my study focused primarily on the participants' concern that their loved one with dementia would somehow embarrass 
themselves or that they would be stigmatised once others outside of close networks learnt of their diagnosis, rather than the participant themselves feeling ashamed of their loved one's behaviour. Goffman (1963) defined stigma as a quality that is discrediting but also reduces the person from being whole, to something that is discounted and tainted. Goffman's (1963) definition of stigma was further distilled by Larson and Corrigan (2008) who developed the concepts of self-stigma, public stigma and stigma by association. The concept of 'selfstigma' - that is the internalisation of ideas and the reactions of those the stigma is directed towards - is of significance in regards to my study. In being the caregiver, and in taking over decision making, the participant took over worrying about not only keeping the person physically safe, but also protecting the individual from shame and embarrassment when the individual was no longer capable of doing this for themselves - that is they assumed the domain of "self-stigma". In this way the concepts of shame and embarrassment are inextricably linked with preservation of dignity. While the work of Werner et al. (2011) suggests that adult children was concerned with stigma by association with parents with dementia and the relative effect this had on their ability to cope in the caregiving role, this did not present as an issue in my study. Conversely, I found that this cohort of participants was more concerned with preserving the dignity of the person with dementia and protecting them from the associated stigma than the need to protect themselves.

The participants viewed the concept of preservation of dignity as hugely important. Promotion of dignity is to maintain the social standing of a person and to provide affirmation of their social role, even when mental or physical capabilities are deteriorating. Additionally it is important to encourage the person to make choices and to continue to be involved in decision making where possible (Holmerova et al., 2007). Actions undertaken by participants that were designed to preserve dignity included pulling the curtains so that neighbours would not see deterioration in behaviour and agreeing not to disclose diagnosis.

Sometimes, early on in the trajectory of their illness, the person with dementia would initiate decisions / behaviours / processes intended to avoid shame and embarrassment and potential stigmatisation. MacIntyre and Cole's (2008) research into caring and Alzheimer's disease found that it was common for the person with dementia to insist that no one was told as they felt there was shame and stigma associated with the diagnosis or that they would be treated differently because of it. The desire to preserve self-identity in the face of the diagnosis and to avoid potential stigmatisation was found to be one of the motivating factors in not 
disclosing their diagnosis to other people outside of their immediate social network (Deb et al., 2007; Phinney, 2006). This situation was true for one of the participants in my study. Unfortunately because of the effect dementia has on cognition and ultimately on behaviour, whether or not the individual wants others to know, symptoms of dementia will ultimately become apparent to others and there will not be the opportunity or ability to hide them. During this process the social isolation that can occur for both the person with dementia and the caregivers can be devastating, by precluding support from extended social networks and the involvement in formal care options such as respite care (Brodaty et al., 2005). This in turn increases caregiver overload. It also has a negative effect on the ability to provide future care in accordance with the person's wishes, as the prime time for discussions around advanced care planning and future care is early in diagnosis before cognitive decline makes it impossible to engagement in this activity. To maximise quality of life and to prepare the caregiver appropriately, timely diagnosis is of paramount importance. Unfortunately diagnosis in the continuum between impact or onset of dementia and death appeared to have occurred too late for this cohort of patients with dementia and their caregivers.

\subsection{Loss of the person}

The participants in this study defined the 'loss of the person' as the time in the course of the illness where the person with dementia was no longer the same person whom the participant had loved and appreciated - out of many of their experiences in their caregiving journey this erosion of the person they loved was profoundly distressing. This description is supported by research undertaken by Meuser and Merwit (2001) who more specifically classified this 'loss of the person' as pertaining to loss of intimacy, companionship, personal freedom, control and loss of personhood. In my study the 'loss of the person' involved all facets that Meuser and Marwit (2001) used in describing this phenomenon. My study highlighted that those with dementia stopped undertaking activities they had always loved and were known for, could not initiate conversations and began to display abnormal behaviours. The culmination of these changes was that they presented as a distinctly different person than they had been prior to the onset of their dementia. Rando (2000) termed this phase in the caregiving journey as "anticipatory grief" - that is where the things that made that person specifically them, unique and special were gone - lamenting the loss of a person who was not like their former self but who was still physically here. Boss (2004) further classified this as 'the ultimate loss of the person' - that is they were present in body but mentally absent. Research undertaken by Davis et al. (2011) also concurred with the findings of my study that loss of 
the person encompassed, and was typified by deterioration and loss of cherished relationships because the effect of the illness on personality and cognitive ability made the person with dementia unrecognisable to the person they had been prior to the illness. Specifically the loss of communication is cited as one of the most devastating effects of dementia (Small et al., 2000) with breakdowns in communication leading to a dramatic decline in their ability to interact and a subsequent deterioration in the quality of the relationship (Watson et al., 2013).

In keeping with the findings of this study, the literature highlights that deciding to admit a person with dementia to a formal care facility was a hugely significant, even life-changing, decision within the caregiving journey for those caring for someone with dementia (Chene, 2006; Gaugler et al., 2007; Nolan \& Dellasega, 2000). Nolan et al. (1996) suggested that there were four sets of processes which influenced whether or not admission to institutional care was viewed as a positive choice, accompanied by acceptance and positive feelings about the placement, or whether it was a choice that the person with dementia felt was forced upon them. These four processes are: Anticipation, Participation, Exploration and Information. While Nolan et al. (1996) developed these processes for use in quantifying and articulating the level of adaptation and acceptance to institutionalisation by the person with dementia, facets of these processes equally apply to the caregiver as evidenced by the findings of my study. In this study, the admission to a formal care facility was precipitated by a perceived crisis and therefore time spent in the anticipation, participation and exploration phases of Nolan et al. (1996) four step process was limited. Consequently time to adapt to the decision and prepare for admission was truncated, often at the expense of the emotional wellbeing and resilience that would have sustained them in their caregiving role in a new context and environment.

Commentary by Victor (1997) suggests that negative feelings regarding institutional care are perpetuated by policy makers and academics who have influenced communities into believing that caring for relatives at home is inherently preferable to institutional care. Furthermore, language used in relation to institutional care is often powerful, influential and negative - an example being where admission to institutional care was classed as the 'final failure' with some caregivers perceiving the admission to institutional care of their relative as failure of their home and abilities (Peacock et al., 2010, 2014; Victor, 1997). It is not surprising then that caregivers whose caregiving situation necessitated the admission to an aged care facility for their loved one experienced angst and distress regarding this. In my 
study, participants who required admission to an aged care facility felt that they had very few options left, but this feeling did not preclude them from guilt and distress regarding this decision. This was particularly where there was conflict within the wider family network as to whether admission was necessary.

As the decision to admit to an aged care facility is often undertaken, in part, to decompress feelings of overload and stress for the caregiver, it is of interest that in my study participants expressed the view that although day-to-day care was being provided by the facility they still felt responsible for oversight of their loved one, provision of social support in the form of visiting and outings and advocating for their standard of care. This is in keeping with findings of other studies that suggest that placement does not end the caregiving role, rather it signals a change for the caregiver where renegotiation and understanding of their new role is required (Davis \& Buckwalter, 2001; Sanders et al., 2008). Furthermore it is recognised that, while placing a loved one in a formal care facility often produces feelings of relief, it is also associated with guilt, grief, increased stress and sadness (Butcher et al., 2001; Paun \& Farran, 2011; Victor, 1997). Conflict is often associated with admission to a formal care facility (Dellasega \& Mastrian, 1995; Maas et al., 2004). This was evident in my study where participants felt that care agencies fell short of their expectations and they had to discuss with care facilities specific treatments to be withheld and for their loved one's safety and comfort to be maintained. Conflict also arose with facilities regarding high level decisions such as placement and funding issues.

Conversely, for some of the participants in my study, admission into a formal care facility was a welcome relief. This occurred where they felt the care delivered was appropriate and that the staff cared about their relative in a way that preserved their dignity while also catering to their relative's physical and psychosocial needs. This concurs with the findings of Peacock et al. $(2010,2014)$ who found that where relatives were welcomed into the facility and felt that they were involved in the care and were well supported by nursing staff, the process of admitting their loved one into a formal care facility was a much more positive experience.

\subsection{Diagnosis}

Common to all of the participants involved in this study was the difficulties they experienced in obtaining a diagnosis for their loved one. Lack of a timely diagnosis hindered the person 
with dementia and their caregiver in attempting to gain access to information regarding dementia. The result was that because of the progressive trajectory of dementia and its deleterious effect on cognition they were less able to decide together on future treatment options (Mitchell et al., 2013). It precludes the person from engaging in discussions around advance care directives with those who will be advocating for that care when the time comes, namely caregivers (Robinson et al., 2011). Furthermore it is acknowledged that, while the diagnosis of dementia is devastating and distressing for the individual and family, diagnosis can be the starting point to 'living well' with dementia (Mitchell et al., 2013). Therefore it can be reasoned that it is the responsibility of the health professionals caring for and assessing the patient and support networks to ascertain the best way to deliver the diagnosis and what support networks exist and what referrals are required in each specific circumstance (Bamford et al., 2004; Mitchell et al., 2013).

As a result of difficulties experienced in obtaining a diagnosis, it was the finding of this study that, while some of the participant had had discussions with their relative about future care decisions, mostly these were lacking in any kind of depth with the majority focusing on simple not for resuscitation decisions or instructions about specific disease types. Only one of the participants in my study was aware of intricacies such as what care their loved one wanted in regards to use of antibiotics once they were deemed incapable of making decisions for themselves. Unfortunately, delay in diagnosis meant that opportunities were missed to develop advanced care plans while the person was cognitively capable of engaging in this activity. The advantages of timely advanced care planning and end-of-life discussions to both the care recipient and caregiver cannot be overstated. In my study, participants expressed distress and guilt over making decisions on behalf of their relative and this was in line with research conducted by Gessert et al. (2001) who found that informal caregivers found this aspect of their role stressful. Arguably an advanced care plan that was developed in collaboration with a cognitively intact relative to be enacted when they were no longer able to make decisions for themselves might have assisted in alleviating some of this distress and guilt (Street \& Ottman, 2006).

Participants in this study also cited lack of preparedness for not only the role of caregiver but also the activities the role would encompass as a hindrance to the quality of care they felt they were able to provide and also their resilience within the role. Despite all of the participants in this cohort being relatively articulate and well educated, their concern about 
their ability to deliver the care, decisions they had made and the appropriateness of care they did deliver was evident. Research suggests that there is a positive correlation between caregivers with a high level of educational attainment and quality of care delivered (Brown et al., 2013). However, levels of education do not necessarily equip people for the caregiving role or provide the levels of resilience required to sustain them in this role. Participants within my study expressed difficulty in accessing information regarding the disease and what to expect of it. In part this was related to delays in obtaining a diagnosis, but also it was because many of them did not know who to ask for help and advice. The progressive nature of dementia is such that the needs of the care recipient and thus the caregiver fluctuate and change. Only one of the participants within my study was in contact with the Alzheimer's Society field worker, despite all but one having had contact with geriatricians during the course of their relative's illness. This is indicative of the variation in management from person to person. While it could be argued individual cases require individualised care specific to that person, the fact that, within my study participants expressed regret at not being linked into support services such as the Alzheimer's Society suggests that health professionals are either not assessing patients and their families adequately for their information and support requirements, or that, more likely, health professionals have a nonstandardised approach to assessment and intervention when it comes to dementia care, which means that important aspects of care of the person with dementia and subsequently care of the caregiver are missed. Health professionals have an important role to play in alleviating perceptions and experiences of burden by caregivers, especially in the light of research where participants still reported that they felt neglected, unheard, and remained confused about care options and where to seek assistance (Williams et al., 2013). This view is supported by Bamford et al. (2004) who assert that there is huge disparity in dementia care and wrap around support services worldwide.

\subsection{Implications for practice}

The findings of this study and subsequent discussion have many implications for practice and areas for innovation. It is acknowledged that nurses play a pivotal role in the care of those with dementia and also in supporting caregivers. However, as highlighted in the findings of this study, there are many areas for potential improvement in the way in which New Zealand's healthcare system cares both for those with dementia requiring care and in providing supports those family members loved ones providing the care. The Ministry of Health's (2014) commitment to improving the care provided to those with dementia as 
outlined in 'Improving the care of people with dementia' will go partway to addressing these needs. However, diligence on the part of health professionals will also be required to ensure that policies, processes and services are developed that truly meet identified concerns and areas of need.

In the light of the participants' perception that they did not feel prepared to undertake the role of caregiver in regards to education and information, it is a suggestion of this researcher that nurses work in collaboration with those with dementia and their families to ascertain educational and support requirements. This would require development within acute settings and GP practices to enable nurses to work alongside families and individuals to understand their needs and expectations of care. While those who participated in this study felt that should have known where to access help and support and chastised themselves for not knowing, it is my view that it is inherently the role of nurses and other allied health professionals to ascertain learning needs and facilitate the support required. Health professionals should ensure they have knowledge around what information is readily available, how to traverse complicated healthcare systems and what support networks are available locally and nationally to support caregivers is integral to understanding, acknowledging and acting upon identified learning needs and requirements for support.

However, being ideally situated to offer appropriate support as required rests on the acquisition of a timely diagnosis. All of the participants articulated difficulty to varying degrees in obtaining a diagnosis for their loved one. GP practices are generally the place where individuals will present or where family members will bring their loved one to talk about early changes in behaviour and similar concerns. Given the difficulties that can occur when a diagnosis of dementia is missed or not disclosed in a timely fashion, this education and support for GPs should be implemented with some urgency.

The development of care pathways that identify next steps would be ideal in assisting health care professionals in managing the care of those with dementia. While all care has to be individualised to ensure that needs are being appropriately met, a care pathway would include a list of recommended referrals, such as linking in with the Alzheimer's Society and Needs Assessment Service, that were offered to all those diagnosed with dementia and their families. Regular follow up with an identified health professional would be included in this pathway so as to ensure that needs were still being met and that issues could be proactively 
solved rather than the crisis management model that pervades care of those with dementia currently in New Zealand. This pathway would also include the ongoing discussions around Advanced Care Planning and End-of-life decision making. Discussions such as these are integral to decompressing some of the guilt and stress that was evident in the findings of this study for those family members who became proxy decision makers as cognition began to fail.

\subsection{Study limitations}

One of the major limitations of this study was the sample size. As discussed in detail in chapter three, recruitment was problematic in a number of ways and this impacted on the sample size. A further limitation was that only one of the participants was a spouse. The experiences of a spouse caregiver are fundamentally different to that of an adult child, although some similarities were noted within the data. It can also be noted as a limitation that - within the New Zealand context - there was an absence of recruitment of Mâori or Pacific participants. A study that would have included these groups would have added a richness of cultural similarities and differences of caregiver experiences. Further research is required to build on this small qualitative study to provide more robust examination of the experiences of caregivers and family members of people with dementia in New Zealand.

\subsection{Conclusion}

The trajectory of dementia and its impact on both the individual and those around them is likely to be devastating, progressive and unrelenting. Given that the majority of those with dementia will be supported to live at home by family, recognition, understanding and acknowledgement of the role undertaken by informal carers is imperative, so that support can be tailored to best meet needs so that caregivers can maintain this important and personcentred approach as long as possible. The purpose of this study was to articulate the lived experience of bereaved informal caregivers who looked after someone with dementia and understanding their decision-making at end-of life for their loved one. This study has described the intricacies of this role and the pressure that it places on those undertaking a caregiver role for a person with dementia. However, in some ways this has also been an atypical love story. It has articulated the extraordinary lengths that caregivers are prepared to go to in order to preserve the dignity of their loved one, their determined advocacy for their relative and the caring that has motivated them to carry on in challenging circumstances. While more research is required in this area, this study has also given voice to the personal experience of failings within a stretched health system that requires urgent attention so that 
wraparound support can be provided to the person with dementia and to caregivers so that they can maintain this important role by feeling empowered to make informed choices around care options and end-of-life decisions. 


\section{Appendices}

\section{Appendix I: Participant Information Sheet}

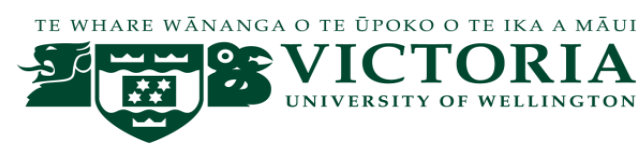

Version 2

27 May 2013

INFORMATION SHEET

Exploration of family/caregivers of people with dementia about their experiences of endof-life care

My name is Lucy Nunns and I am studying for a Master of Nursing Degree.

supervisor is Dr Kay de Vries at the Graduate School of Nursing, Midwifery \& Health at Victoria University of Wellington.

\section{Invitation}

You have been invited to take part in this research on your experiences as a caregiver of a person with dementia at end of life and during the dying phase. If you accept this invitation it will mean giving up approximately an hour or two of your time to participate in an interview.

\section{Why is the research being done?}

The purpose of this study is to understand decision making issues and dilemmas that occur for caregivers when planning end-of-life care for persons with dementia and to explore experiences of preparedness and support for dementia caregivers, before, during and following the death of the person with dementia.

\section{Benefits and risks of taking part}

It is up to you to decide. If you are interested in participating you will asked to sign a consent form to show you have agreed to take part. You are free to withdraw up to two weeks after the interview, without giving a reason. It is recognised that you will be bereaved and that the interview may stir up memories that are distressing. However it has been found that the process of retell distressing life events can itself be therapeutic. I 
have clinical experience working with both bereaved persons and older people with dementia however you are free to stop the interview at any time without giving a reason. If, following the interview, you feel that you need bereavement support I will provide information on bereavement servises that are available for your support.

We cannot promise the study will help you directly but the information we get from this study will contribute to knowledge about bereavement experiences of caregivers of people with dementia and also contribute to raising awareness for the public and professionals about the experiences of caregiving and dementia. The findings will be used to inform further policy planning and development on the use of Advance Care Plans for people with dementia and their caregivers. Recommendations regarding education and training on dementia care at end-of-life will be made as a result of the study.

\section{The interview (What will I have to do?)}

Once you have agreed to take part in the project, you will be asked to participate in an audio-recorded interview to discuss your experiences of being a caregiver of the person with dementia. The interview will be conducted at a negotiated date and time and a a site of your choice.

\section{The results}

The results will be written as a series of articles submitted to journals for publications and presented at conferences. All information which is collected about you during the course of the research will be kept strictly confidential. A summary of the study results can be sent to you if you choose.

\section{Data storage and destruction}

All data will be kept securely on personal password protected computer. Hardcopies of transcribed audio-tape recorded data will be stored in a locked. Dat a will be stored for 10 years and then destroyed.

\section{Research rights}

In New Zealand all health research involving human subjects must be approved by a health and Disability Ethics Committee, which may be contacted if you have any 
concerns. Ethics approval has been granted for this study by Victoria University of Wellington Human Ethics Committee (Reference Number 19882). If you would like advice as to your rights as a participant you may approach a Health and Disability Consumer Advocate by phoning: 0800423638 (Mid/lower North Island).

\section{Contact details:}

Student:

\section{Lucy Nunns}

Masters Student

Telephone No.

Mobile No.

Email lucy.nunns@nmdhb.govt.nz

\section{Supervisior:}

\section{Dr Kay de Vries}

GSNMH

Victoria University of Wellington

Wellington

Telephone: 044636650

Kay.devries@vuw.ac.nz 


\title{
CONSENT FORM (APPENDIX 4)
}

\section{Exploration of family/caregivers of people with dementia about their experiences of end-of-life care}

\author{
Principal Investigator: Lucy Nunns
}

I have had the opportunity to consider the information, ask questions and discuss this study. I understand that I may ask further questions at any time.

I understand that taking part in this study is voluntary (my choice) and know that I have the right to withdraw from the study at any time and up to two weeks after the interview/s, but after that the interview would become part of the research data. I understand I can decline to answer any particular questions.

I agree to provide information to the researcher on the understanding that anonymity and confidentiality will be maintained at all stages of the research (the information will be used only for this research and publications arising from this research and will not use my name, information identifying location of events and people will be disguised or removed, and that no opinions will be attributed to me in any way that will identify me).

The information will be kept confidential to the Researcher (Lucy Nunns), her supervisor, (Kay deVries), and the person who transcribes the recordings of my interview/s.

I understand that there is no payment for my or anyone else's participation.

I understand that the audio-recorded interview will be destroyed at the end of the project, and that the transcribed interviews will be retained in storage for 10 years, after which time they will be destroyed.

I agree to participate in an interview: -

Yes

No.

I agree to the interview being audio taped: -

Yes

No. 
I would like a copy of the interview when it has been transcribed: Yes

No.

I would like a summary of the overall research results: - Yes

No.

I also understand that I have the right to ask for the tape recorder to be turned off at any time during the interview.

Yes

No

I

this study.

(full name) hereby consent to take part in

Signature

Date

Address for the interview and / or results summary to be sent to: 


\section{MEMORANDUM}

\begin{tabular}{l|l}
\hline TO & Lucy Nunns \\
\hline COPY TO & Kay de Vries \\
\hline FROM & Dr Allison Kirkman, Convener, Human Ethics Committee \\
\hline DATE & 28 May 2013 \\
\hline PAGES & 1 \\
\hline SUBJECT & $\begin{array}{l}\text { Ethics Approval: 19882 } \\
\text { Exploration of family/whanau/caregivers of people with } \\
\text { dementia about their experiences of end of life care }\end{array}$ \\
\hline
\end{tabular}

Phone 0-4-4635676

Fax 0-4-4635209

Email_Allison.kirkman@vuw.ac.nz

Thank you for your application for ethical approval, which has now been considered by the Standing Committee of the Human Ethics Committee.

Your application has been approved from the above date and this approval continues until 31 July 2015. If your data collection is not completed by this date you should apply to the Human Ethics Committee for an extension to this approval.

Best wishes with the research.

Allison Kirkman

Human Ethics Committee 


\section{Interview Schedule: Questions and Prompts.}

\section{History of the dementia:}

Diagnosis made by who/ where/ when?

How long before diagnosis were symptoms noticed by family?

What were the family dynamics re the dementia?

What were the actions taken as a result of the diagnosis?

Who gave the information about the progression of dementia?

What sort of information were you given?

Was dementia as a terminal illness ever discussed at any stage?

Were they expecting the dementia to ultimately lead to death?

What sort of symptoms did the person with dementia have as they approached death e.g. pain, breathlessness, fatigue, agitation?

Were these dealt with appropriately e.g. were medications used and if so which ones?

Were they offered the opportunity to make an advance care plan?

Who assisted them to do this?

If they had one was it detailed?

If they had one was it acted on?

If they had an ACP was it useful?

If they didn't have one in hindsight do they think it would it have been useful to have had one? 


\section{Appendix V: Example of Coding}

41 getting pneumonia and he had a syringe driver on with some lovely calm

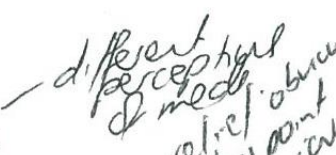
alice $\mathrm{PO}^{\mathrm{n}} \mathrm{e}$ medications in them and he took three days to pass away calmly, sort of calmly.

$$
\text { So that was what his death was like and I guess I instigated, I instigated all of it yinese }
$$
right from when he had dementia 15 years ago really as far as Mum couldn't cope because if he didn't I don't know what would have happened to him. He might the incide ts

still be alive wearing a nappy and being fed in a highchair, not able to walk. He'd desvibed.

$$
\rightarrow \text { fear of whet te mishf become. }
$$

run marathons, he'd done everything, my Dad was a very fit person but yeah he did

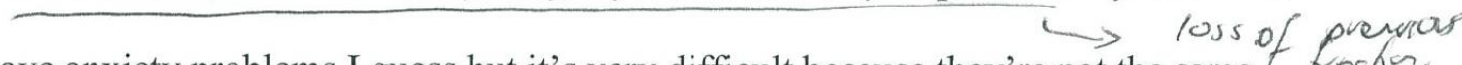
have anxiety problems I guess but it's very difficult because they're not the same f Lnchen. - luss of the persm, erosion Af persually. person when they do have dementia and quite often death isn't on the cards, it's

just something that happens out of luck really I think.

5.09 mins

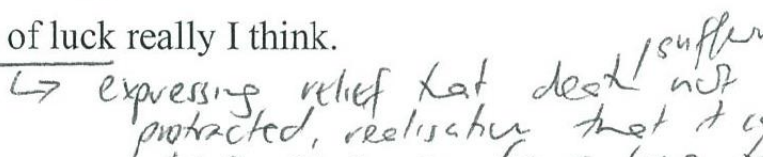

You've talked about the time when he was sort of very heavily medkated, when it

started to transit into something else did you feel that you were well prepared for

that, was that Alex was it?

Yep I mean he had, been having a lot of medication changes aft

I can't remember he was on something like 150 clozapine(?) three times a day and

just heaps and heaps and heaps of medicines. He wasn't the same person he was

like a drug addict in many ways and he was very confused as well and just that

underlying anger. So I don't know what else could have happened, I mean

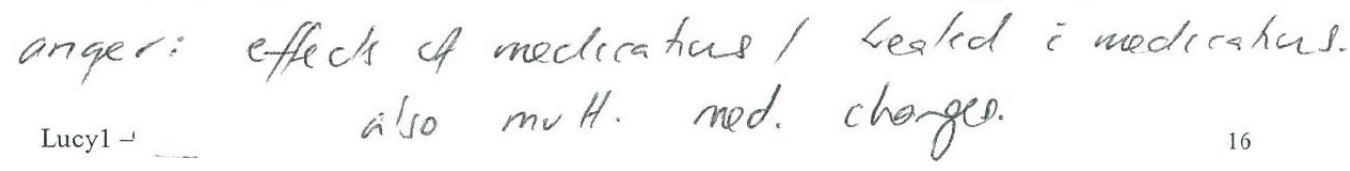




\section{Reference List}

Abrams, L.S. (2010). Sampling 'hard to reach' populations in qualitative research: The case for incarcerated youth. Qualitative Social Work, 9(4)536-550.

Doi:10,1177/1473325010367821.

Ahern, K.J. (1999). Ten tips for reflexive bracketing. Qualitative Health Research, 9,407411.Doi:10.1177/104973239900900309.

Alvesson, M. Skoldberg, K. (2000). Reflexive methodology: New vistas for qualitative research. London: Sage.

Alzheimer's New Zealand Incorporated. (2011). Dementia Economic Impact Report. New Zealand: Ministry of Health.

Annestedt, L., Emstahl, S., Ingvad, B., Samuelsson, S.M. (2000). Family caregiving in Dementia: An analysis of the caregiver's burden and the "breaking point" when home care becomes inadequate. Scandinavian Journal of Public Health. 2000;28:23-31.

Atkinson, P. Delamont, S. (2006a). In the roiling smoke: Qualitative enquiry and contested fields. International Journal of Qualitative Studies in Education, 19(6)747-755. Doi:10.1080/09518390600975974.

Atkinson, P. Delamont, S. (2006b). Rescuing narrative from qualitative research. Narrative Inquiry, 16(1)164-172. http:dx.doi.org/10.1075/ni.16.1.21atk.

Bailey, P.H. (1996). Assuring quality in narrative analysis. Western Journal of Nursing Research,18:186-194. doi:10.1177/019394599601800206.

Bakker, C., de Vugt, M.E., van, Vliet, D., Verhey, F.R., Pijnenburg, Y.A., VernooijDassen, M.J., Koopmans, R.T. (2013). The use of formal and informal care in early onset dementia: Results from the NeedYD study. American Journal of Geriatric Psychiatry, 21(1)37-45. doi.org.helicon.vuw.ac.nz/10.1016/j.jagp.2012.10.004.

Bamford, C., Lamont, S., Eccles, M., Robinson, L., May, C., Bond, J. (2004). Disclosing a diagnosis of dementia: A systematic review. International Journal of Geriatric Psychiatry, 19:151-169. DOI:10.1002/gps.1050

Barry, L.C., Prigeson, H.G. (2002). Perspectives on preparedness for a death among bereaved persons. Conn Med, 66:691-696.

Bergman, E.J., Haley, W.E., Small, B.J. (2011). Who uses bereavement services? An examination of service use by bereaved dementia caregivers. Aging and Mental Health, 15(4)531-540. doi:10.1080/13607863.2010.543661.

Birch, D., Draper, J. (2008). A critical review exploring the challenges of delivering effective palliative care to older people with dementia. Journal of Clinical Nursing, 17(9)1144-1163. doi:10.1111/j.1365-2702.2007.02220.x.

Black, B.S., Fogarty, L.A., Phillips, H., Finucane, T., Loreck, D.J., Baker, A., Rabins, P.V. (2009). Surrogate decision makers' understanding of dementia patients' prior wishes for end-of-life care. Journal of Aging \& Health, 21(4)627-650. https://dx.doi:10.1177/0898264309333316.

Blum, N. (1994). Deceptive practises in managing a family member with Alzheimer's disease. Symbolic Interaction, 17(1), 21-36.

Boerner, K., Schulz, R., Horowitz, A. (2004). Positive aspects of caregiving and adaptation to bereavement. Psychology and Aging, 19(4)668-675. doi.org/10.1037/08827974.19.4.668.

Boss, P. (2004). Ambiguous loss research, theory and practice: Reflections after 9/11. Journal of Marriage and the Family, 66:551-566.

Boustani, M. Peterson, B., Hanson, L., Harris, R., Lohr, K.N. (2003). Screening for dementia in primary care: A summary of the evidence for the U.S. preventive 
services task force. Annals of Internal Medicine, 138(11)927-937.

doi:10.7326/0003-4819-138-11-200306030-00015.

Bowling, A. (2002). Research methods in health. (2 ${ }^{\text {nd }}$ ed). Buckingham: Open University Press.

Brodaty, H., Donkin, M. (2009). Family caregivers of people with dementia. Dialogues in Clinical Neuroscience, 11(2)217-228.

Brodaty, H., Thomson, C., Thompson, C., Fine, M. (2005). Why caregivers of people with dementia and memory loss don't use services. International Journal of Geriatric Psychiatry, 20(6)537-546.

Brooke, J., Kirk, M. (2014). Advance care planning for people living with dementia. British Journal of Community Nursing, 19(10)490-495. doi:10.12968/bjen.2014.19.10.490.

Broussard, L. (2006). Understanding qualitative research: A school nurses perspective. The Journal of School Nursing, 22(4)212-218.

Doi:10.1177/10598405050220040501.

Brown, A.F., Vassar, S.D., Connor, K.I., Vickrey, B.G. (2013). Collaborative care management reduces disparities in dementia care quality for caregivers with less education. Journal of the Geriatrics Society, 61(2)243-251. doi:10.1111/jgs.12079.Epub2013 Jan 15.

Bryman, A. (2004) Social Research Methods (2nd edition). Oxford: Oxford University Press.

Buchbinder, E. (2010). Beyond checking: Experiences of the validation interview. Qualitative Social Work, 10(1)106-122. Doi:10.1177/1473325010370189.

Buckman, R. (1996). Talking to Patients about cancer. British Medical Journal, 313:699700.

Burleson, B.R. (2003). The experience and effects of close emotional support: What the study of cultural and gender differences can tell us about close relationships, emotions and interpersonal communication. Personal Relationships, 10:10-23.

Butcher, H. K., Holkup, P. A., Park, M., Maas, M. (2001). Thematic analysis of the experience of making a decision to place a family member with Alzheimer's disease in a special care unit. Research in Nursing \& Health, 24(6)470-480.

Butcher, H.K. Buckwalter, K.C. (2001). Exasperations and blessings: meaning- making and the care-giving experience. Journal of Aging and Identity, 7(2)113-132. Doi.10.1023/a:1015439218276.

Campbell, P., Wright, J, Oyebode, J., Job, D., Crome, P., Bentham, P., Lendon, C. (2008). Determinants of burden in those who care for someone with dementia. International Journal of Geriatric Psychiatry, 23(10)1078-1085. doi:10.1002/gps.2071.

Campbell, R. (2001). Heidegger: Truth as alaetheia. In R. Small (Ed.). A hundred years of phenomenology: Perspectives on a philosophical tradition. Burlington: Ashgate.

Carlander, I., Sahlberg-Blom, E., Hellstrom, I., Ternestedt, B. (2011). The modified self: family caregivers' experiences of caring for a dying family member at home. Journal of Clinical Nursing, 20:1097-1105. https://dx.doi:101111/j.13652702.2010.03331.x.

Chase, S. (2005). Narrative inquiry: Multiple lenses, approaches, voices. In N. Denzin \& Y. Lincoln (Eds.), The sage handbook of qualitative research ( $3^{\text {rd }}$ ed., 651-678). Sage: Thousand Oaks, CA.

Chene, B. (2006). Dementia and residential placement: A carers perspective. Qualitative Social work, 5(2)187-215. doi:10.1177/1473325006064257. 
Cherlin, E., Fried, T., Prigeson, H.G., Schulman-Green, D., Johnson-Hurzeler, R., Bradley, E.H. (2005). Communication between physicians and family caregivers about care at the end of life: When do discussions occur and what is said? Journal of Palliative Medicine, 8:1176-1185. doi:10.1089/jpm.2005.8.1176.

Cho, S., Zarit, S.H., Chiriboga, D.A. (2009). Wives and daughters: The differential role of day care use in the nursing home placement of cognitively impaired family members. The Gerontologist, 49(1), 57-67. Doi:10.1093/geront/gnp010.

Clarke, K.A. (2007). Uses of a research diary: learning reflectively, developing understanding and establishing transparency. Nurse Researcher, 17(1)68-76.

Cohen, C., Colantonio, A., Vernich, L. (2002) Positive aspects of caregiving: Rounding out the caregiving experience. International Journal of Geriatric Psychiatry, 17: 184-188. doi:10.1002/gps.561.

Colaizzi, P.F. (1978). Psychological research as the phenomenologist views it. In R.S. Valle, \& M. King (Eds.), Existential phenomenological alternatives for psychology (48-71). New York: Plenum.

Cornett, P.F., Hall, J.R. (2008). Issues in disclosing a diagnosis of dementia. Archives of Neuropsychology, 23(3)251-256. Doi:10.1016/j.acn.2008.01.001.

De la Cuesta-Benjumea, (2011) Strategies for the relief of burden in advanced dementia care-giving. Journal of Advanced Nursing, 67(8), 1790-1799. doi: 10.1111/j.13652648.2010.05607.x

Dautzenburg, P.L., van Marum, van Der Hammen, R., Paling, H.A. (2003). Patients and families desire a patient to be told the diagnosis of dementia: a survey by questionnaire on a Dutch memory clinic. International Journal of Geriatric Psychiatry, 18(9)777-779.

Davies, N., Maio, L., Rait, G., Iliffe, S. (2014). Quality end-of-life care for dementia: What have family carers told us so far? A narrative synthesis. Palliative Medicine, 1-12. DOI: $10.1177 / 0269216314526766$

Davis, L.I., Gillis, L., Deshefy-Longhi, T., Chesnutt, D.H., Molly, M. (2011). The nature and scope of stressful spousal caregiving relationships. Journal of Family Nursing, 17(2)224-240. doi:10.1177/1074840711405666.

Davis, L.L., Buckwalter, K. (2001). Family caregiving after nursing home admission. Journal of Mental Health and Aging, 7,361-379.

de Vries, K., McChrystal, J. (2010). Using attachment theory to improve the care of people with dementia. International Journal of Work Organisation and Emotion, 3(3)287-301. https:/dx.doi:10.1504/IJWOE.2010.032927.

de Vries, K., Nowell, A. (2011). Dementia deaths in hospice: A retrospective case note audit. International Journal of Palliative Nursing, 17(12), 581-585. doi:10.1046/j.1365-2648.1999.01091.x.

de Vries, K., La Fontaine, J., Brooker, D. (2010). Review of Literature: Information and Education Needs of People with Dementia and their Family Caregivers. Project Report. Association for Dementia Studies, University of Worcester.

De Witt, L., Ploeg, J. (2006). Critical appraisal of rigour in interpretative phenomenological research. Journal of Advanced Nursing 55,215-229. doi: 10.111/j.1365-2648.2006.03898.

Deb, S., Hare, M., Prior, L. (2007). Symptoms of dementia among adults with Down's Syndrome: A qualitative study. Journal of Intellectual Disability Research, 51(9),726-739.

Dellasega, C., Mastrian, K. (1995). The process and consequences of institutionalising an elder. Western Journal of Nursing Research, 17(2)123-140. 
Dening, K.H., Jones, L., Sampson, E.L. (2011). Advance care planning in dementia: A review. International Psychogeriatrics, 23(10), 1535-1551.

Doi:10.1017/s1041610211001608.

Dowling, P., Bwon, A. (2010). Doing research / reading research: Re-interrogating educations. $2^{\text {nd }}$ edn. New York: Routledge.

Downs, M., Cook, A., Rae, C., Collins, K.E. (2000). Caring for patients with dementia: The GP perspective. Aging and Mental Health, 4,301-304.

Draucker, C.B. (1999). The critique of Heideggerian hermeneutical nursing research. Journal of Advanced Nursing 3(2),360-373. doi:10.1046/j.13652648.1999.01091.x.

Drury, V., Francis, K., Chapman, Y. (2007). Taming the rescuer: The therapeutic nature of qualitative interviews. International Journal of Nursing Practice, 13,383-384. doi:10.1111/j.1440-172X.2007.00654.X

Dunham, C.C., Cannon, J.H. (2007). "They're still in control enough to be in control": Paradox of power in dementia caregiving. Journal of Aging Studies, 22, 45-53. Doi:10.1016/j.jagaing.2007.02.003.

Edwards, A.B. Zarit, S.H., Stephens, M.A.P., Townsend, A. (2002). Employed family caregivers and cognitively impaired elderly: An examination of role strain and depressive symptoms. Aging and Mental Health, 6(1), 55-61.

Doi:10.1080/13607860120101149.

Ewing, G., Rodgers, M., Barclay, S., McCabe, J., Martin, A., Todd, C. (2004). Recruiting patients into a primary care based study of palliative care: Why is it so difficult? Journal of Palliative Medicine, 18, 452-459.

Fauth, E.B., Gibbons, A. (2014). Which behavioural and psychological symptoms of dementia are the most problematic? Variability by prevalence, intensity, distress ratings, and associations with caregiver depressive symptoms. International Journal of Psychiatry, 29, 263-271. Doi:10:1002/gps.4002.

Finlay, L. (2003). The reflexive journey: Mapping multiple routes, in Finlay, L. and Gough, B. (eds) Reflexivity: A Practical Guide for Researchers in Health and Social Sciences. Oxford: Blackwell.

Finlay, L. (2009). Debating phenomenological research methods. Phenomenology and Practice, 3(1), 6-25.

Forbes, S., Bern-Klug, M., Gessert, C. (2000). End-of-life decision making for nursing home residents with dementia. Journal of Nursing Scholarship, 32, 251-259. doi:10.1111/j.1547-5069.2000.00251.x.

Fox, C., Maidment, I. Moniz-Cook, E., White, J. Thyrian, J.R., Young, J., Chew-Graham, C.A. (2013). Optimising primary care for people with dementia. Mental Health in Family Medicine, 10(3), 143-151.

Frid, I, Ohlen, J., Bergbom, I. (2000). On the use of narratives in research. Journal of Advanced Nursing, 32(3), 695-703.

Fried, T.R., Drickamer, M. (2009). Garnering support for advanced care planning. JAMA, 303(3): 269-270. doi:10.1001/jama.2009.1956

Fudge, H., Neufeld, A., Harrison, M.J. (1997). Social networks of women caregivers. Public Health Nursing, 14(1), 20-27.

Garand, L., Dew M.A., Lingler, J.H., DeKosky, S.T. (2011). Incidence and predictors of advance care planning among persons with cognitive impairment. American Journal of Geriatric Psychiatry 19(8), 712-720. Doi: 10.1097/JGP.0b0318e1faebef. 
Gaugler, J.E., Teaster, P. (2006). The family caregiving career: Implications for community-based long-term care and practice policy. Journal of Aging \& Social Policy, 18(3-4),141-151. DOI:10.1300/J031v18n03_10.

Gaugler, J.E., Anderson, K.A., Leach, C.R., Smith, C.D., Schmitt, F.A., Mendiondo, M. (2004). The emotional ramifications of unmet need in dementia caregiving. American Journal of Alzheimer's Disease \& other Dementias, 19(6), 369-380. doi:10.1177/153331750401900605.

Gaugler, J.E., Davey, A., Pearlin, L.I., Zarit, S.H. (2000). Modelling caregiver adaptation over time: The longitudinal impact of behaviour problems. Psychology and Aging, 15(3),437-450.

Gaugler, J.E., Pot, A.M., Zarit, S.H. (2007). Long term adaptation to institutionalisation in dementia caregivers. The Gerontologist, 47(6), 730-740. doi: 10.1093/geront/47.6.730.

Gessert, C.E., Forbes, S., Bern-Klug, M. (2001). Planning end-of-life care for patients with dementia: Roles of families and health professionals, Omega, 42(4),273-291.

Gillick, M.R. (2012). Doing the right thing: a geriatrician's perspective on medical care for the person with advanced dementia. Journal of Law, Medicine \& Ethics, 40(1),51-56.

Giorgi, A. (1994). A phenomenological perspective on certain qualitative research methods. Journal of Phenomenological Psychology, 25,190-220.

Giorgi, A. (1997). The theory, practice, and evaluation of the phenomenological method as a qualitative research procedure. Journal of Phenomenological Psychology, 28(2),235-260.

Givens, J.L., Kiely, D.K., Carey, K., Mitchell, S.L. (2009). Healthcare proxies of nursing home residents with advanced dementia: Decisions they confront and their satisfaction with decision-making. Journal of the American Geriatric Society, 57,1149-1155. doi: 10.111/j.1532-5415.2009.0234.x.

Goffman, E. (1963). Stigma: Notes on the management of spoiled identity. Englewood Cliffs, NJ: Prentice-Hall.

Handcock, M.S., Gile, K.J. (2011). Comment: On snowball sampling. Sociological Methodology, 41(1),367-371. doi: 10.1111/.1476-9531.2011.01243.x.

Hansen, E.C., Hughes, C., Routley, G., Robinson, A.L. (2008). General practitioners' experience and understandings of diagnosing dementia: Factors impacting on early diagnosis. Journal of Social Science \& Medicine, 67(11),1176-1183. Doi: 10. 1016/j.socscimed.2008.09.020.

Harrison Dening, K., Jones, L., Sampson, E.L. (2011). Advance care planning for people with dementia: A review. International Psychogeriatrics, 23,1535-151. doi:10.1017/S1041610211001608.

Heidegger, M. (1950). The Origin of the Work of Art. Translated by Roger Berkowitz and Philippe Nonet (2006) http://www.academia.edu/2083177/The_Origin_of_the_Work_of_Art_by_Martin Heidegger

Heidegger, M. (1927) Being and Time. Translation by: John Macquarrie, Edward Robinson. Trove Publishers:

Henderson, M., Addington-Hall, J.M., Hotopf, M. (2005). The willingness of palliative care patients to participate in research. Journal of Pain and Symptom Management, 29(2) 116-118.

Hennings, J., Froggat, K., Payne, S. (2013). Spouse caregivers of people with advanced dementia in nursing homes: A longitudinal narrative study. Palliative Medicine, 27(7), 683-691. Doi:10:1177/0269216313479685. 
Hesse-Biber, S.N., Leavy, P. (2002). The practice of qualitative research ( $\left.2^{\text {nd }} \mathrm{ed}.\right)$. Thousand Oaks, CA: Sage.

Hirschman, K.B., Corcoran, A.M., Straton, J.B., Kapo, J.M. (2010). Advance care planning and hospice enrolment: who really makes the decision to enrol? Journal of Palliative Medicine, 13(5), 519-523. doi:10.1089/jpm.2009.0370.

Hirschman, K.B., Kapo, J.M., Karlawish, J.H.T. (2008). Identifying the factors that facilitate or hinder advance care planning by persons with dementia. Ahzheimer's Disease and Associated Disorders, 22(3), 293-298. doi:10.1097/WAD.0b)13e318169d669.

Holloway, I., Wheeler, S. (1996). Qualitative Research in Nursing and Healthcare $\left(3^{\text {rd }}\right.$ ed). Oxford, United Kingdom: Blackwell Publishing.

Holmerova, I., Juraskova, B., Kalvach, Z., Rohanova, E., Rokosova, M., Vankova, H. (2007). Dignity and palliative care in dementia. The Journal of Nutrition, Health and Aging, 11(6),489-494.

Husband, H.J. (2000). Diagnostic disclosure in dementia: an opportunity for intervention? International Journal of Geriatric Psychiatry, 15(6), 544-547. doi:10.1002/10991166(200006)15;6,544::AID-GPS241.3.0.CO;2-8.

Iliffe, S. Manthorpe, J., Eden A. (2003). Sooner or later? Issues in the early diagnosis of dementia in general practice: a qualitative study. Family Practice, 20(4), 376-381.

Iliffe, S., Robinson, L., Brayne, C., Goodman, C., Rait, G., Manthorpe, J., \& DeNDRON Primary Care Clinical Studies Group. (2009). Primary care and dementia: 1. Diagnosis, screening and disclosure. International Journal of Geriatric Psychiatry, 24(9),895-901. Doi:10.1002/gps.2204.

Jasper, M.A. (2005). Using reflective writing within research. Journal of Research in Nursing, 10(3),247-260.

Jervis, L.L., Boland, M.E., Fickenscher, A. (2010). American Indian family caregivers' experiences with helping elders. Journal of Cross Cultural Gerontology, 25(4), 355-369. doi:10.1007/s10823-010-9131-9.

Keightley, J., Mitchell, A. (2004). What factors influence mental health professionals when deciding whether or not to share a diagnosis of dementia with the person? Aging and Mental Health, 8(1),13-20.

Koch, T. (1995). Interpretative approaches in nursing research: The influence of Husserl and Heidegger. Journal of Advanced Nursing, 21(5),827-836. doi:10.1046/j.13652648.1995.21050827.x.

Kramp, M.K. (2004). Exploring life and experience through narrative enquiry. In K deMarrais \& S.D. Lapan (Eds.), Foundations for Research. Malwah, NJ: Lawrence Erlbaum Associates.

Larson, J.E., Corrigan, P. (2008). The stigma of families with mental illness. Academic Psychiatry, 32(2), 87-91. Doi:10.1176/aapi.ap.32.2.87.

Lloyd, J., Patterson, T., Muers J. (2014). The positive aspects of caregiving in dementia: A critical review of the qualitative literature. Dementia. Doi:10.1177/1471301214564792.

Lopez, K.A., Willis, D.G. (2004). Descriptive versus interpretive phenomenology: Their contributions to nursing knowledge. Qualitative Health Research, 14(5), 726-735. Doi:1177/1049732304263638.

Maas, M., Reed, D., Park, M., Specht, J., Schutte, D., Kelley, L., Tripp-Reimer, T. (2004). Outcomes of family involvement in care intervention for caregivers of individuals with dementia. Nursing Research, 53(2), 76-86. 
McIntyre, M., Cole, A. (2008). Love stories about caring and Alzheimer's disease: A performative methodology. Journal of Health Psychology, 13(2),213-225. doi:10.1177/1359105307086701.

Meuser T.M., Marwit, S.J. (2001). A comprehensive, stage-sensitive model of grief in dementia caregiving. The Gerontologist, 41(5),658-670.

Ministry of Health. (2014). Improving the lives of people with dementia. New Zealand: New Zealand Government.

Mitchell, G., McCollum, P., Monaghan, C. (2013). Disclosing a diagnosis of dementia: a background to the phenomenon. Nursing Older People, 25(10),16-21. doi:10.7748/nop2013.12.25.10.16.e497.

Mitchell, S.L, Teno, J.M., Miller, S.C., Mor, V. (2005). A national study of the location of death for older persons with dementia. Journal of the American Geriatrics Society 53(2), 299-305. doi:10.1111/j.1532-5415.2005.53118.x.

Mitchell, S.L., Kiely, D.K., Miller, S.C., Connor, S.R., Spence, C., Teno, J.M. (2007). Hospice care for patients with dementia. Journal of Pain and Symptom Management, 34(1),7-16.

Moniz-Cook, E., Manthorpe, J., Carr, I., Gibson, G., Vernooij-Dassen, M. (2006). Facing the future: A qualitative study of older people referred to a memory clinic prior to assessment and diagnosis. Dementia, 5(3), 375-395.

Moustakas, C. (1994). Phenomenological research methods. Thousand Oaks, CA: Sage.

Murray, A. (2014). The effect of dementia on patients, informal carers and nurses. Nursing Older People, 26(5), 27-31. https://dx.doi.org/10.7748/nop.26.5.27.e573.

Murray, B.L. (2003). Qualitative research interviews: Therapeutic benefits for the participants. Journal of Psychiatry and Mental Health Nursing, 10, 231-238.

Neufeld, A., Harrison, M.J. (2003). Unfulfilled expectations and negative interactions: Non-support in the relationships of women caregivers. Journal of advanced Nursing, 41(4), 323-331.

Nolan, M., Dellasega, C. (2000). 'I really feel I've let him down': supporting family carers during long-term care placement for elders. Journal of Advanced Nursing, 31(4), 759-767. DOI:10.1046/j.1365-2648.2000.01346.

Nolan, M.R., Grant, G., Keady, J. (1996). Understanding family care: A multidimensional model of caring and coping. Buckingham: Open University Press.

O’Dwyer, S.T, Moyle, W.T., Zimmer-Gembeck, M., De Leo, D. (2013). Suicidal ideation in carers of people with dementia: A pilot study. International Journal of Geriatric Psychiatry, 28, 1182-1188. doi:10.1002/gps.3941.

Ory, M.G., Hoffman, R.R., Yee, J.L., Tennstedt, S., Schulz, R. (1999). Prevalence and impact of caregiving: A detailed comparison between dementia and nondementia caregivers. The Gerontologist, 39(2), 177-185.

Ouldred, E., Bryant, C. (2008). Dementia care. Part 3: end-of-life care for people with advanced dementia. British Journal of Nursing. DOI: http://dx.doi.org/10.12968/bjon.2008.17.5.28826

Overcash, J.A. (2004). Narrative research: A viable methodology for clinical nursing. Nursing forum 39(1), 15-22. Doi:10.1111/j.0029-6473.2004.x.

Papastavrou, E., Kalokerinou, A., Papcostas, S.S., Tsangari, H., Sourtzi, P. (2007). Caring for a relative with dementia: family caregiver burden. Journal of Advanced Nursing, 58(5), 446-457. DOI:10.1111/j.1365-2648.2007.04250.x.

Parahoo, K. (1997). Nursing research: Process, Principles \& Issues. London: Macmillan Publishing.

Patton, M.Q. (2002). Qualitative Research and Evaluation Methods. (3 ${ }^{\text {rd }}$ ed.) Sage: London. 
Paun, O., Farran, C.J. (2011). Chronic grief management for dementia caregivers in transition: Intervention development and implementation. Journal of Gerontological Nursing, 37(12), 28-35. Doi:10:3928/00989134-20111103-04.

Peacock, S., Duggleby, W., Koop, P. (2014). The lived experience of family caregivers who provided end-of-life care to persons with advanced dementia. Palliative and supportive care, 12, 117-126. Doi:10.1017/S1478951512001034.

Peacock, S., Forbes, D., Markle-Reid, M., Hawranik, P., Morgan, D., Jansen, L., Henderson, S.R. (2010). The positive aspects of the caregiving journey with dementia: Using a strengths-based perspective to reveal opportunities. Journal of Applied Gerontology, 29, 640-659. doi:10.1177/0733464809341471.

Penrod, J., Preston, D.B, Cain, C.E., Starks, M.T. (2003). A discussion of chain referral as a method for sampling hard-to-reach populations. Journal of Transcultural Nursing, 14(2), 100-107.

Phinney, A. (2006). Family strategies for supporting involvement in meaningful activity by persons with dementia. Journal of Family Nursing, 12, 80-101.

Pinquart, M., Sorenson, S. (2003). Differences between caregivers and noncaregivers in psychological health and physical health: A meta-analysis. Psychology and Aging, 18(2), 250-267. Doi:10.1037/0882-7974.18.2.250.

Pratt, R., Wilkinson, H. (2003). A psychosocial model of understanding the experience of receiving a diagnosis of dementia. The International Journal of Social Research and Practice, 2(2), 181-199. Doi:10.1177/1471301203002002004.

Rando, T. (2000). Clinical Dimensions of Anticipatory Mourning: Theory and practice in working with the dying, their loved ones and their caregivers. Champaign, Il: Research Press.

Razani, J., Corona, R, Quillici, J., Matevosyan, A.A., Funes, C., Larco, A., Lu, P. (2014). The effects of declining functional abilities in dementia patients and increasing psychological distress on caregiver burden over a one-year period. Clinical Gerontology, 37(3), 235-252.

Razani, J., Kakos, B., Orieta-Barbalace, C., Wong, J.T., Casas, R., Lu, P., Josephson, K. (2007). Predicting caregiver burden from daily functional abilities of patients with mild dementia. Journal of the American Geriatrics Society, 55(9), 1415-1420. Doi.org.helicon.vuw.ac.nz/10.1111/j.1532-5415.2007.01307.x.

Robinson, L., Abley, C., Bond, J., Campbell, S., Keady, J., Samsi, K., Manthorpe, J. (2011). Becoming a person with dementia - a systematic review: Exploring older peoples' experiences in the transition from cognitive impairment to receiving a diagnosis of dementia. International Psychogeriatrics, 23, 205-206. doi:10.10107/S1041610211001293.

Robinson, L., Gemski, A., Abley, C., Bond, J., Keady, J., Campbell, S., Manthorpe, J. (2011). The transition to dementia - individual and family experiences of receiving a diagnosis: a review. International Psychogeriatrics 23(7), 1026-1043. doi.org/10.1017/S1041610210002437.

Robinson, L., Iliffe, S., Brayne, C., Goodman, C. Rait, G., Manthorpe, J., \& DeNDRON Primary Care Clinical Studies Group (2010). Primary care and dementia 2: Long term care at home: Psychosocial interventions, information provision, carer support and case management. International Journal of Geriatric Psychiatry, 25(7), 657664. doi:10.1002/gps.2405.

Rolls, L., Relf, M. (2006). Bracketing interviews: Addressing methodological challenges in qualitative interviewing in bereavement and palliative care. Mortality 11(3), 286-305. 
Romero-Moreno, R., Losada, A., Marquez, M., Laidlaw, K., Fernandez-Fernandez, V., Lopez, J. (2014). Leisure, gender and kinship in dementia caregiving:

Psychological vulnerability of caregiving daughters with feelings of guilt. Journals of Gerontology, Series B: Psychological Sciences and Social Sciences, 69(4), 502513. doi:10.1093/geronb/gbt027.

Rosetto, K.R. (2014). Qualitative research interviews: Assessing the therapeutic values and challenges. Journal of Social and Personal Relationships, 31(4), 482-489. DOI:10.1177/0265407514522892.

Samia, L., Hepburn, K., Nichols, L. (2012). "Flying by the seat of our pants": what dementia family caregivers want in an advanced caregiver training program. Research in Nursing and Health 35(6), 589-609. Doi:10.1002/nur.21504. Epub 2012 Aug 21.

Sampson, E.L., Jones, L., Thune-Boyle, I.C., Kukkastenvehmas, R., King, M., Leurent, B., Blanchard, M.R. (2010). Palliative assessment and advance care planning in sever dementia: an exploratory randomised control trail of a complex intervention. Journal of Palliative Medicine, 25(3), 197-209. doi:10.1177/0269216310391691.

Samuelson, A.M., Annstedt, L., Elmstahl, Samuelson, S., Grafstrom, M. (2001). Burden of responsibility experienced by family caregivers of elderly dementia sufferers: Analysis of strain, feelings and coping strategies. Scandinavian Journal of Caring Sciences, 15(1), 25-33. Doi:10:1046/j.1471-6712.2001.1510025.x.

Sandelowski, M., Barroso, J. (2004). Finding the findings in qualitative studies. Journal of Nursing Scholarship, 34(3), 213-219. Doi:10.1111/j. 1547-5069.2002.00213.x

Sanders, S. Corley, C.S. (2012). Are they grieving? A qualitative analysis examining grief in caregivers of individuals with Alzheimer's disease. Social Work in healthcare, 37(3), 35-53. Doi:10.1300/jj010v37n03_03.

Sanders, S., Ott, C. H., Kelber, S.T., Noonan, P. (2008). The experience of high levels of grief in caregivers of persons with Alzheimer's disease and related dementia. Death Studies, 32, 495-523. Doi:10.108007481180802138845.

Schneider, J., Murray, J., Banerjee, S., Mann, A. (1999). EUROCARE: A cross-national study of co-resident spouse carers for people with carer burden. International Journal of Geriatric Psychiatry, 14(8), 651-661. Doi:10.1016/j.encep.2007.10.009.

Schreiber, R.S. Stern, P.N. (2001). Using Grounded Theory in Nursing. New York: Springer Publishing Company.

Schubert, C.C., Boustiani, M., Callahan, C.M. Perkins, A.J., Hui, S., Hendrie, H.C. (2008). Acute care utilization by dementia caregivers within urban primary care practices. Journal of General Internal Medicine, 23(11), 1736-1140. doi:10.1007/s11606-008.

Schulz, R. O’Brien, A.T. Bookwala, J., Fleissner, K. (1995). Psychiatric and physical morbidity effects of dementia caregiving: Prevalence, correlates and causes. The Gerontologist, 35(6), 771-791.

Schwartz, C., Meisenhelder, J.B., Yusheng, R., Reed, G. (2003). Altruistic social interest behaviours are associated with better mental health. Psychosomatic Medicine, 65, 778-785. doi:10.1037/a0014991.

Semiatin, A.M., O’Connor, M.K. (2012). The relationship between self-efficacy and positive aspects of caregiving in Alzheimer's disease caregivers. Aging Mental Health 16(6), 683-638. doi.org.helicon.vuw.ac.nz/10.1080/13607863.2011.651437.

Shim, B., Barroso, J., Gillis, C.L., Davis, L.L. (2013). Finding meaning in caring for a spouse with dementia. Applied Nursing Research, 26, 121-126.

Doi:101016/japnr.2013.05.001. 
Silverman, D. (2001). Interpreting Qualitative Data: Methods for analysing talk, text and interaction. $2^{\text {nd }}$ edn. London: Sage.

Silverman, D. (Ed). (2011). Qualitative Research, $3^{\text {rd }}$ Ed. London: Sage Publishers.

Small, B.J., Fratiglioni, L., Viitanen, M.,Winblad, B., Backman, L. (2000). The course of cognitive impairment in preclinical Alzheimer disease: Three- and 6-year followup of a population-based sample. Arch Neurol, 57: 839-844. doi: 10.1101/cshperspect.a006171

Smith, J.A., Osborn, M. (2008). Interpretative phenomenological analysis. In JA Smith (Ed) Qualitative Psychology: A Practical Guide to Methods $\left(2^{\text {nd }}\right.$ Ed) London: Sage.

Steeman, E., Godderis, J., Grpdonck, M., De Bal, N., Dierckx de Casterle, B. (2007). Living with dementia from the perspective of older people: is it a positive story. Aging Mental Health 1(2), 119-130. doi:10.1080/13607860600963364.

Street, A.F., Ottman, G. (2006). State of the science review of advance care planning models. La Trobe University: Bundoora.

Teel, C.S. Carson, P. (2003). Family experiences in the journey through dementia diagnosis and care. Journal of Family Nursing, 9(1), 38-58. Doi:10.1177/1074840702239490.

Teno, J.M. (2010). Advance directives for nursing home residents: achieving compassionate, competent, cost effective care. JAMA, 283(11), 1481-1482. doi:10.1001/jama.283.11.1481.

ter Muelen, R., Wright, K. (2012). Family solidarity and informal care: The case of care for people with dementia. Bioethics, 26(7), 361-368. doi:10111/j.14678519.2012.01992.x.

Tobin, G.A., Begley, C.M. (2004). Methodological rigour within a qualitative framework. Journal of Advanced Nursing, 48, 388-396. doi/10.1111/j.13652648.2004.03207.x/pdf.

Torke, A.M., Holtz, L.R., Hui, S., Castellucci, P., Connor, S., Eaton, M.A., Sachs, G. (2010). Palliative care for patients with dementia: A national survey. Journal of the American Geriatrics Society, 58(11), 2114-2121. doi:10.111/j.15325415.2010.03141.x.

Tracy, S.J. (2010). Qualitative Quality: Eight "big tent" criteria for excellent qualitative research. Qualitative Inquiry, 16(10), 837-851. doi:10.1177/1077800410383121.

Tufford, L., Newman, P. (2009). Bracketing in qualitative research. Qualitative Social Work 11(1)80-96. Doi:10.1177/1473325010368316.

Van der Steen, J.T. (2010). Dying with dementia: what we know after more than a decade of research. Journal of Alzheimer's disease, 22(1), 37-55. doi:10.3233/JAD-2010100744.

Van Hout, H., Vernooij-Dassen, M.,Bakker, K., Blom, M., Grol, R. (2000). General practitioners on dementia: Tasks, practices and obstacles. Patient Education and Counselling, 39, 219-225.

Vernooij-Dassen, M.J.F.J., Moniz-Cook, E.D., Woods, R.T., De Lepeleire, J., Leuschner, A., Zanetti, O., the INTERDEM group. (2005). Factors affecting timely recognition and diagnosis of dementia across Europe: from awareness to stigma. International Journal of Geriatric Psychiatry, 20, 377-386.

Victor, G.R. (1997). Community Care and Older People. Stanley Thorne: Cheltenham.

Volicer, L., Cantor, M.D., Derse, A.R., Edwards, D.M., Prudhomme, A.M., Gregory, D.C., Fox, E. (2002). Advance care planning by proxy for residents of long-term care facilities who lack decision-making capacity. Journal of the American Geriatrics Society, 50, 761-767. DOI:10.1046/j.1532-5415.2002.50175.x. 
Watson, B., Aizawa, L., Savundranayagam, M.Y., Orange, Y.B. (2013). Links among communication, dementia and caregiver burden. Canadian Journal of SpeechLanguage Pathology Audiology, 36(4), 276-283.

Werner, P., Mittelman, M.S., Goldstein, M.A., Heinik, J. (2011). Family stigma and caregiver burden in Alzheimer's disease. The Gerontologist, 52(1), 89-97. doi:10.1093/geront/gnrl117.

Whitlatch, C.J. (2013). Centered-person care in the early stages of dementia: Honoring individuals and their choices. Generations; 37(3), 30.

Williams, K.L., Morrison, V., Robinson, C.A. (2013). Exploring caregiving experiences: Caregiver coping and making sense of illness. Aging Mental Health, 18(5), 600609. doi:10.1080/13607863.2013.860425.

Windle, P.E. (2006). Exploring qualitative research for peranethesia nurses. Journal of PeriAnethesia Nurses, 21(4), 57-60. Doi:10.1016/j.jopan.2005.12.004.

Wojnar, D.M., Swanson, K.M. (2007). Phenomenology: An exploration. Journal of Holistic Nursing, 25, 172. doi:10.1177/0898010106295172.

World Health Organization. World Health Report (2002). Reducing Risks, Promoting Healthy Life. Geneva: WHO. 